\title{
EVIDÊNCIAS EMPÍRICAS DE LEILÕES NA INTERNET:
}

\section{SELOS NA eBay}

\author{
Adhemar Villani Júnior
}

Dissertação apresentada à Faculdade de Economia, Administração

Contabilidade, da Universidade de São Paulo, para obtenção do título de Mestre em Teoria Econômica.

Orientador: Profa. Dra. Marilda Antônia de Oliveira Sotomayor 
"There's a difference between knowing the path and walking the path", Morpheus, MATRIX. 


\section{Agradecimentos}

À minha família pela formação de meu caráter e apoio irrestrito.

À minha orientadora Marilda Sotomayor pelo seu exemplo de conduta e confiança em meu trabalho.

Aos membros da banca de qualificação, professores Maurício Bugarin e Paulo Picchetti, pelos comentários e sugestões.

Aos companheiros Fábio Sparremberger, Luís Cláudio Barcelos, Anderson Schneider e Marcelo Araújo, pela participação nos experimentos.

Ao amigo João Mello pelos seus conselhos.

À Valéria e a Bete que sempre me auxiliaram nas questões relativas às normas e procedimentos da pós-graduação.

À Universidade de São Paulo e a FEA pelo apoio financeiro e de infraestrutura. 


\section{Sumário}

\begin{tabular}{|c|c|}
\hline Lista de Figuras. & \\
\hline Lista de Tabelas. & $i i$ \\
\hline Resumo & iiii \\
\hline Abstract & iv \\
\hline 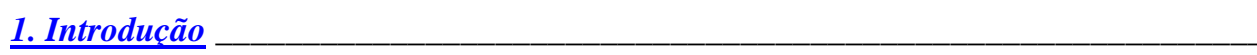 & 1 \\
\hline 2. Modelo Teórico & 6 \\
\hline 2.1 Maldicão do Vencedor: Experimentos em Laboratório & 11 \\
\hline 2.1.1 Registros Históricos da Maldição do Vencedor & 11 \\
\hline 2.1.2 O Primeiro Experimento & 15 \\
\hline 2.1.3 O Segundo Experimento: Mudança de Incentivo & 19 \\
\hline . História dos Leilôes na Internet: 0 Surgimento da eBav. & 23 \\
\hline 4. Coleta de Dados de Leilốs na Internet & 25 \\
\hline 4.1 Breve Descricão do Mercado de Selos & 26 \\
\hline 4.2 Descriç̃̃o dos Dados & 27 \\
\hline 4.3 Funcionamento do Leilão na eBay & 29 \\
\hline 4.4 Programas Desenvolvidos & 30 \\
\hline 4.4.1 spider1.pl & 32 \\
\hline 4.4 .2 spider2.pl & 32 \\
\hline 4.4 .3 spider $3 . \mathrm{pl}$ & 33 \\
\hline 4.4 .4 blemish.pl & 33 \\
\hline 4.4 .5 dados.pl & 34 \\
\hline 4.4.6 latebid.pl & 34 \\
\hline 4.4 .7 prices. $\mathrm{pl}$ & 34 \\
\hline 4.4 .8 bids.pl & 35 \\
\hline 5. Análise dos Dados Obtidos & 35 \\
\hline 5.1 Estatísticas & 36 \\
\hline
\end{tabular}

5.2 Determinantes dos Preços de Venda, Número de Jogadores e Precos Mínimos

5.3 Submissão Tardia de Lances 41

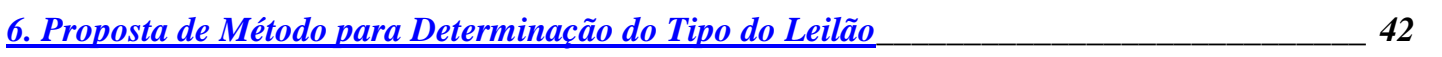

6.1 Uso do Método Simplificado de Paarsch 43

6.2 Método Proposto 46

6.3 Teste do Método com Dados de Laboratório 49

6.3.1 Sensibilidade do cálculo de b* 51 
6.4 O Histograma dos Precos de Desistência no Caso da

Distribuição Uniforme 53

6.5 Uso do Método Proposto 54

6.6 Aplicação do Método: Explicação da Submissão Tardia de

\begin{tabular}{|lc|}
\hline Lances & 56 \\
\hline . Conclusão e Comentários Finais & 57 \\
\hline Anexo & 61 \\
\hline Bibliografia & 65 \\
\hline
\end{tabular}




\section{Lista de Figuras}

Figura 1 - Tela inicial

\begin{tabular}{|cc}
\hline Figura 2 - Desistência do jogador 2 & 16 \\
\hline Figura 3 - Desistencia do jogador 4 & 16 \\
\hline
\end{tabular}

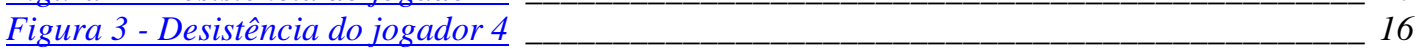

\begin{tabular}{ll}
\hline \hline Figura 4 - Desistência do jogador 3 & 16 \\
\hline
\end{tabular}

Figura 5 - Diagrama de funcionamento dos programas 


\section{Lista de Tabelas}

Tabela 1-Relação entre as variáveis 5

Tabela 2 - Estatísticas do primeiro experimento 18

\begin{tabular}{ll}
\hline Tabela 3 - Estatísticas do segundo experimento & 21 \\
\hline Tabela 4 - Resultados do segundo experimento & 22 \\
\hline
\end{tabular}

Tabela 4 - Resultados do segundo experimento

22

\begin{tabular}{ll} 
Tabela 5 - Payoffs dos jogadores no segundo experimento & 22 \\
\hline Tabela 6 - Estatisticas para o Conjun & 36
\end{tabular}

Tabela 6-Estatísticas para o Conjunto de Dados Gold 36

Tabela 7 - Resultados para as especificacões de Paarsch (a)

44

Tabela 8 - Resultados para as especificacões de Paarsch (b) _ 46

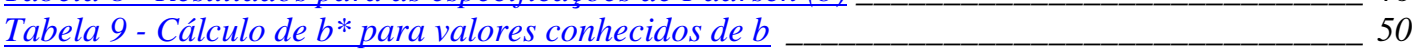

Tabela 10 - Média e variância de $b^{*}$ para valores conhecidos de b e de $n \quad 50$

\begin{tabular}{ll}
\hline Tabela 11 - Histograma dos preços de desistência para 2 casos selecionados & 54 \\
\hline
\end{tabular}

Tabela 12 - Comparativo dos histogramas de preços de desistência: Real x Teórico _ _ 55 


\section{Resumo}

Os leilões na Internet têm ganhado muita popularidade, tornando-se uma das mais bem sucedidas formas de comércio eletrônico na atualidade. Apresento um modelo teórico para descrever um leilão ascendente, semelhante ao que ocorre na eBay, e verifico suas previsões comportamentais através de dois experimentos. Os resultados mostraram um distanciamento grande entre as previsões teóricas e o que foi observado na prática, no que se refere às estratégias utilizadas, mas acredito que isso se deva à falta de experiência dos participantes dos experimentos. Desenvolvo, então, programas que automatizam a coleta de dados de leilões de selos na eBay e analiso as variáveis que influenciam preços, número de compradores e lances iniciais (preços mínimos). Não houve surpresas em tal análise, no sentido de observar-se resultados contra-intuitivos, mas destaco a reputação dos vendedores como fator relevante para a determinação de preços finais e número de compradores participantes. Além disso, também destaco a ocorrência da submissão tardia de lances, fenômeno recorrente nos leilões na Internet. Proponho, por fim, um método simples que busca determinar o tipo de modelo de leilão, se de valor comum ou de valor privado, e aplico o método nos dados obtidos dos leilões de selos. O resultado foi o de que os leilões analisados estão enquadrados no modelo de valor comum. 


\begin{abstract}
On-line auctions are one of the most popular and successful types of electronic commerce nowadays. I present a theoretical framework to address the kind of ascending auction implemented at eBay, and I check its predictions through two experiments. The results of the experiments did not confirm the theory, but I believe this is due to the bidders' lack of previous experience. I also present an algorithm that automatically gathers data from auctions of stamps at eBay. These data is then used on an exploratory analysis that tries to shed some light on the determinants of final prices, minimum bids and the number of bidders. There were no surprises in this analysis, but I would highlight the measurable effect that seller's reputation has on final prices and the number of bidders. Furthermore, it was possible to observe the occurrence of late bidding. At last, I propose a simple method that determines to which paradigm the on-line auction of stamps at eBay belongs: private value or common value. The result was that the auction of stamps at eBay belongs to the common value paradigm.
\end{abstract}




\section{Introdução}

O leilão pela Internet é uma das mais importantes implementações práticas do que se convenciona chamar atualmente de e-commerce (comércio eletrônico). Estima-se que só a eBay transaciona em um único dia cerca de cinco milhões de itens, postos à venda em categorias que variam de bonecas Barbie até computadores usados. De um modo superficial, leilões on-line surgem como uma aproximação da idealização econômica de um mercado competitivo onde um grande número de compradores e vendedores se engaja em transações. Mais importante de tudo é a possibilidade de confrontar teoria e prática, em função da grande disponibilidade de dados.

Primeiramente apresento um modelo teórico, compreendendo as especificações das regras de um leilão e da forma como os compradores avaliam o objeto leiloado, e que servirá de referência ao longo do trabalho. Este modelo é simples o suficiente para permitir sua fácil compreensão, mas abrangente o bastante para abordar as questões levantadas neste trabalho. $\mathrm{O}$ modelo considera a participação de $\mathrm{n}$ compradores idênticos que disputam um único objeto indivisível através de um leilão, conhecido como leilão japonês, que apresenta as seguintes regras:

O leilão começa com o anúncio de um preço bem baixo para o objeto leiloado. A partir daí, o preço corrente do objeto é incrementado continuamente, enquanto não houver alguma manifestação por parte de pelo menos um comprador de que este deseja desistir do leilão. Quando algum comprador manifesta publicamente a sua desistência, o leilão é interrompido e verifica-se se mais algum (ns) comprador (es) deseja (m) desistir. O leilão recomeça, com o preço corrente subindo novamente de forma contínua, se ao final do processo de desistência descrito anteriormente ainda houver pelo menos dois compradores que não tenham desistido. Se houver um único comprador remanescente, então este é declarado o vencedor e leva o objeto pagando o preço corrente, enquanto os demais compradores não pagam nada. Se ocorrer a desistência de todos os compradores ainda participantes do leilão em um dado preço, um deles é escolhido o vencedor de maneira aleatória. 
O leilão japonês foi escolhido como aproximação do tipo de leilão que é utilizado na Internet para a negociação de selos no site da eBay. A descrição exata do funcionamento do leilão de selos na eBay é dada mais adiante na seção 4.3, intitulada de Funcionamento do Leilão na eBay.

O modelo teórico comporta tanto a possibilidade de as avaliações do objeto leiloado serem baseadas no modelo de valor privado, como a de avaliações baseadas no modelo de valor comum. Para explicar a diferença entre essas duas formas de avaliação, considere que cada comprador receba uma determinada informação. Então, no modelo de valor privado, cada comprador avalia o objeto leiloado em função apenas da informação que recebe. Já no modelo de valor comum, cada comprador avalia o objeto leiloado em função não só de sua informação, mas em função das informações recebidas por todos os demais compradores. A complicação existente no modelo de valor comum é a de que tais informações não são de conhecimento público.

Uma importante característica de leilões de valor comum é a possibilidade de ocorrência da chamada maldição do vencedor. Explicado de maneira simples, a maldição do vencedor ocorre quando o comprador falha ao não distinguir a diferença entre a avaliação esperada do objeto e a avaliação esperada do objeto condicional ao fato de ele ser o vencedor. Isso abre possibilidade para que o vencedor de um leilão possa ter payoff esperado abaixo do valor que poderia obter. Para deixar clara essa possibilidade, apresento os resultados de dois experimentos implementados com o intuito de detectar a ocorrência desse efeito, e também para saber se o mesmo é diminuído ou eliminado com a experiência dos compradores em evitar a maldição do vencedor, adquirida ao longo dos leilões em que tenham participado.

Para evitar a maldição do vencedor, os compradores reduzem seus lances (ou preços de desistência em um leilão ascendente) em uma quantidade que aumenta à medida que cresce o número de compradores presentes no leilão. Dado que essa redução nos lances, relacionada com o número de compradores presentes, não ocorre em um leilão de valor privado, abre-se a possibilidade para o desenvolvimento de uma 
proposta metodológica, que será apresentada mais adiante, que tem como objetivo a determinação do tipo de modelo do leilão: valor comum ou valor privado. A importância de se avaliar a questão da experiência no experimento é devida à necessidade de se obter um indício de que efetivamente os compradores atentam para a maldição do vencedor, sendo a experiência um motivo razoável para que isso aconteça.

Foram realizados dois experimentos, onde foram implementados leilões japoneses que contaram com a participação de quatro compradores. Os compradores avaliavam cada objeto leiloado de acordo com um caso particular do modelo de valor comum, onde o objeto valia rigorosamente a mesma coisa para todos os compradores. Vale ressaltar, contudo, que, no início de cada leilão, cada comprador só possuía vinte e cinco por cento da informação necessária ao cálculo da avaliação do objeto. No primeiro experimento, foram realizadas três sessões de trinta leilões cada e os compradores só souberam do valor verdadeiro do objeto de cada leilão ao término de cada uma das sessões. Já no segundo experimento, foi realizada uma única sessão de trinta leilões em que o valor verdadeiro do objeto era imediatamente divulgado ao término de cada leilão.

Os resultados do primeiro experimento mostraram que o mesmo não atingiu satisfatoriamente seus objetivos. Isso se deveu ao fato de que as suas regras eram inadequadas, decorrentes da restrição de verba para a execução do experimento, e de dificuldades na obtenção de voluntários. Em razão disso, os compradores escolhiam sempre a estratégia de fazer, deliberadamente, com que o vencedor fosse "amaldiçoado" e, portanto, pagasse um valor acima do valor verdadeiro do objeto. Por conseguinte, a questão da experiência acabou não sendo avaliada.

Em razão da insatisfação com os resultados obtidos no primeiro experimento, foi elaborado um segundo experimento, com regras que incentivaram unicamente a maximização do payoff individual, e não a minimização do payoff dos adversários, como ocorreu no primeiro experimento. Os resultados foram a ocorrência de uma maldição do vencedor menos acentuada, e nenhum indício de que a experiência 
ajudou a reduzir o efeito da maldição do vencedor ao longo dos leilões realizados neste novo experimento.

Em seguida, apresento um algoritmo para a coleta automatizada de dados de leilões na Internet, composto basicamente por três programas, inspirado na idéia exposta em Lucking-Reiley et al. [2000]. Esse algoritmo é implementado para leilões na eBay, mas a sua adaptação a outros casos não requer grandes modificações. O motivo para o desenvolvimento desses programas foi o de que a coleta manual de dados de leilões na Internet é uma tarefa monótona e que consome muito tempo. Além disso, pouco se perde, em termos de informações que podem ser obtidas, ao se utilizar o algoritmo de coleta automatizada de dados.

Os dados coletados neste trabalho se referem a leilões de selos não usados de 1901 até 1940 dos Estados Unidos. O motivo da escolha pelos leilões de selos da eBay se deveu a inexistência de trabalhos que abordam esse mercado, embora a quantidade de dados disponíveis para o seu estudo seja abundante. Vale aqui dizer que alguns dos trabalhos mais recentes sobre leilões na Internet, utilizados como referência nesta dissertação, têm tratado do mercado de moedas para colecionadores. As perguntas que procurei responder de posse dos dados foram:

Quais são as variáveis que influenciam os preços de venda, o número de jogadores e os preços mínimos?

$\diamond$ Que tipo de modelo de leilão, se de valor comum ou de valor privado, é o leilão de selos na eBay?

Assim, de posse dos dados, foi feita então uma análise exploratória das variáveis que influenciavam os preços de venda, o número de jogadores e os preços mínimos nos leilões, bem como foi detectada a submissão tardia de lances, que é a tendência dos compradores em submeterem lances instantes antes do encerramento do leilão. A seguir, apresento uma tabela com os principais resultados dessa análise: 
Tabela 1 - Relação entre as variáveis

\begin{tabular}{|c|c|c|c|c|}
\cline { 3 - 5 } \multicolumn{2}{c|}{} & \multicolumn{3}{c|}{ Variáveis influenciadas } \\
\cline { 3 - 5 } \multicolumn{1}{c|}{} & $\begin{array}{c}\text { Preço de } \\
\text { venda }\end{array}$ & $\begin{array}{c}\text { Número de } \\
\text { jogadores }\end{array}$ & $\begin{array}{c}\text { Preço } \\
\text { mínimo }\end{array}$ \\
\hline \multirow{4}{*}{$\begin{array}{c}\text { Bariáveis qualidade } \\
\text { que } \\
\text { do selo }\end{array}$} & $\begin{array}{c}\text { Preço } \\
\text { mínimo }\end{array}$ & + & & + \\
\cline { 2 - 5 } & $\begin{array}{c}\text { Número de } \\
\text { compradores }\end{array}$ & + & - & \\
\cline { 2 - 5 } & $\begin{array}{c}\text { Duração } \\
\text { do leilão }\end{array}$ & + & & \\
\cline { 2 - 5 } & $\begin{array}{c}\text { Comentários negativos } \\
\text { a respeito do vendedor }\end{array}$ & - & - & + \\
\cline { 2 - 5 } & $\begin{array}{c}\text { Comentários positivos } \\
\text { a respeito do vendedor }\end{array}$ & & + & \\
\hline
\end{tabular}

Obs: O sinal de "+" (respec. "-“) significa que um aumento na variável que influencia causa um aumento (respec. decréscimo) na variável que é influenciada. A ausência dos indicadores "+" ou "-“" significa que não foi encontrada relação entre as variáveis, ou então que tal relação não se aplica ao caso. Por fim, a eBay permite que o comprador vencedor e o vendedor reportem sua opinião a respeito do outro após a efetivação da transação. As variáveis que se referem a "comentários" dizem respeito à quantidade de tais opiniões (consulte o apêndice A).

O fenômeno da submissão tardia de lances é explicado de acordo com o modelo do leilão. Primeiramente, mostro que um método simplificado, proposto por Paarsch [1992] para determinar o tipo de modelo dos leilões de selos analisados, e assim descobrir o motivo para a ocorrência da submissão tardia de lances, é inadequado ao caso em estudo. Então proponho um novo método de determinação do tipo de modelo do leilão baseado no modelo teórico utilizado no trabalho. Esse método é simples o suficiente para permitir sua fácil implementação e é razoavelmente robusto de acordo com os testes feitos através de dados gerados por simuladores.

Os resultados obtidos, através da aplicação do método que proponho, indicaram que os leilões analisados estão enquadrados no modelo de valor comum. Isso significa que a explicação da submissão tardia de lances é que os compradores não têm incentivos para revelarem seus sinais antes do último instante, no qual ocorre o encerramento do leilão. Caso os resultados apontassem para o modelo de valor privado, a existência da submissão tardia de lances poderia ser decorrente do congestionamento de rede que ocorre no encerramento do leilão na eBay, de acordo com a explicação proposta por Roth e Ockenfels [2000]. 
Por fim, faço uma crítica dos procedimentos empregados neste trabalho e apresento os comentários finais.

Este trabalho é organizado conforme segue. A seção 2 apresenta o modelo teórico que é utilizado neste trabalho, bem como são apresentados os resultados dos dois experimentos realizados. A seção 3 mostra como surgiram os leilões na Internet e o site da eBay. A seção 4 apresenta os programas desenvolvidos para a coleta e a manipulação dos dados obtidos de leilões na eBay. A seção 5 mostra a análise feita a partir dos dados coletados. Na seção 6 é proposto o método de determinação do tipo de leilão de selos da eBay, baseado no modelo teórico utilizado. Por fim, a seção 7 apresenta as conclusões e comentários finais do trabalho.

\section{Modelo Teórico}

O objetivo desta seção é o de apresentar um arcabouço teórico que será utilizado ao longo do trabalho. O modelo aqui apresentado segue o descrito em Klemperer [1999], apêndice D, para avaliações do objeto leiloado baseadas no modelo de valor comum ou privado.

Sejam n compradores neutros ao risco, onde cada comprador i têm seu sinal privado $\mathrm{t}_{\mathrm{i}}$ retirado de $[0 ; \tau]$ de acordo com uma função de distribuição de probabilidade qualquer. Estes compradores disputam um único objeto. Para cada comprador i temse $v_{i}=\alpha . t_{i}+\beta . \quad j_{j \neq i} t_{j}$, onde $v_{i}$ é a avaliação do objeto leiloado para o comprador $i, \alpha \in$ $\mathrm{R}^{+} \cup\{0\}$ e $\beta \in \mathrm{R}^{+} \cup\{0\}$. Veja que quando $\beta=0$ tem-se o caso convencional de valor privado, senão tem-se o caso de valor comum.

A regra do leilão, apresentada na introdução, é descrita em Bulow e Klemperer [2000], seguindo Bikhchandani e Riley [1993], no que os teoristas de leilões chamam de "leilão japonês". 
Seja $\mathrm{t}_{(\mathrm{j})}$ o j-ésimo maior sinal determinado. No equilíbrio de Nash simétrico de um leilão ascendente, cada comprador desiste quando ele é indiferente entre ganhar ou não o objeto ao preço corrente ${ }^{\square}$. Então, o primeiro comprador a desistir sai no preço $(\alpha+(n-1) \cdot \beta) . t_{(n)}$, visto que este seria o valor verdadeiro do objeto para ele se todos os demais compradores tivessem o mesmo sinal que o dele. Os compradores remanescentes observam este fato, descobrindo o valor de $t_{(n)}$, e a próxima desistência ocorre ao preço $\beta . t_{(n)}+(\alpha+(n-2) \cdot \beta) . t_{(n-1)}$, visto que este seria o valor verdadeiro do objeto para o comprador que está desistindo se todos os demais compradores remanescentes tivessem o mesmo sinal que o dele. Mais uma vez, os compradores remanescentes observam este fato, descobrindo o valor de $t_{(n-1)}$, e assim por diante, onde o leilão segue até a desistência final que ocorre ao preço $P=\beta . \quad j=3^{n}$ $t_{(j)}+(\alpha+\beta) \cdot t_{(2)}$.

Para checar que este é o equilíbrio, analisemos o que ocorreria, por exemplo, ao comprador de sinal $t_{(2)}$ caso este se desvie de sua estratégia. Se $t_{(2)}$ espera para desistir e vence o leilão, então o preço final $\left(\mathrm{P}^{*}\right)$ será dado pelo preço no qual o comprador de sinal $t_{(1)}$ desiste, ou seja, $P^{*}=\beta . \quad{ }_{j=3}^{n} t_{(j)}+(\alpha+\beta) \cdot t_{(1)}$. Entretanto o valor do objeto para o comprador de sinal $t_{(2)}$ é $v=\beta . \quad{ }_{j=3}{ }^{n} t_{(j)}+\alpha \cdot t_{(2)}+\beta . t_{(1)}$. Logo ele tem prejuízo, pois $\mathrm{P}^{*}>\mathrm{v}$. Se por outro lado $\mathrm{t}_{(2)}$ desiste antes do preço ao qual ele desistiria em equilíbrio, então o preço final será $P^{*}=\beta$. $\quad{ }_{j=3}{ }^{n} t_{(j)}+(\alpha+\beta) \cdot t^{*}$, onde $t^{*}<t_{(2)}$. Então $t_{(2)}$

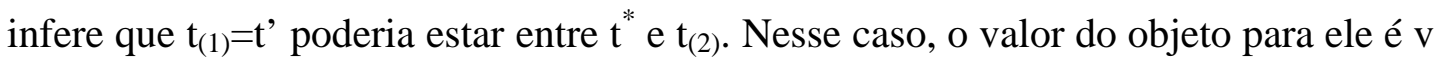
$=\beta . \quad{ }_{j=3}{ }^{n} t_{(j)}+\alpha \cdot t_{(2)}+\beta . t^{\prime}$. Se $t_{(2)}$ esperasse e pagasse $P=\beta . \quad{ }_{j=3}{ }^{n} t_{(j)}+(\alpha+\beta) \cdot t^{\prime}$, então teria lucro, pois $v>P$, visto que $\mathrm{t}_{(2)}>\mathrm{t}^{\prime}$ nesse caso. Portanto, não vale a pena desistir antes.

O mesmo raciocínio vale para os demais compradores que não vencem o leilão. Para o comprador de sinal $\mathrm{t}_{(1)}$ (vencedor do leilão) aplica-se também o mesmo raciocínio, mas apenas no que diz respeito a desistir antes do preço ao qual ele deve desistir em equilíbrio.

Para ajudar no entendimento do equilíbrio descrito acima, apresento a seguir um

\footnotetext{
${ }^{1}$ Este pode não ser o único equilíbrio. Veja Bikhchandani e Riley [1991].
} 
exemplo com a participação de apenas dois compradores.

\section{Exemplo com dois compradores jogando o equilíbrio simétrico:}

Considere que o comprador $\mathbf{1}$ tem sinal $\mathbf{t}_{\mathbf{1}}$ e o comprador $\mathbf{2}$ tem sinal $\mathbf{t}_{\mathbf{2}}$. Além disso:

$$
t_{1}>t_{2} \rightarrow t_{1}=t_{(1)}, t_{2}=t_{(2)}
$$

Quando $\mathrm{P}=0$, tem-se que nenhum comprador desistiu ainda. Assim, os preços de desistência planejados nesse momento por 1 e por $\mathbf{2}$ são:

$$
\begin{aligned}
& P_{1}=(\alpha+\beta) \cdot t_{1}=(\alpha+\beta) \cdot t_{(1)} \\
& P_{2}=(\alpha+\beta) \cdot t_{2}=(\alpha+\beta) \cdot t_{(2)}
\end{aligned}
$$

Logo, ocorrerá a venda para $\mathbf{1}$ ao preço $\mathbf{P}_{\mathbf{2}}$.

Para verificarmos que este é o equilíbrio, vejamos, primeiro, o que ocorre se o comprador 2 resolve desviar-se de sua estratégia:

- $\quad$ Caso I: ele desiste acima de $\mathbf{P}_{\mathbf{2}}$;

- $\quad$ Caso II: ele desiste antes de $\mathbf{P}_{\mathbf{2}}$.

\section{Caso I:}

Sendo $\mathbf{t}_{\mathbf{1}}>\mathbf{t}_{\mathbf{2}}$, se ele espera, corre o risco de ter prejuízo, pois:

- $\quad$ se ele vence, levará o objeto ao preço $\mathbf{P}_{1}=(\boldsymbol{\alpha}+\boldsymbol{\beta}) \cdot \mathbf{t}_{1}>\mathbf{v}_{\mathbf{2}}=\boldsymbol{\alpha} \cdot \mathbf{t}_{\mathbf{2}}+\boldsymbol{\beta} \cdot \mathbf{t}_{1}, \operatorname{logo}$ terá prejuízo;

- $\quad$ se ele não vence, terá payoff ZERO.

Caso II:

Se ele sai antes, ao preço $\mathbf{P}^{\prime}<\mathbf{P}_{\mathbf{2}}$, corre o risco de deixar de ganhar um payoff positivo, na possibilidade do sinal do outro jogador ser menor do que o sinal dele, pois:

- $\quad$ sendo $t_{1}<t_{2}$ e $P^{\prime}<P_{1} \rightarrow P^{\prime}<P_{1}=(\alpha+\beta) . t_{1}<v_{2}=\alpha . t_{2}+\beta . t_{1}<P_{2}=(\alpha+\beta) . t_{2}$ $\rightarrow$ payoff ZERO quando podia ter payoff positivo;

- caso contrário, terá payoff ZERO.

Já para o comprador 1, se ele resolve desviar-se de sua estratégia:

- $\quad$ Caso I: ele desiste acima de $\mathbf{P}_{\mathbf{1}}$ : não aumenta seu payoff;

- Caso II: ele desiste antes de $\mathbf{P}_{1}$ : não aumenta seu payoff e ainda corre $\mathbf{o}$ risco de deixar de vencer.

Note que quando o comprador de segundo maior sinal desiste, ele sabe (assumindo comportamento em equilíbrio) que o sinal remanescente é maior, ou igual, do que o seu. Então ele tem certeza de que o valor verdadeiro do objeto para ele não pode ser menor do que o preço ao qual ele desiste e que o valor esperado do objeto para ele é 
maior do que este preço de desistência. Esse comportamento de desistir a um preço menor do que a avaliação esperada do objeto para o comprador, e que não parece ser lógica à primeira vista, ilustra a maldição do vencedor ${ }^{[} \mathrm{O}$ ponto relevante para $\mathrm{o}$ comprador não é o valor esperado do objeto, mas sim o valor esperado do objeto condicional ao fato de ele vencer o leilão. Apenas quando um dado comprador vence o leilão é que ele se importa com seu valor, de forma que ele desiste exatamente no valor condicional ao fato de ele ser vencedor. Em outras palavras, vencer um leilão significa má notícia a respeito dos sinais dos demais compradores, logo os preços de desistência devem ser ajustados para baixo de forma a evitar que um dado comprador tenha prejuízo caso ele acabe vencendo o leilão.

No restante do trabalho, considerarei apenas o caso particular em que, para a $\in$ $\mathrm{R}^{+} \cup\{0\}$ e $\mathrm{b} \in \mathrm{R}^{+} \cup\{0\}:$

$\alpha=\frac{a}{a+(n-1) \cdot b} \quad e$

b

$\beta=\frac{}{a+(n-1) \cdot b}$, de forma que $v_{i}$ seja a seguinte média ponderada dos sinais

dos jogadores:

$v_{i}=\frac{a \cdot t_{i}+b \cdot \quad j \neq i t_{j}}{a+(n-1) \cdot b}$.

Com isso, temos $0 \leq v_{i} \leq \tau$ para qualquer $i \in\{1, \ldots, n\}$.

Antes de prosseguir, apresento um exemplo extraído de Thaler [1994], com o intuito de esclarecer o problema da maldição do vencedor, isto é, a questão da diferença entre o valor esperado do objeto e o valor esperado do objeto condicional ao fato de

\footnotetext{
${ }^{2}$ Outras definições deste conceito serão apresentadas ao longo do trabalho, mas todas elas compartilham a mesma idéia.
} 
ser o vencedor.

Suponha que exista uma companhia petrolífera B que está realizando um projeto de exploração em uma nova bacia sedimentar. Caso este projeto torne-se um sucesso absoluto, então o valor de B, sob a atual administração, será de 100 unidades monetárias. Mas se o projeto fracassar totalmente, então a empresa estará falida e valerá zero unidades monetárias. Vamos supor ainda que todos os valores entre zero e 100 sejam igualmente possíveis de ocorrer, correspondendo aos resultados intermediários do projeto, compreendidos entre o sucesso absoluto e o fracasso total. Logo, podemos inferir que o valor da companhia B, sob a atual administração, é uma variável aleatória extraída de uma distribuição uniforme [0;100].

Você foi escolhido pela companhia petrolífera A para assessorá-la em sua intenção de comprar a companhia B. Sabe-se que B vale 50\% mais sob a administração de A do que sob a atual administração de B, mas a oferta de compra deve ser feita sem que ninguém, à exceção da companhia $\mathrm{B}$, saiba do resultado do projeto de exploração. Dessa forma, a oferta pela companhia B será feita de modo que ela sabe o resultado do projeto, e assim conhece seu valor sob sua atual administração, mas a companhia A não sabe o resultado do projeto, e assim não conhece o valor que ela teria sob a sua administração. Além disso, a empresa B é obrigada a aceitar a oferta de compra caso o valor ofertado seja maior ou igual do que o valor sob a atual administração.

Portanto, você deve decidir qual o valor entre 0 e 150 que será ofertado pela empresa B. Qual valor você ofertará?

Normalmente, alguém poderia pensar sobre esse problema da seguinte forma: como a empresa B tem valor esperado de 50 sob a atual administração, e assim terá o valor esperado de 75 para a empresa $A$, se for feita uma oferta entre 50 e 75 , então a empresa A terá um lucro positivo na operação. Entretanto tal análise está errada, pois não leva em conta a assimetria de informação que existe no problema. A análise correta deve calcular o valor esperado da empresa B condicionado ao fato de a proposta ser aceita. Para ver isso, suponha que você oferte 40 . Se a oferta for aceita, 
então a empresa B não pode valer mais do que 40 sob a atual administração. Como todos os valores abaixo de 40 são igualmente possíveis, então o valor esperado da companhia B sob a atual administração, condicional ao fato de ela valer menos do que 40, é 20. Logo, ela vale 30 para você, representante da companhia A. Ao ofertar 40, você terá um prejuízo de 10 unidades monetárias. De fato, qualquer proposta maior do que zero implicará em prejuízo esperado de $25 \%$ do valor de sua oferta. Assim, este exemplo produz um caso extremo de maldição do vencedor no qual qualquer oferta acima de zero leva a um prejuízo esperado para o comprador.

Weiner, Bazerman e Carroll [1987] investigaram os resultados de um experimento baseado neste exemplo e obtiveram indícios de que a maldição do vencedor realmente ocorre e, mais ainda, que a aprendizagem para se evitar tal fato não ocorre de maneira trivial. A subseção a seguir apresenta dois experimentos que tiveram por objetivo ajudar no entendimento desse fenômeno. Veremos que a maldição do vencedor ocorreu e que não houve aprendizagem dos compradores de forma a evitarem a ocorrência desse fenômeno.

\subsection{Maldição do Vencedor: Experimentos em Laboratório}

\subsubsection{Registros Históricos da Maldição do Vencedor}

Esta subseção segue a descrição encontrada em Kagel e Roth [1997], com a tradução e adaptação feita pelo autor.

A ocorrência da maldição do vencedor foi inicialmente reportada em 1971, em um artigo de Capen, Clapp, e Campbell, três engenheiros de petróleo que trabalhavam na Atlantic Richfield Company. Eles afirmavam que as companhias detentoras de áreas de exploração de petróleo, obtidas através de leilões, não conseguiam obter todo o volume de óleo que inicialmente esperavam extrair. Além disso, o vencedor de tais leilões de áreas de exploração era, normalmente, a companhia que possuía a projeção de retorno mais alta dentre todas os participantes do leilão. Mais do que isso, tal estimativa se revelava superestimada ao longo do tempo. 
A mais importante característica em um leilão de concessão de áreas de exploração de petróleo é a de que todas as companhias tentam estimar um valor comum, que é o valor do óleo contido em uma certa área. Se supusermos que as estimativas que as companhias fazem desse valor não são viesadas, ou seja, elas acertam o valor verdadeiro "na média", a estimativa de uma companhia é muito relevante para os demais competidores. A razão para isso é que o valor verdadeiro esperado, dado uma única estimativa, é maior do que o valor verdadeiro esperado dado que tal estimativa é a maior dentre todas as estimativas feitas pelos competidores. O motivo por trás da ocorrência da maldição do vencedor é o de que o vencedor de um leilão de valor comum, conforme o caso descrito acima, freqüentemente tem a maior estimativa, mas não leva isso em consideração.

Entretanto, a hipótese de que competidores persistentemente cometem erros afronta as noções convencionais de equilíbrio. Por isso, muitos teoristas econômicos não viam com bons olhos essa hipótese, principalmente depois que o estudo do comportamento estratégico em equilíbrio tornou-se mais detalhado ${ }^{\text {B }}$. Não ficou claro, naquele momento, que a explicação para o motivo pelo qual as empresas petrolíferas devem reduzir seus lances em leilões de concessão de áreas de exploração pudesse ser encontrada na teoria de leilões, e assim cogitou-se buscar tal explicação em outras áreas, como a de teoria dos cartéis.

O debate acerca desse assunto continuou a existir, mesmo com a citação de novas evidências de leilões de valor comum que confirmavam a tese de que a maldição do vencedor freqüentemente fazia com que os vencedores tivessem payoffs reduzidos, ou até mesmo payoffs negativos. Um dos motivos para isso é o de que os dados obtidos eram intricados e incompletos, além do que o valor verdadeiro de objetos de valor comum, como o das áreas de exploração de petróleo, não pode ser conhecido mesmo após a realização do leilão.

A grande utilidade de se fazer uso de experimentos de laboratório, nesse caso, é a de

\footnotetext{
${ }^{3}$ Sobre esse assunto, veja Wilson [1977] e Milgrom e Weber [1982].
} 
pode-se verificar se a maldição do vencedor é um fenômeno recorrente ou não, e também a quais fatores ele responde. Bazerman e Samuelson [1983] desenharam um experimento para saber se a maldição do vencedor podia ser observada em condições de laboratório e como ela poderia estar relacionada com a incerteza que os competidores têm acerca do valor verdadeiro do objeto leiloado. Nesse experimento, os competidores deveriam estimar o número de moedas em uma jarra, que verdadeiramente continha 800 centavos de dólar (as moedas eram pennies, que equivalem a 1 centavo de dólar cada; assim, havia 800 moedas na jarra). Um pequeno prêmio foi oferecido para a estimativa mais próxima do valor verdadeiro, apenas com o intuito de estimular uma participação séria dos competidores. Cada competidor deveria, então, fazer um lance pela jarra. $\mathrm{O}$ competidor que ofertasse mais pela jarra seria declarado o vencedor e pagaria o valor ofertado, recebendo em troca o valor contido na jarra. Os competidores deveriam também escrever o intervalo de confiança de $90 \%$ em torno de sua estimativa do valor contido na jarra, e submeter lances para outros objetos similares (por exemplo, uma jarra de nickels, que equivalem a 5 centavos de dólar cada) que também valiam US $\$ 8$.

O principal resultado foi a detecção da ocorrência da maldição do vencedor, com uma média dos lances vencedores em torno de US\$10, sendo, portanto, US\$2 acima do valor verdadeiro dos objetos. Já as médias das estimativas situaram-se em torno de US\$5. Assim, os leilões foram normalmente vencidos por competidores de estimativas altas, e tais estimativas foram altas o suficiente para que o vencedor submetesse um lance acima do valor verdadeiro do objeto leiloado. A análise dos vários fatores que contribuíram para a determinação do valor dos lances sugere que, quando o valor reportado era mais incerto, a maldição do vencedor ocorria em leilões com poucos participantes. Além disso, como o valor que deve ser descontado da estimativa mais alta é maior quando ela é a maior dentre trinta estimativas do que quando é a maior dentre cinco, não é surpresa que a maldição do vencedor seja mais facilmente observada quando existem muitos competidores.

"Enquanto os resultados mostram que a maldição do vencedor não é difícil de ser observada, os participantes do experimento não tinham experiência prévia e, logo, 
poderia se atribuir os resultados ao fato de que os participantes cometiam erros por serem novatos. Além disso, havia uma grande variação nos lances submetidos, e então os resultados poderiam ser atribuídos a erros de alguns poucos participantes (Bazerman e Samuelson reportaram que a média dos lances vencedores foi sensível à alguns lances de valor muito alto). Alguém poderia supor que em um ambiente econômico natural, no qual questões sobre a maldição do vencedor surgiriam, os participantes teriam a oportunidade de aprender com seus erros, e aqueles que não aprendessem acabariam por serem excluídos do mercado devido a suas perdas. Portanto, é razoável imaginar que o fenômeno observado nesse experimento talvez não ocorra em ambientes nos quais possa ser obtida experiência e onde a falência seja possível.

O experimento de Kagel e Levin [1986] foi elaborado com o intuito de abordar tais questões e também para controlar, ao invés de simplesmente medir, a incerteza acerca do valor do objeto leiloado. O experimento envolveu leilões no qual um valor $\mathrm{x}_{0}$ foi escolhido de uma distribuição uniforme, e cada competidor recebeu um sinal privado $\mathrm{x}_{\mathrm{i}}$ retirado de uma distribuição uniforme $\left[\mathrm{x}_{0}-\varepsilon, \mathrm{x}_{0}+\varepsilon\right]$, para um dado $\varepsilon$ conhecido (que variou de US\$12 até US\$30). Se o lance mais alto for $b$, o vencedor ganha $\mathrm{x}_{0}$-b e os demais recebem zero. Os participantes receberam uma dotação inicial em dinheiro, e a oportunidade de submeter lances em uma série de leilões. Os participantes que esgotassem suas dotações eram declarados falidos e não mais podiam participar dos leilões. Além disso, depois de cada leilão, os participantes recebiam bastante feedback a respeito dos resultados: não apenas o lance vencedor era divulgado, mas sim todos os lances, postados ao lado do sinal que cada um recebeu, além do valor de $\mathrm{x}_{0}$. Dessa forma, os participantes tinham a oportunidade de aprender não somente a partir de seus erros, mas também com os erros e acertos dos outros. Em particular, todos os participantes tiveram a oportunidade de ver o payoff obtido pelo vencedor. Por fim, todos os participantes já tinham tido experiência em leilões experimentais.

Os principais resultados deste experimento foram que os lances observados ficaram acima dos lances em equilíbrio de Nash, supondo neutralidade ao risco. Os payoffs 
geralmente foram positivos para grupos de três ou quatro participantes (com payoffs de $65 \%$ do valor dos payoffs de equilíbrio) e negativos para grupos de seis ou sete participantes. De forma geral, os dados foram consistentes com a conclusão de que a maldição do vencedor diminui com a experiência, mas que mudanças no ambiente, particularmente no número de participantes, requerem períodos de adaptação no qual os payoffs ficam abaixo dos valores que teriam quando já se acumula experiência adicional."

\subsubsection{O Primeiro Experimento}

O objetivo deste experimento foi o de verificar na prática se os compradores em um leilão japonês ajustam seus preços de desistência em função da maldição do vencedor ou não. Mais que isso, o experimento deveria também mostrar se a experiência adquirida em leilões anteriores pode atenuar ou eliminar eventuais prejuízos decorrentes da não observação da maldição do vencedor. Isso revelaria uma evidência de que compradores experientes conseguem ou não adequar seus preços de desistência em função da maldição do vencedor.

Foram escolhidos 4 participantes voluntários para o experimento. Todos eram estudantes de mestrado em economia da USP e que não tinham conhecimento da teoria de leilões. Cada um recebeu $\mathrm{R} \$ 10$ pela participação no experimento.

A execução do leilão foi feita através de um software desenvolvido em Pascal (curse.pas). Tal software apresenta na tela o preço corrente do objeto leiloado, além dos nomes dos compradores que ainda estão ativos. Aqueles que desistirem têm seus nomes e os preços de desistência publicados na tela.

Utilizando o teclado, o leiloeiro incrementa o valor do objeto de 0 até $100 \mathrm{em}$ incrementos de 1 . Os jogadores que desejam sair em um dado preço devem também utilizar o teclado para fazê-lo.

Abaixo está um exemplo de leilão implementado através do software desenvolvido. 
No caso, as desistências ocorreram quando o preço atingiu 12 (para o jogador 2), 27 (para o jogador 4) e 72 (para o jogador 3). O jogador 1 foi então declarado o vencedor do leilão, pagando o preço de 72 .

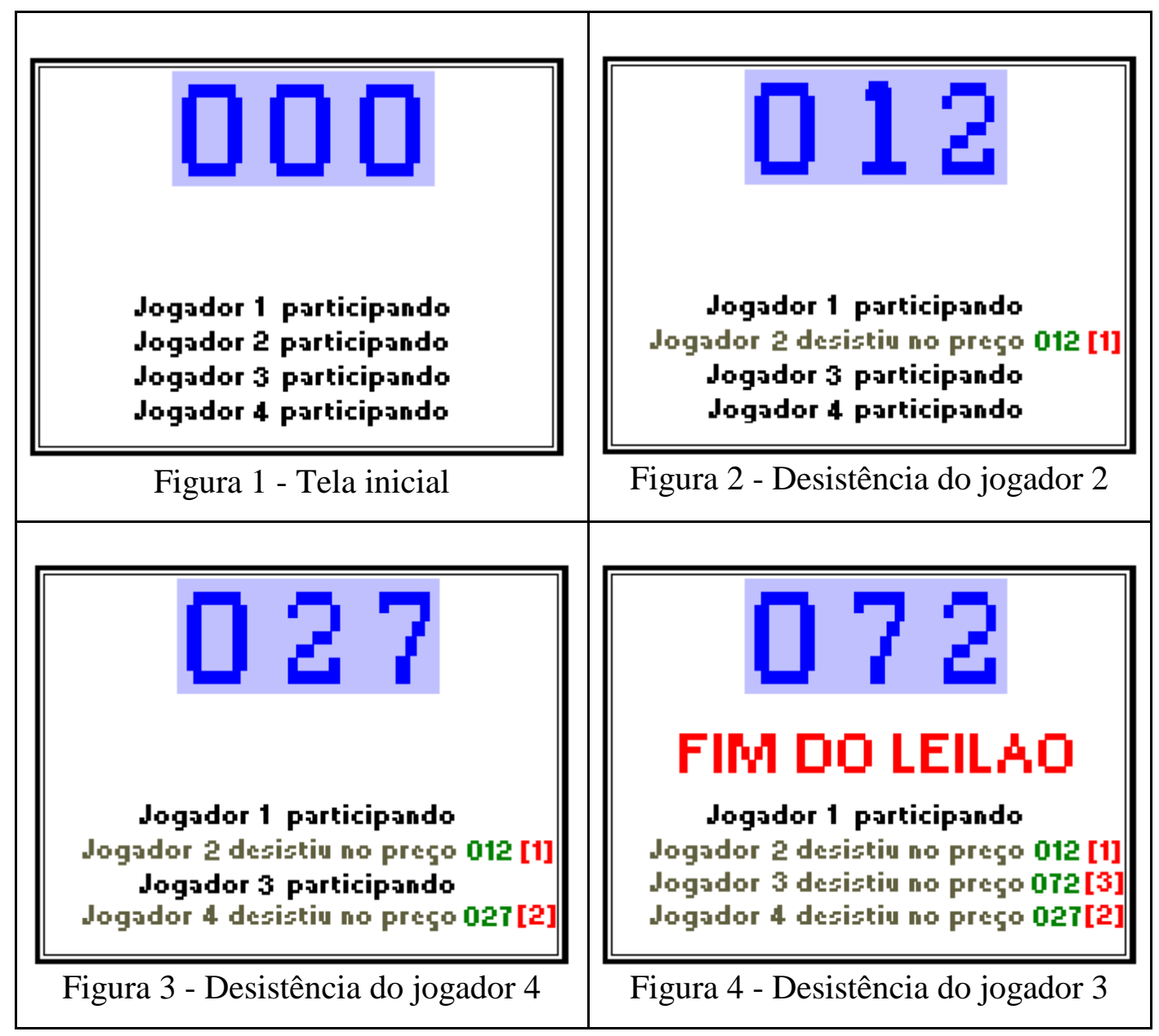

O experimento foi dividido em 3 sessões compostas de 30 leilões cada. Em cada leilão, cada jogador recebeu seu sinal privado retirado de uma distribuição uniforme discreta $[0 ; 100]$ e, fazendo $\mathrm{a}=\mathrm{b}=1$, o valor do objeto leiloado (hipotético) é o mesmo para todos os jogadores, sendo definido como a média aritmética de seus sinais ${ }^{\square}$. Em cada sessão, os resultados dos leilões (payoffs dos jogadores) só eram conhecidos ao final da sessão. Assim, os jogadores participam da segunda sessão conhecendo os resultados da primeira sessão, e participam da terceira sessão conhecendo os resultados da primeira e da segunda sessão. Entre as sessões foi dado um intervalo de 40 minutos, e entre cada leilão foi dado um intervalo de 30 segundos. 
Em cada sessão, os payoffs de um dado jogador ao longo dos leilões são somados, e para aquele que tiver o maior payoff na sessão é dado $\mathrm{R} \$ 6$. Para o segundo maior payoff na sessão é dado $\mathrm{R} \$ 3$. Finalmente, para o terceiro maior payoff na sessão é dado $\mathrm{R} \$ 1.50$.

\subsubsection{Incentivo para que os competidores maximizem seus payoffs}

Idealmente, os jogadores devem ser recompensados, ou penalizados, a cada leilão realizado. Isso significa que se um jogador obtém payoff $\mathrm{X}$ em um leilão, este valor deve ser somado à seu patrimônio e ponto final. Isso não foi feito devido a limitação de recursos.

Para a execução do experimento, havia uma verba de $\mathrm{R} \$ 100$. Este valor foi definido por mim, visto que foi retirado de minha bolsa de estudos, e era condicionado à minha disponibilidade financeira.

Dessa verba, $\mathrm{R} \$ 10$ foram destinados à alimentação durante os coffee-breaks, compostos de bolachas, balas, refrigerantes e água. Logo sobraram R $\$ 90$ destinados à premiação dos jogadores.

Quando busquei encontrar voluntários para o experimento, tentei reunir um grupo homogêneo, no que diz respeito a escolaridade e nível cultural. Estando no curso de mestrado, procurei, então, voluntários entre meus colegas de mestrado. Mas logo percebi que não haveria interesse em participar do experimento, que durou ao todo 5 horas, sem a garantia de que algum dinheiro fosse ganho. Mais que isso, como o experimento foi realizado em uma sexta-feira, dia de realização de seminários em que são oferecidos sanduíches e refrigerantes, haveria um custo de oportunidade adicional de almoço. Por isso, estipulei um pagamento incondicional de $\mathrm{R} \$ 10$ a cada jogador, independente de sua performance, além de $\mathrm{R} \$ 5$ de compensação pelo "almoço" perdido. A data foi marcada de forma a fazer com que todos os voluntários concordassem em participar.

\footnotetext{
${ }^{4}$ Veja que cada jogador só possui $25 \%$ da informação necessária para calcular o valor do objeto.
} 
Portanto, sobraram $\mathrm{R} \$ 30$ destinados ao incentivo dos jogadores em maximizar seus payoffs nos leilões. Dado que eu deveria garantir que nenhum jogador saísse do experimento sem os $\mathrm{R} \$ 15$ pela participação e almoço perdido, payoffs negativos não poderiam implicar em descontos nos valores recebidos pelos participantes. Mais que isso, os ganhos de premiação não poderiam superar $\mathrm{R} \$ 30$. O que fazer então?

O experimento foi feito em 3 sessões. Assim, havia $\mathrm{R} \$ 10$ para cada sessão. De forma a incentivar a maximização de payoffs, ao mesmo tempo em que existisse um limite para os ganhos e inexistissem perdas, estabeleci a regra de que, em cada sessão, os payoffs dos jogadores nos 30 leilões seriam somados, e prêmios do $1^{\circ}$ ao $3^{\circ}$ colocados seriam distribuídos.

Tal solução apresenta um problema. O prêmio de um jogador dependerá do resultado obtido pelos demais. Assim, os jogadores têm duas formas de maximizar seus prêmios: maximizar seu payoff ou minimizar o payoff dos demais competidores.

\subsubsection{Resultados}

$\mathrm{Na}$ tabela abaixo reporto algumas estatísticas do experimento. As tabelas completas com os resultados dos leilões do primeiro e segundo experimentos estão no apêndice.

Tabela 2 - Estatísticas do primeiro experimento

\begin{tabular}{|l|r|r|r|}
\cline { 2 - 4 } \multicolumn{1}{c|}{} & Sessão I & Sessão II & Sessão III \\
\hline Vencedor tinha o maior sinal & $63.33 \%$ & $56.67 \%$ & $60.00 \%$ \\
\hline Vencedor teve payoff negativo & $56.67 \%$ & $56.67 \%$ & $60.00 \%$ \\
\hline Média do valor verdadeiro do objeto & 49.00 & 48.50 & 49.56 \\
\hline Payoff médio & -0.67 & -1.60 & -0.08 \\
\hline $\mathbf{1}^{\text {a desistência / valor do objeto (média) }}$ & $94.98 \%$ & $106.96 \%$ & $100.42 \%$ \\
\hline $\mathbf{2}^{\text {a }}$ desistência / valor do objeto (média) & $99.80 \%$ & $110.77 \%$ & $104.72 \%$ \\
\hline $\mathbf{3}^{\text {a desistência / valor do objeto (média) }}$ & $110.41 \%$ & $112.23 \%$ & $105.69 \%$ \\
\hline
\end{tabular}

Obs: a $n$-ésima desistência é o n-ésimo preço de desistência observado. Por exemplo, a $l^{a}$ desistência é o preço de desistência mais baixo registrado.

Desde a primeira sessão, e com maior intensidade na $2^{\mathrm{a}}$ e $3^{\mathrm{a}}$ sessões, ficou claro que a estratégia adotada pelos participantes se aproximava muito da de minimização do 
payoff do vencedor. Conforme relatado pelos próprios participantes, não havia interesse na revelação de seus sinais e, mais que isso, aqueles de sinal mais baixo optavam por desistir a preços muito acima do valor de seus sinais, com o intuito de causar perdas ao vencedor, mesmo correndo o risco de acabarem por vencer o leilão.

O comportamento observado mais comum foi o de todos os jogadores tentarem desistir ao mesmo tempo, desde que o preço corrente do leilão estivesse próximo de 50, em algo semelhante a um "estouro de boiada". Bastava um competidor desistir que, imediatamente, os outros também tentavam desistir, restando apenas o competidor que tinha realmente o interesse em vencer o leilão no preço corrente, ou que foi o menos ágil no processo de desistência.

Os resultados apontaram a ocorrência da maldição do vencedor, mas o comportamento dos participantes, que deliberadamente tentavam fazer com que o vencedor fosse amaldiçoado, não permite a conclusão de que sua causa foi a não distinção entre valor esperado do objeto leiloado e valor esperado do objeto condicional ao fato de se vencer o leilão.

Como última conseqüência do comportamento observado dos jogadores, a questão da experiência acabou por não ser avaliada.

O resultado deste experimento mostrou que o mesmo não foi elaborado corretamente de forma a atingir seus objetivos. Identifico duas questões que impediram o seu sucesso, e que influenciaram de maneira crucial na elaboração do experimento:

- falta de verba para premiação, que implicava em limitação nos valores pagos; e

- inviabilidade de se conseguir voluntários dispostos a participar do experimento sem a garantia de lucro e, mais ainda, podendo ter prejuízo.

\subsubsection{O Segundo Experimento: Mudança de Incentivo}

Com base nos resultados obtidos no experimento anterior, foi elaborado um novo 
experimento, composto de 30 leilões, com regras que incentivaram unicamente os participantes a maximizarem seus payoffs. Nesta regra, os jogadores devem ser recompensados, ou penalizados, a cada leilão realizado, o que significa que se um jogador obtém payoff $\mathrm{X}$ em um leilão, este valor deve ser somado ao seu patrimônio e ponto final. Na prática isso foi feito com a definição de uma cotação E (em reais) para a unidade de contagem utilizada no leilão. Assim, se o jogador em um dado leilão teve payoff de $\mathrm{X}$, então ele recebe (respectivamente, paga) X.E do (respectivamente, para o) realizador do experimento.

Alguns fatores permitiram a realização de um novo experimento, que contou com a participação dos mesmos voluntários do experimento anterior. $\mathrm{O}$ primeiro foi $\mathrm{o}$ interesse dos voluntários em participar do novo experimento, mesmo sabendo que correriam o risco de terem prejuízo. Isso provavelmente foi devido a um aumento de confiança dos participantes em obterem lucro, devido à experiência que eles adquiriram anteriormente, bem como ao fato de eles participarem de um experimento já conhecendo bem suas regras básicas de funcionamento, reduzindo eventuais incertezas.

O segundo fator foi que a observação dos resultados anteriores revelou que a probabilidade de se pagar prêmios altos aos compradores (ou receber dos compradores pagamentos decorrentes de payoffs negativos) é baixa. Isso estimula a implementação do experimento com as novas regras, mesmo com a existência de limitações de verba.

O terceiro diz respeito a inibição de conluios. Um conluio poderia tomar a seguinte forma: os 4 jogadores estabelecem uma cota de leilões a serem vencidos por cada um (por exemplo 1/4) e intencionalmente fazem com que os preços nos leilões fiquem muito baixos, causando um grande prejuízo para o realizador do experimento. Nesse sentido, duas medidas foram tomadas. A primeira foi a exigência do pagamento de ingresso dos voluntários, no valor de $\mathrm{R} \$ 10$, para participarem do experimento, ingresso esse não restituível. Com isso, buscou-se fazer com que todos os participantes pertencentes a um conluio tivessem a intenção de pelo menos recuperar 
o dinheiro gasto através do conluio, o que por si só já amplificaria o problema de definição da ordem em que eles venceriam os leilões, e, assim, quem recuperaria antes sua parte. A segunda medida foi a de que o valor da cotação E, em cada leilão, só era anunciada no início do respectivo leilão. Isso conferiu ao realizador do experimento um poder de dissuasão, dado que se, por exemplo, fosse detectada a formação de um conluio em 2 leilões consecutivos, nos leilões seguintes o realizador do experimento poderia estipular um valor baixo para $\mathrm{E}$, o que implicaria no fato de que os compradores que ainda não tivessem vencido sua cota de leilões acabariam por ter prejuízo.

Com relação à questão da aquisição de experiência, os resultados dos leilões eram imediatamente divulgados após sua realização, incluindo a revelação dos sinais dos jogadores. Com isso, buscou-se mais uma vez detectar se os participantes, que já possuíam experiência, conseguiriam reduzir ou eliminar a maldição do vencedor ao longo dos leilões.

\subsubsection{Resultados}

Na tabela abaixo reporto algumas estatísticas do novo experimento.

Tabela 3 - Estatísticas do segundo experimento

\begin{tabular}{|l|r|}
\hline Vencedor tinha o maior sinal & $73.33 \%$ \\
\hline Vencedor teve payoff negativo & $40.00 \%$ \\
\hline Média do valor verdadeiro do objeto & 48.59 \\
\hline Payoff médio & 0.35 \\
\hline $\mathbf{1}^{\mathbf{a}}$ desistência / valor do objeto (média) & $82.34 \%$ \\
\hline $\mathbf{2}^{\mathbf{a}}$ desistência / valor do objeto (média) & $93.76 \%$ \\
\hline $\mathbf{3}^{\mathbf{a}}$ desistência / valor do objeto (média) & $100.58 \%$ \\
\hline
\end{tabular}

Obs: a n-ésima desistência é o n-ésimo preço de desistência observado. Por exemplo, a $l^{a}$ desistência é o preço de desistência mais baixo registrado.

Comparativamente ao experimento anterior, percebe-se, através da diminuição dos preços de desistência normalizados pelo valor do objeto, um forte indício de que os jogadores não mais deliberadamente procuraram imputar a maldição do vencedor. 
Os resultados dos 30 leilões são mostrados a seguir, onde os 4 jogadores são identificados por $\mathrm{J} 1, \mathrm{~J} 2$, J3 e $\mathrm{J} 4$.

Tabela 4 - Resultados do segundo experimento

\begin{tabular}{|c|c|}
\hline Leilão & $\mathrm{E}(\mathrm{R} \$)$ \\
\hline 1 & 0.05 \\
\hline 2 & 0.05 \\
\hline 3 & 0.05 \\
\hline 4 & 0.05 \\
\hline 5 & 0.05 \\
\hline 6 & 0.10 \\
\hline 7 & 0.10 \\
\hline 8 & 0.10 \\
\hline 9 & 0.10 \\
\hline 10 & 0.10 \\
\hline 11 & 0.10 \\
\hline 12 & 0.10 \\
\hline 13 & 0.10 \\
\hline 14 & 0.10 \\
\hline 15 & 0.10 \\
\hline 16 & 0.15 \\
\hline 17 & 0.15 \\
\hline 18 & 0.15 \\
\hline 19 & 0.15 \\
\hline 20 & 0.15 \\
\hline 21 & 0.15 \\
\hline 22 & 0.15 \\
\hline 23 & 0.15 \\
\hline 24 & 0.15 \\
\hline 25 & 0.20 \\
\hline 26 & 0.20 \\
\hline 27 & 0.25 \\
\hline 28 & 0.25 \\
\hline 29 \\
\hline 30 \\
\hline 0.35 \\
\hline 0.50 \\
\hline
\end{tabular}

\begin{tabular}{|c|c|c|c|c|}
\hline \multicolumn{4}{|c|}{ Sinais } & \multirow{2}{*}{$\begin{array}{c}\text { Valor do } \\
\text { Objeto }\end{array}$} \\
\hline J1 & $\mathrm{J} 2$ & $\mathrm{~J} 3$ & $\mathrm{~J} 4$ & \\
\hline 40 & 36 & 73 & 53 & 50.5 \\
\hline 87 & 63 & 24 & 29 & 50.75 \\
\hline 98 & 64 & 23 & 68 & 63.25 \\
\hline 13 & 67 & 26 & 2 & 27 \\
\hline 18 & 85 & 12 & 7 & 30.5 \\
\hline 28 & 3 & 54 & 73 & 39.5 \\
\hline 87 & 37 & 1 & 89 & 53.5 \\
\hline 59 & 57 & 16 & 25 & 39.25 \\
\hline 57 & 66 & 33 & 86 & 60.5 \\
\hline 79 & 83 & 98 & 15 & 68.75 \\
\hline 77 & 19 & 64 & 67 & 56.75 \\
\hline 38 & 44 & 48 & 61 & 47.75 \\
\hline 79 & 0 & 51 & 18 & 37 \\
\hline 41 & 16 & 10 & 21 & 22 \\
\hline 41 & 15 & 94 & 5 & 38.75 \\
\hline 90 & 38 & 17 & 31 & 44 \\
\hline 41 & 73 & 40 & 32 & 46.5 \\
\hline 51 & 17 & 52 & 64 & 46 \\
\hline 70 & 84 & 2 & 80 & 59 \\
\hline 82 & 46 & 8 & 19 & 38.75 \\
\hline 88 & 45 & 31 & 1 & 41.25 \\
\hline 84 & 48 & 33 & 88 & 63.25 \\
\hline 62 & 66 & 62 & 56 & 61.5 \\
\hline 51 & 69 & 52 & 71 & 60.75 \\
\hline 97 & 82 & 32 & 61 & 68 \\
\hline 13 & 25 & 80 & 59 & 44.25 \\
\hline 45 & 1 & 67 & 56 & 42.25 \\
\hline 28 & 48 & 7 & 90 & 43.25 \\
\hline 98 & 92 & 56 & 65 & 77.75 \\
\hline 0 & 54 & 77 & 11 & 35.5 \\
\hline
\end{tabular}

\begin{tabular}{|c|}
\hline $\begin{array}{c}\text { Receita } \\
\text { Obtida }\end{array}$ \\
\hline 40 \\
\hline 47 \\
\hline 55 \\
\hline 40 \\
\hline 38 \\
\hline 37 \\
\hline 50 \\
\hline 36 \\
\hline 49 \\
\hline 57 \\
\hline 61 \\
\hline 45 \\
\hline 45 \\
\hline 35 \\
\hline 40 \\
\hline 40 \\
\hline 40 \\
\hline 48 \\
\hline 61 \\
\hline 45 \\
\hline 41 \\
\hline 67 \\
\hline 53 \\
\hline 56 \\
\hline 59 \\
\hline 48 \\
\hline 40 \\
\hline 46 \\
\hline 63 \\
\hline 34 \\
\hline
\end{tabular}

\begin{tabular}{|l|l|l|l|}
\hline \multicolumn{4}{|c|}{ Desistências Obtidas } \\
\hline $\mathrm{J} 1$ & $\mathrm{~J} 2$ & $\mathrm{~J} 3$ & $\mathrm{~J} 4$ \\
\hline 40 & 40 & 40 & \\
\hline & 47 & 40 & 40 \\
\hline & 48 & 42 & 55 \\
\hline 40 & 40 & & 32 \\
\hline 38 & & 35 & 35 \\
\hline 28 & 34 & 37 & \\
\hline 50 & 35 & 35 & \\
\hline & 36 & 36 & 36 \\
\hline 46 & 49 & 41 & \\
\hline 57 & 55 & & 35 \\
\hline & 37 & 56 & 61 \\
\hline 38 & & 45 & 45 \\
\hline 45 & 32 & & 32 \\
\hline 35 & 35 & 35 & \\
\hline 40 & 37 & & 29 \\
\hline & 40 & 40 & 40 \\
\hline 35 & & 40 & 35 \\
\hline 41 & 41 & 48 & \\
\hline 55 & 61 & 49 & \\
\hline & 45 & 45 & 34 \\
\hline & 41 & 41 & 29 \\
\hline & 54 & 60 & 67 \\
\hline 50 & 53 & & 50 \\
\hline 52 & 56 & 56 & \\
\hline & 59 & 59 & 59 \\
\hline 44 & 44 & & 48 \\
\hline 39 & 35 & & 40 \\
\hline 45 & 46 & 46 & \\
\hline & 63 & 63 & 59 \\
\hline 1 & 34 & & 30 \\
\hline
\end{tabular}

\begin{tabular}{|c|c|c|c|}
\hline \multicolumn{4}{|c|}{ Payoffs Obtidos } \\
\hline $\mathrm{J} 1$ & $\mathrm{~J} 2$ & $\mathrm{~J} 3$ & $\mathrm{~J} 4$ \\
\hline 0 & 0 & 0 & 10.5 \\
\hline 3.75 & 0 & 0 & 0 \\
\hline 8.25 & 0 & 0 & 0 \\
\hline 0 & 0 & -13 & 0 \\
\hline 0 & -7.5 & 0 & 0 \\
\hline 0 & 0 & 0 & 2.5 \\
\hline 0 & 0 & 0 & 3.5 \\
\hline 3.25 & 0 & 0 & 0 \\
\hline 0 & 0 & 0 & 11.5 \\
\hline 0 & 0 & 11.75 & 0 \\
\hline-4.25 & 0 & 0 & 0 \\
\hline 0 & 2.75 & 0 & 0 \\
\hline 0 & 0 & -8 & 0 \\
\hline 0 & 0 & 0 & -13 \\
\hline 0 & 0 & -1.25 & 0 \\
\hline 4 & 0 & 0 & 0 \\
\hline 0 & 6.5 & 0 & 0 \\
\hline 0 & 0 & 0 & -2 \\
\hline 0 & 0 & 0 & -2 \\
\hline-6.25 & 0 & 0 & 0 \\
\hline 0.25 & 0 & 0 & 0 \\
\hline-3.75 & 0 & 0 & 0 \\
\hline 0 & 0 & 8.5 & 0 \\
\hline 0 & 0 & 0 & 4.75 \\
\hline 9 & 0 & 0 & 0 \\
\hline 0 & 0 & -3.75 & 0 \\
\hline 0 & 0 & 2.25 & 0 \\
\hline 0 & 0 & 0 & -2.75 \\
\hline 14.75 & 0 & 0 & 0 \\
\hline 0 & 0 & 1.5 & 0 \\
\hline
\end{tabular}

Os payoffs médios teóricos, calculados com base no comportamento em equilíbrio obtido do modelo teórico, os payoffs obtidos e suas proporções, são reportados abaixo.

Tabela 5 - Payoffs dos jogadores no segundo experimento

\begin{tabular}{|l|c|c|c|}
\cline { 2 - 4 } \multicolumn{1}{c|}{} & Payoffs médios teóricos (1) & Payoffs médios obtidos (2) & Proporção (2)/(1) \\
\hline J1 & 2.35833 & 0.96667 & $40.99 \%$ \\
\hline J2 & 1.31667 & 0.05833 & $04.43 \%$ \\
\hline J3 & 1.26667 & -0.06667 & - \\
\hline J4 & 1.05000 & 0.43333 & $41.27 \%$ \\
\hline
\end{tabular}

Vê-se nas tabelas acima um indício de que a causa da maldição do vencedor esteve presente no experimento, demonstrada de forma dramática pelos compradores de sinal mais baixo. Tais compradores desistiram em preços muito acima do valor de 
seus sinais, contrariando as previsões, feitas de acordo com o modelo teórico mostrado no trabalho. Esse comportamento fez com que os compradores de sinal elevado tivessem muita dificuldade em avaliar o valor dos sinais dos compradores desistentes em um dado leilão. Com isso, não é surpresa que o efeito que a maldição do vencedor provoca nos payoffs dos vencedores tenha sido observado. Ainda assim, sua intensidade foi menor do que a registrada no experimento anterior.

Com relação à questão da aquisição de experiência, não foi possível encontrar indícios de que os compradores reduziram ou eliminaram o efeito da maldição do vencedor ao longo dos leilões.

\section{História dos Leilões na Internet: o Surgimento da eBay}

Antes de tudo, é importante diferenciar a Internet da World Wide Web. A Internet é o meio pelo qual estão interligados diversos computadores e redes de computadores pelo mundo. Já a World Wide Web, ou apenas Web, é uma criação mais recente do que a Internet, e que faz com que seja uma tarefa fácil e agradável a obtenção de informações da Internet.

Antes do surgimento da Web, já era possível trocar informações entre dois computadores ligados na Internet. O problema é que não se tinha a facilidade que se tem hoje em acessar um texto editado com imagens, por exemplo, através de um navegador. As informações eram trocadas basicamente em forma de arquivos que deviam ser tratados caso a caso. O que a Web trouxe de novo foi a possibilidade de acesso a documentos multimídia da forma como conhecemos hoje em dia, através de navegadores que mostram textos, imagens e sons ao mesmo tempo e organizadamente.

Os parágrafos restantes desta subseção seguem a descrição obtida de Lucking-Reiley [1999], e foram traduzidos e adaptados pelo autor. 
"Os leilões na Internet ocorriam antes mesmo da Internet se tornar acessível ao público em geral através da Web. Antes do final de 1993, já se podia encontrar leilões sendo realizados através de newsgroups e de listas (conjunto de emails) de discussão. Exemplos desses tipos de leilões eram os realizados em um newsgroup dedicado ao comércio de cartões de um jogo chamado "Magic: the Gathering". Nesse newsgroup, centenas de vendedores promoviam leilões de seus cartões, sendo que a duração de cada leilão ia desde alguns dias até semanas. Cada vendedor oferecia normalmente dúzias de blocos de cartões independentes simultaneamente, em um tipo de leilão ascendente: os compradores submetiam suas propostas via email, e os vendedores postavam diariamente o lance corrente mais alto. Também havia algumas variações na forma como o leilão ocorria: por exemplo, um leilão poderia terminar em uma data pré-fixada, enquanto outro poderia manter-se aberto a propostas até que se passassem três dias sem que houvesse a submissão de novos lances.

Os primeiros sites de leilões na Web parecem ter sido o da Onsale, aberto em maio de 1995, e o da eBay, que iniciou suas operações em setembro de 1995. Estes foram os primeiros a utilizar a nova tecnologia que era oferecida pela Web, incluindo a submissão de lances automatizados, e de mecanismos de busca e categorias “clicáveis" que permitiam aos compradores localizar seus objetos de interesse. Assim como os leilões que ocorriam em newsgroups, os leilões na Web eram e continuam a ser leilões que duram dias ou semanas, e possibilitam aos compradores participar quando e onde for mais conveniente.

A Onsale começou como um site mercante, vendendo seus próprios artigos, principalmente computadores e eletrônicos. O CEO da Onsale, Jerry Kaplan, entendia que os leilões proporcionariam diversão aos compradores, e que a natureza competitiva das transações seria apreciada principalmente por homens, pois estes normalmente não encaravam o ato de comprar como sendo diversão. Entretanto, este modelo de negócios não teve muito sucesso, e a empresa mudou de estratégia. Em 1997, a Onsale começou a incluir em seu site um serviço de leilão por listagem, ou seja, um leilão no qual eram as pessoas que ofereciam seus artigos para leilão em 
categorias pré-estabelecidas. Este serviço de leilão por listagem foi posteriormente transferido à Yahoo!. Em 1998, a Onsale anunciou que iria começar a vender em seu site artigos eletrônicos à preços de atacado, e em julho de 1999, a Onsale fundiu-se com um outro varejista online chamado Egghead.

Em contraste, a eBay começou encorajando as pessoas a listarem seus próprios leilões em seu site. Desde o início, a maioria dos itens oferecidos na eBay tem sido de artigos para colecionadores (cartões esportivos, revistas em quadrinhos, etc.), mas há também muitos outros tipos de artigos. Os vendedores na eBay podem escolher um conjunto de parâmetros para cada leilão: duração do leilão, lance inicial e o estabelecimento de um preço de reserva secreto. O site cresceu rapidamente, a uma taxa de $12 \%$ ao mês. Em julho de 1999, a eBay tinha em seu site quase 10 milhões de leilões sendo realizados, com um volume em dólares de 190 milhões. Existem muitos outros sites de leilões com um modelo de negócio semelhante ao da eBay, mas nenhum chegou perto do tamanho que a eBay tem hoje.

Em 1998, duas grandes empresas da Web, Yahoo! e Amazon, apresentaram seus serviços de leilão pessoa-a-pessoa de acordo com o modelo utilizado pela eBay. Entretanto, a eBay tem a vantagem de possuir significante economia de escala: vendedores preferem listar seus artigos onde exista um maior número de compradores visitando o site, e os compradores preferem visitar sites com grande variedade de artigos sendo oferecidos."

\section{Coleta de Dados de Leilões na Internet}

Apesar da grande atenção dada à teoria de leilões nos últimos anos, o estudo empírico de leilões sempre foi limitado pela falta de dados disponíveis. Com o advento da Internet, e mais especificamente com o surgimento de sites de leilão na $\mathrm{Web}^{\mathrm{G}}$, tem-se hoje um ambiente muito rico para exploração devido a grande

\footnotetext{
${ }^{5}$ Para entender como surgiram os leilões na Internet e saber como e o que está se negociando, veja Lucking-Reiley [1999].
} 
disponibilidade de dados presente nesses sites. Além disso, como as informações estão disponíveis em meio eletrônico, a possibilidade de obtenção das mesmas a baixo custo e a alta velocidade, através de programas especializados, torna a coleta desses dados um ponto que deve merecer atenção por parte daqueles que tem interesse no estudo empírico de leilões.

Neste trabalho, escolhi para estudo o mercado de selos negociados na eBay. Mais especificamente, estudo os leilões de selos dos Estados Unidos, não usados, produzidos de 1901 até 1940. O motivo da escolha pelos leilões de selos da eBay se deveu a inexistência de trabalhos que abordam esse mercado, embora a quantidade de dados disponíveis para o seu estudo seja abundante. Vale dizer que alguns dos trabalhos mais recentes sobre leilões na Internet, utilizados como referência nesta dissertação, têm tratado do mercado de moedas para colecionadores negociados na eBay.

\subsection{Breve Descrição do Mercado de Selos}

Para uma descrição introdutória mais completa sobre filatelia, recomendo a leitura de Inside Scoop para selos, acessível em http://pages.ebay.com/community/library. Os parágrafos seguintes foram adaptados pelo autor dessa fonte.

O primeiro selo postal adesivo foi usado na Inglaterra em 1840 e significava o prépagamento da postagem através de sua presença na carta, com o cancelamento dos selos feito através de marcas de tinta de forma a prevenir a sua reutilização. A coleção de selos começou então quase que imediatamente, sendo que a mais antiga citação é a de um anúncio no London Times, em 1841, onde uma jovem procurava ajuda para decorar seu quarto de vestir com selos. No decorrer dos anos, com o aumento do número e variedade dos selos, a coleção de selos se tornou muito popular e por volta de 1860 era possível encontrar colecionadores em todo o mundo civilizado. Hoje, o motivo pelo qual as pessoas colecionam selos vai desde a satisfação de seu desejo de ordenamento e aquisição, até o prazer que a admiração de pequenas obras de arte proporciona. 
Tipicamente, os colecionadores se especializam em uma categoria, como a de selos não usados de 1901 a 1940 dos Estados Unidos. Os selos são normalmente acondicionados em álbuns e sua apreciação é feita por meio de lupas, tendo em vista a reduzida dimensão dos selos.

Os fatores que influenciam o valor de um selo são: impressão, cor, centralização, estado da goma adesiva e o cancelamento, no caso de selos usados. Além disso, são considerados defeitos que influenciam no preço de um selo a presença de rasgos, manchas, sujeira, falta de picote, amassos, entre outros. A fonte de referência mais citada para a precificação dos selos é o The Scott Catalog, com preços divulgados para selos em condição de estado muito boas / excelentes.

\subsection{Descrição dos Dados}

Os dados de interesse para este trabalho são os de leilões já realizados. A eBay deixa disponível o acesso aos dados de leilões encerrados nos últimos 30 dias, e só no segmento em estudo (selos não usados de 1901 a 1940 dos Estados Unidos) isso representa mais de 10000 leilões.

Os dados que foram coletados e utilizados no trabalho foram:

preço final: preço final do selo atingido no leilão;

preço inicial: preço inicial do selo estabelecido pelo vendedor para o leilão; número de lances: total de lances registrados no leilão;

número de compradores: total de compradores participando do leilão; rating positivo do vendedor: número de comentários positivos do vendedor feitos por outras pessoas;

rating neutro do vendedor: número de comentários neutros do vendedor feitos por outras pessoas;

rating negativo do vendedor: número de comentários negativos do vendedor feitos por outras pessoas; 
informação de defeitos no selo: é 0 se não for reportado nenhum defeito e é 1 caso contrário;

número de informações positivas do selo: total de características positivas do selo descritas pelo vendedor;

número de informações negativas do selo: total de características negativas do selo descritas pelo vendedor;

valor de catálogo: preço de catálogo do selo em condições de estado excelentes;

data de início do leilão: data de início do leilão, com dia, mês, ano, hora, minuto e segundo;

data de encerramento do leilão: data de encerramento do leilão, com dia, mês, ano, hora, minuto e segundo;

buy it now: é 0 se não tiver sido usado para encerrar o leilão e 1 caso contrário. Se essa opção foi efetivamente utilizada, significa que o leilão foi encerrado imediatamente após a submissão da primeira oferta

foto do selo: é 0 se o vendedor não apresentar uma foto do selo na descrição e 1 caso contrário;

preço de reserva secreto: é 0 se não for utilizado preço de reserva secreto e 1 caso contrário;

custos de envio: despesas de envio e seguro que o vendedor cobra para enviar o selo ao comprador;

Inicialmente, coletei manualmente dados de aproximadamente 350 leilões que terminaram em um único dia. Os dados foram: preço final e inicial; número de lances e de compradores; ratings positivo, negativo e neutro do vendedor (consolidado); informação de defeitos no selo; valor de catálogo; datas de início e encerramento do leilão; buy it now; foto do selo; preço de reserva secreto; custos de envio. Daqui em diante chamarei este conjunto de dados como sendo o Conjunto de Dados 0.

Constatei a não utilização de preços de reserva secreto em nenhum leilão deste conjunto inicial. Posteriormente, por inspeção em outros dias, verifiquei também a

\footnotetext{
${ }^{6}$ Veja a subseção 4.3 para mais informações.
} 
não utilização de preços de reserva secreto. Por isso, não mais coletei tal informação no conjunto de dados a seguir. $\mathrm{O}$ mesmo ocorreu com a presença de uma fotografia digitalizada do selo. Praticamente todos os leilões apresentam tal informação, e por isso também não mais coletei essa informação. Nessa primeira coleta, os ratings do vendedor foram consolidados em um único valor, dado pela soma das avaliações positiva (com sinal positivo) e negativa (com sinal negativo) do mesmo.

Os dados obtidos de maneira automática, que geraram o daqui por diante chamado Conjunto de Dados Gold, foram: preço final e inicial; número de lances e de compradores; ratings positivo, negativo e neutro do vendedor; número de informações positivas e negativas de cada selo leiloado; valor de catálogo; datas de início e encerramento do leilão; buy it now.

Observe que os dados de custo de envio do selo não foram coletados. Isso se deveu à extrema dificuldade de se automatizar a coleta de tal informação.

\subsection{Funcionamento do Leilão na eBay}

A oferta de lances na eBay é uma variante dinâmica de um leilão de segundo preço, chamada de "proxy bidding". Cada comprador deve informar o preço máximo que está disposto a pagar pelo objeto leiloado ${ }^{\square}$ O computador da eBay compara este valor com o preço mais alto já oferecido pelo objeto no leilão e, caso o valor seja maior, este comprador passa a ser então o atual comprador de oferta mais alta. Esta oferta é igual ao preço anteriormente mais alto somado do acréscimo mínimo permitido. Toda vez que um comprador tem seu lance coberto por outro, ou vence o leilão, ele é notificado por e-mail do fato. O papel da eBay termina aqui. O comprador e vendedor devem então entrar em contato e combinar a forma de fechar a transação. Os leilões normalmente têm custo de envio e seguro cobrados pelo vendedor, e este valor é adicional ao preço pago pelo objeto.

Além disso, o vendedor pode estabelecer se o leilão terá ou não preço de reserva

\footnotetext{
${ }^{7}$ Este valor pode ser atualizado enquanto o leilão não for encerrado.
} 
secreto. Neste caso, os compradores apenas são avisados se o preço de reserva já foi ou não atingido no decorrer do leilão. O preço de reserva não é revelado nem ao fim do leilão.

Os compradores podem ter a opção, quando ainda não tiverem sido ofertados quaisquer lances, de encerrar imediatamente o leilão e comprar o objeto através da opção Buy it Now. O vendedor estabelece um preço acima do lance inicial (preço mínimo) e, se algum comprador ofertar este preço sem que nenhum lance tenha sido dado anteriormente por ninguém, então o leilão acaba e o comprador leva o objeto pelo preço determinado pelo vendedor para a opção Buy it Now.

Os vendedores podem se diferenciar dos demais através do sistema de feedback da eBay. Ao término de um leilão, a eBay permite que o vendedor e o comprador vencedor façam comentários sobre seus comportamentos durante a transação do objeto. Dessa forma é criada a reputação de ambas as partes em termos de número de comentários positivos, neutros e negativos.

\subsection{Programas Desenvolvidos}

O desenvolvimento dos programas para coleta de dados foi inspirado na idéia proposta em Lucking-Reiley et al. [2000]. Todos os programas foram feitos em Perl e rodaram a partir de um PC Pentium 133 com o sistema operacional Windows, conectado à Internet através de uma conexão convencional de $36 \mathrm{~K}$.

A linguagem de programação Perl foi escolhida em função de seu bom desempenho em tarefas que envolvem manipulação de textos e interação com a Internet. Além disso, Perl também tem a característica de ser, atualmente, uma das linguagens mais poderosas no quesito portabilidade. Isso significa que é possível utilizar, sem qualquer modificação, os programas desenvolvidos neste trabalho em uma máquina que esteja rodando em um sistema operacional como, por exemplo, o UNIX. A importância dessa portabilidade reside no fato de que, se for possível utilizar uma estação de trabalho rodando em plataforma UNIX com acesso em alta velocidade à 
Internet, pode-se ter um ganho muito grande em termos de velocidade e capacidade de processamento. Apenas para dar uma idéia do que isso significa, a coleta completa dos dados de 2000 leilões, que leva aproximadamente 8 horas no equipamento que utilizei neste trabalho, poderia levar apenas 24 minutos em uma estação de trabalho rodando em plataforma UNIX e que operasse a modestíssima capacidade de 20 vezes a capacidade de processamento de meu equipamento.

A idéia básica do algoritmo de coleta dos dados dos leilões é descrita por dois passos:

Passo 1: busca-se os números de identificação dos leilões em que temos interesse. Todo leilão na eBay possui esse número de identificação (ID);

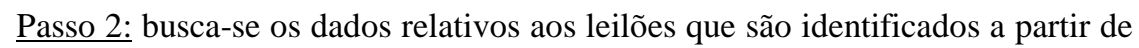
um subconjunto de ID's;

Os programas desenvolvidos buscam informações na eBay e as manipulam, conforme descrição do funcionamento de cada programa feita a seguir. O diagrama a seguir mostra a lógica de funcionamento dos programas, bem como os arquivos que são gerados durante suas execuções.

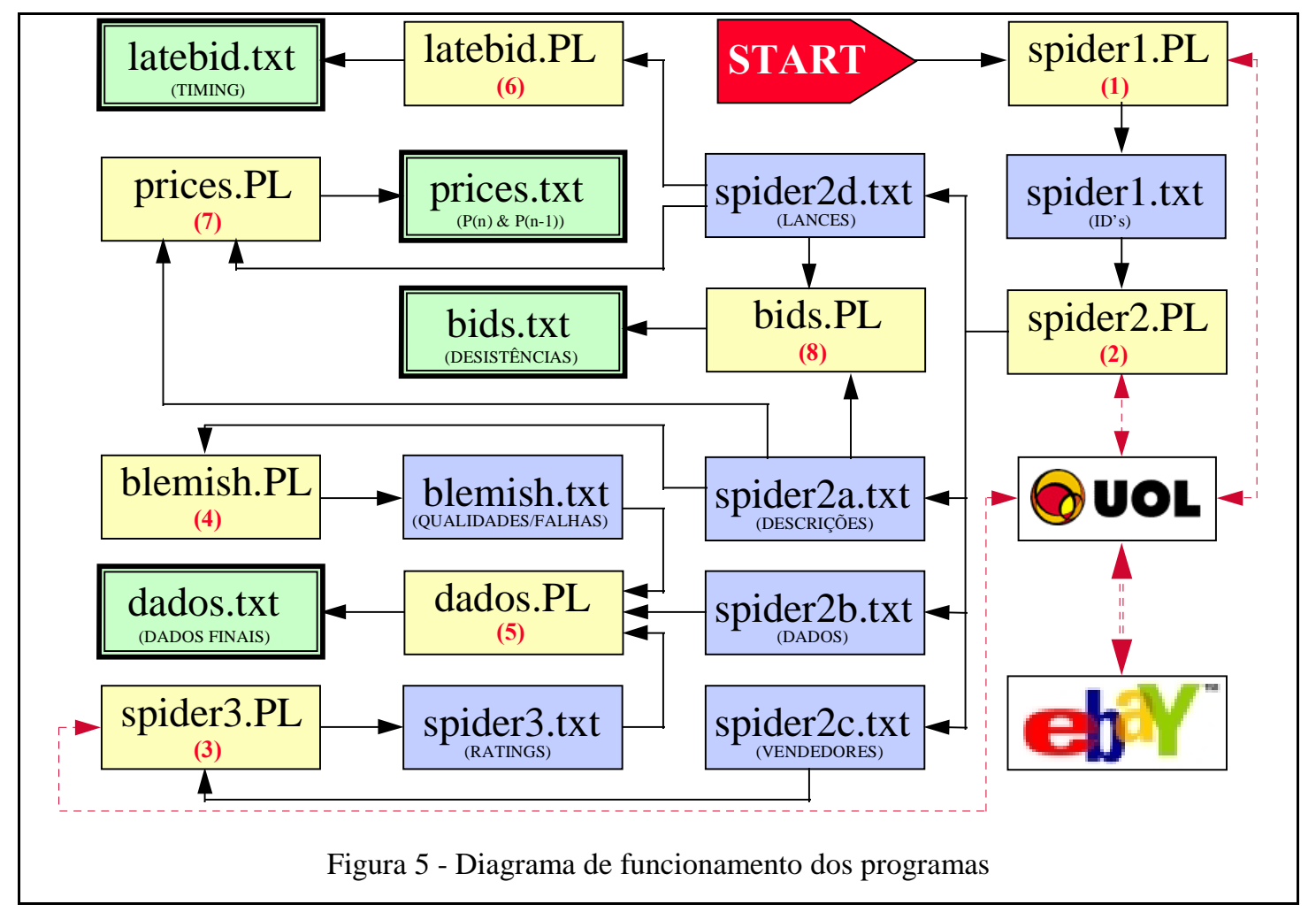




\subsection{1 spider1.pl}

O primeiro programa desenvolvido, spiderl.pl, tem como objetivo coletar os ID's dos leilões completados nos últimos 30 dias e guardá-los em um arquivo (spider1.txt).

A descrição do programa é dada abaixo:

\# Obtenha a data atual

\# Determine quais páginas contém ID’s de leilões realizados nos últimos 30 dias

\# Monte o endereço das páginas que contém ID's de leilões realizados nos últimos 30 dias:

< http://cayman.ebay.com/aw/listings/completed/category3461/dayXpageY.html >

\# Obtenha os ID's dos leilões presentes nas páginas

\# Grave os ID's no arquivo c:Itestelspider1.txt

\subsection{2 spider $2 . p l$}

Um segundo programa, spider2.pl, varre o arquivo spider1.txt pegando seus ID's, ou um subconjunto deles, e coleta na eBay as descrições dadas pelos vendedores (salvas em spider2a.txt), os dados dos leilões (salvos em spider2b.txt), os nomes dos vendedores (salvos em spider2c.txt) e os históricos dos lances (salvos em spider2d.txt).

A descrição do programa é dada abaixo:

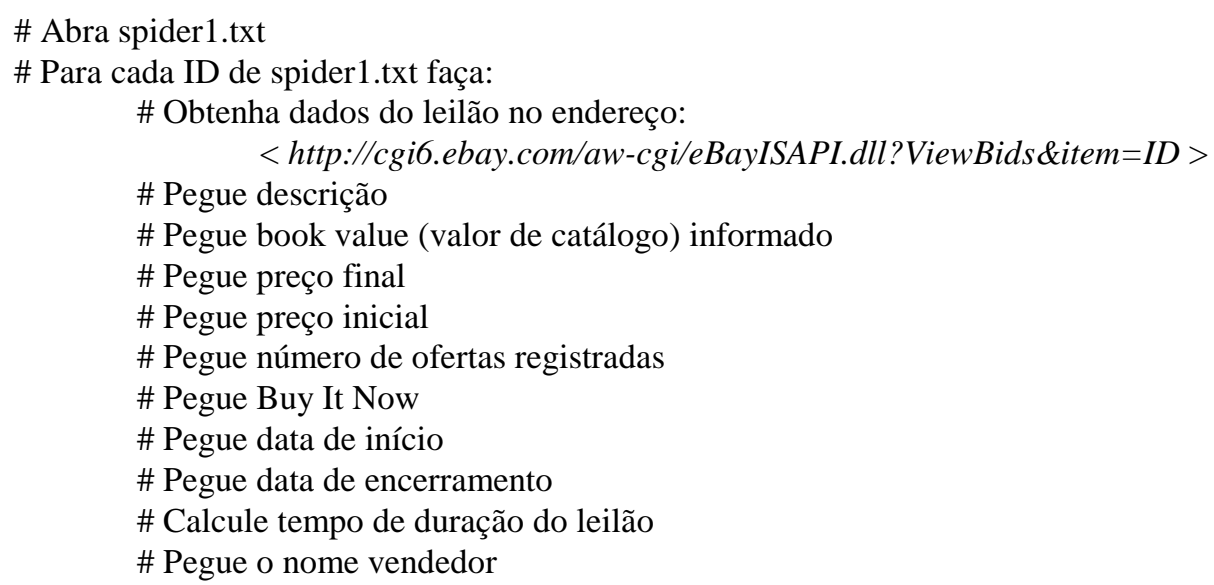


\# Pegue nome, lance, data e tempo antes do encerramento do(s) comprador(es)

\# Grave as descrições no arquivo c:Itestelspider2a.txt

\# Grave os dados numéricos no arquivo c: Itestelspider2b.txt

\# Grave os nomes dos vendedores no arquivo c:Itestelspider2c.txt

\# Grave os nomes, lances de datas dos lances no arquivo c:Itestelspider2d.txt

\subsection{3 spider3.pl}

Um terceiro programa, spider3.pl, varre o arquivo spider2c.txt pegando os nomes dos vendedores, e coleta na eBay os ratings positivo, negativo e neutro dos mesmos, salvando as informações no arquivo spider3.txt.

A descrição do programa é dada abaixo:

\# Abra spider2c.txt

\# Para cada vendedor de spider2c.txt faça:

\# Obtenha dados do vendedor no endereço:

< http://cgi2.ebay.com/aw-cgi/eBayISAPI.dll?ViewFeedback\&userid=SELLER >

\# Pegue rating positivo

\# Pegue rating neutro

\# Pegue rating negativo

\# Grave os ratings no arquivo c:Itestelspider3.txt

\subsection{4 blemish.pl}

O quarto programa desenvolvido, blemish.pl, varre o arquivo spider2a.txt pegando as descrições dos selos leiloados, e determina o número de informações positivas e negativas, salvando essas informações no arquivo blemish.txt.

A descrição do programa é dada abaixo:

\# Abra spider2a.txt

\# Para cada descrição de spider2a.txt faça:

\# Pegue a condição de "hinge"

\# Pegue a centralização

\# Pegue a condição da cola do selo

\# Pegue a condição "jumbo"

\# Pegue os defeitos

\# Grave as informações positivas e negativas dos selos no arquivo c:Itestelblemish.txt 


\subsection{5 dados.pl}

O quinto programa, dados.pl, consolida as informações de spider2b.txt, blemish.txt e spider3.txt em um único arquivo chamado dados.txt.

A descrição do programa é dada abaixo:

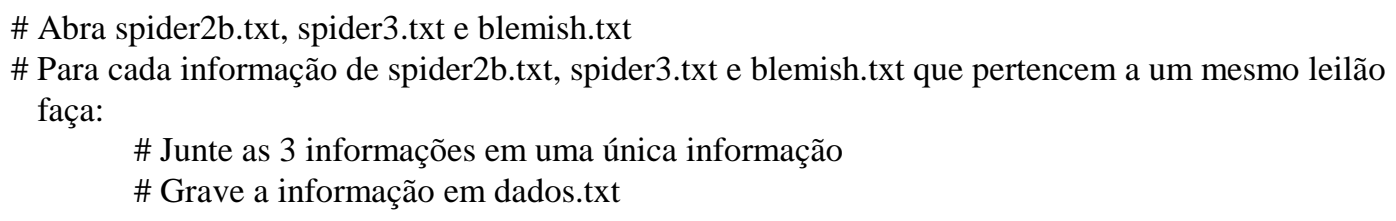

\subsection{6 latebid.pl}

O sexto programa, latebid.pl, varre o arquivo spider2d.txt pegando os lances e as datas em que foram feitos. De posse dessas informações, ele gera o arquivo latebid.txt com o número de lances dados por dia e por hora faltantes para o encerramento do leilão de maneira consolidada.

A descrição do programa é dada abaixo:

\# Abra spider2d.txt

\# Para cada lance pertencente a cada conjunto de lances de spider2d.txt faça:

\# Calcule quantos dias faltaram para o encerramento do leilão

\# Calcule quantas horas faltaram para o encerramento do leilão

\# Grave o número de lances por dia e hora faltantes para o encerramento do leilão em latebid.txt

\subsection{7 prices.pl}

O sétimo programa, prices.pl, coleta o primeiro e segundo preços de desistência, obtidos de spider2d.txt, bem como o book value (valor de catálogo) informado, obtido de spider2b.txt, e armazena as informações em prices.txt Apenas as informações de leilões que tenham $\mathrm{N}$ compradores serão processadas. 
A descrição do programa é dada abaixo:

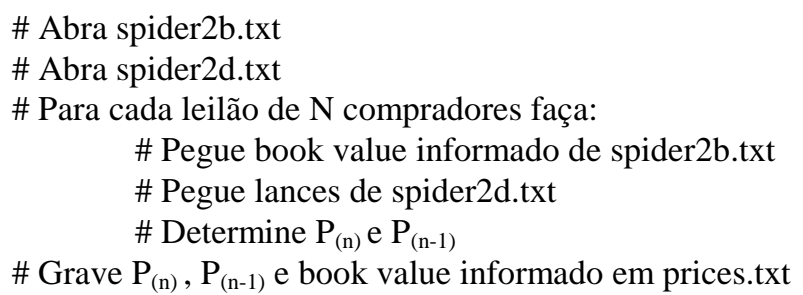

\subsection{8 bids.pl}

O oitavo programa, bids.pl, coleta todos os preços de desistência, obtidos de spider2d.txt, bem como o book value informado e do número de compradores, obtido de spider2b.txt, e armazena as informações em bids.txt.

A descrição do programa é dada abaixo:

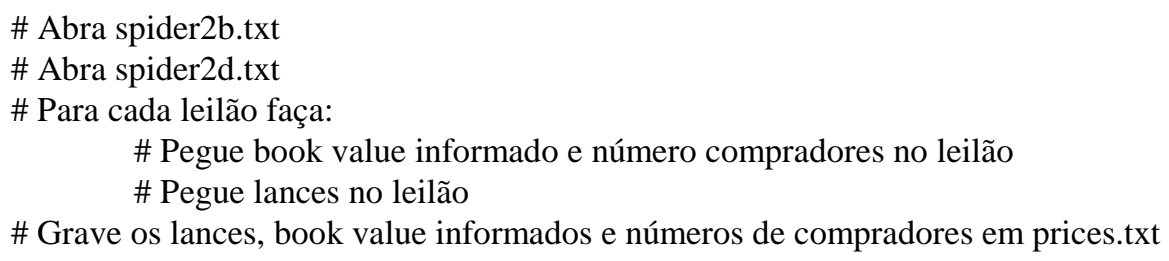

\section{Análise dos Dados Obtidos}

O objetivo desta seção é o de fazer uma análise exploratória dos dados obtidos. Serão apenas apresentados os resultados obtidos para o Conjunto de Dados Gold, em razão de possuírem um volume de observações muito maior do que o Conjunto de Dados 0. Contudo, vale ressaltar que a análise dos dados do Conjunto de Dados 0 confirmou os resultados obtidos para o Conjunto de Dados Gold. 


\subsection{Estatísticas}

Tabela 6 - Estatísticas para o Conjunto de Dados Gold

(Os dados foram extraídos de leilões concluídos entre 14 e 19/06/2001)

\begin{tabular}{|c|c|c|c|c|}
\hline \multicolumn{5}{|l|}{ Total de leilões: } \\
\hline$\%$ Vendas & $63.55 \%$ & \multicolumn{3}{|c|}{ (Percentual de leilões que resultaram em vendas) } \\
\hline$\% \mathrm{Bad}$ & $1.70 \%$ & \multicolumn{3}{|c|}{ (Percentual de leilões em que havia algum problema como selo) } \\
\hline$\%$ Buy it now & $1.45 \%$ & \multicolumn{3}{|c|}{ (Percentual de leilões que terminaram através da opção Buy it Now) } \\
\hline & Média & Desv. P. & Mín. & Máx. \\
\hline Preço final & 28.24 & 83.62 & 0.01 & 1255.05 \\
\hline Preço mínimo & 24.01 & 78.34 & 0.01 & 1525.00 \\
\hline Rating + & 2792.32 & 3303.30 & 0.00 & 19287.00 \\
\hline Rating 0 & 9.33 & 15.62 & 0.00 & 95.00 \\
\hline Rating - & 6.07 & 13.12 & 0.00 & 51.00 \\
\hline Valor catálogo & 241.36 & 2108.23 & 2.50 & 57500.00 \\
\hline Núm. bidders & 1.82 & 2.15 & 0.00 & 16.00 \\
\hline Bom & 2.18 & 1.36 & 0.00 & 6.00 \\
\hline Bad & 0.02 & 0.14 & 0.00 & 2.00 \\
\hline Núm. lances & 2.69 & 3.72 & 0.00 & 30.00 \\
\hline Duração (dias) & 7.08 & 1.88 & 0.00 & 10.00 \\
\hline
\end{tabular}

As principais características são:

- O elevado rating positivo de muitos vendedores, assim como os seus pseudônimos utilizados, indicam que muitas lojas e pequenos negociantes de selos se valem da eBay para a realização de seus negócios;

- O valor dos selos negociados geralmente não ultrapassa US\$50, o que de certa forma estimula a transação via Internet devido ao receio de muitos internautas de serem enganados e terem grandes prejuízos;

- As descrições dos selos, bem como a linguagem utilizada nas mesmas, é, de modo geral, padronizada, facilitando a identificação do selo e suas condições gerais. Essa característica é estimulada pela própria eBay que sugere aos vendedores agirem desta maneira. 


\subsection{Determinantes dos Preços de Venda, Número de Jogadores e Preços Mínimos}

Nesta subseção procuro identificar relações entre algumas variáveis de interesse através de regressões lineares.

Lucking-Reiley et al. [1999] apresentam uma análise exploratória semelhante dos determinantes dos preços em leilões de moedas colecionáveis de um centavo na eBay. Os dados do trabalho se basearam em 20000 leilões que ocorreram entre julho e Agosto de 1999, coletados através de um programa "spider". Deste grande conjunto de dados foi selecionada uma amostra de 461 moedas de 1 centavo do tipo "Indianhead" em excelente estado de conservação, para as quais foi possível obter uma avaliação mais precisa de seus valores de mercado, a partir de um site especializado no assunto. $\mathrm{O}$ trabalho resultou em 3 importantes achados. Primeiro, o feedback de um vendedor teve um efeito mensurável nos preços atingidos nos leilões, sendo que o feedback negativo teve um efeito muito maior do que o feedback positivo. Segundo, preços mínimos e preços de reserva tenderam a ter um efeito positivo no preço final do leilão, embora esta conclusão não leve em consideração o fato de que tais instrumentos diminuem a probabilidade de que um leilão resulte em uma venda. Além disso, os preços mínimos apenas apresentaram um efeito significativo quando houve um único participante no leilão. Terceiro, quando um vendedor escolheu um período de duração maior para a duração do leilão, isso ocasionou um aumento significativo no preço final do leilão.

Com relação a influência do feedback do vendedor no preço final do leilão, Houser e Wooders [2000] obtiveram resultados semelhantes para o caso de leilões de processadores Intel Pentium III de 500Mhz, que também ocorreram na eBay. Sua conclusão foi a de que uma boa reputação do vendedor resulta em um efeito positivo no preço final atingido no leilão.

A seguir apresento os resultados obtidos para o Conjunto de Dados Gold, analisando as variáveis determinantes do preço de venda, número de compradores e preço 
mínimo ${ }^{8}$. Os resultados foram coerentes com as conclusões obtidas por LuckingReiley et al. [1999] e Houser e Wooders [2000], à exceção da análise sobre a utilização ou não de preços de reserva secretos, dado que esse assunto não se aplicou ao caso estudado neste trabalho.

- Influência nos preços de venda

Na regressão abaixo, tem-se que:

· BOM: número de qualidades boas do selo;

· DUR: duração do leilão em segundos;

- NBI: número de compradores;

- NEG: rating negativo do vendedor;

· PIN/BVI: preço mínimo normalizado pelo valor de catálogo informado;

- POS: rating positivo do vendedor.
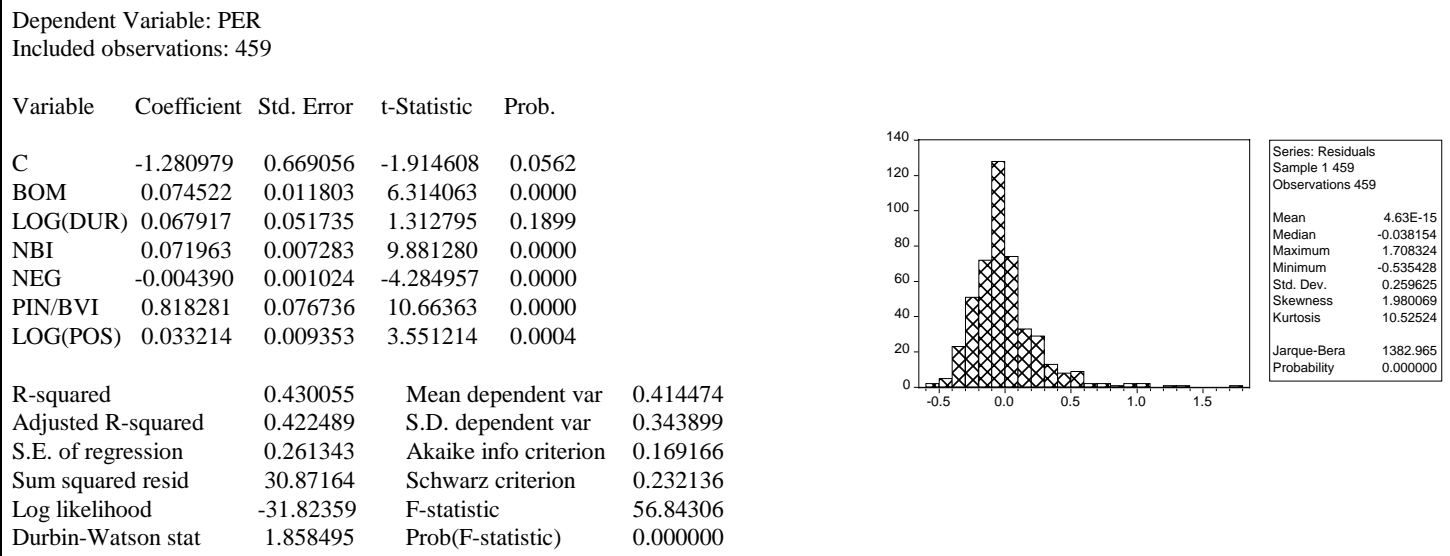

Da regressão acima, percebe-se que a boa qualidade do selo leiloado coerentemente aumenta o preço final de maneira significativa. De certa forma surpreendente foi a inexistência de influência significativa das qualidades negativas no preço final.

Apesar de ter-se que tomar cuidado ao avaliar a influência da duração do leilão no

\footnotetext{
${ }^{8}$ A utilização do logaritmo de algumas variáveis teve a intenção de favorecer a normalização dos resíduos.
} 
preço, em razão da alta variância do coeficiente e de seu baixo valor, o aumento na duração do leilão influencia de maneira positiva no preço final.

O aumento no número de compradores influencia de maneira positiva no preço final, indicando que o vendedor deve buscar aumentar o número de compradores participando do leilão.

Vê-se a inexistência de influência significativa dos comentários positivos sobre o vendedor, mas uma influência negativa, embora pequena, dos comentários negativos a respeito do vendedor. Isso indica uma característica popularmente conhecida em que "uma notícia ruim vale por dez notícias boas".

Influenciando positivamente no preço de venda aparece o preço mínimo normalizado pelo valor de catálogo. Tal relação deve ser tomada com bastante cuidado visto que só estamos utilizando na regressão acima leilões que resultaram em venda. Assim, o preço mínimo influencia positivamente no preço do selo condicional ao fato de ocorrer a venda.

- Influência no número de compradores

$\mathrm{Na}$ regressão abaixo, tem-se que:

- BOM: número de qualidades boas do selo;

- NEG: rating negativo do vendedor;

- PIN/BVI: preço mínimo normalizado pelo valor de catálogo informado;

- POS: rating positivo do vendedor. 

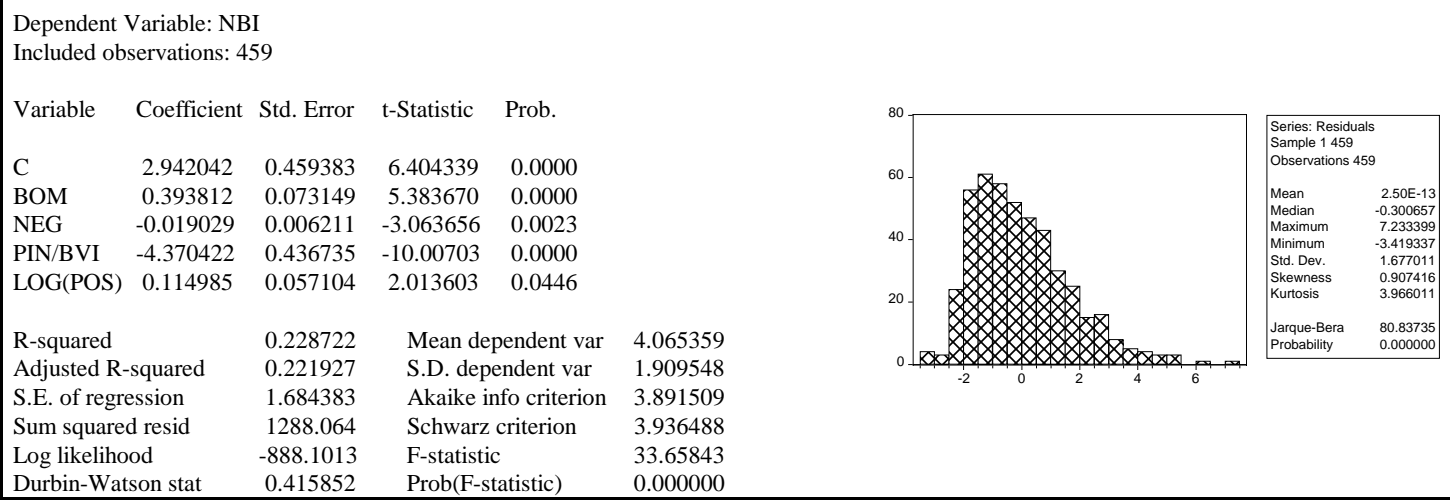

Percebe-se na regressão acima que a boa qualidade do selo aumenta o número de compradores no leilão ${ }^{2}$.

O número de comentários negativos sobre o vendedor coerentemente influencia negativamente no número de compradores. Isso é de se esperar, dado que os compradores normalmente não desejarão fazer negócios com pessoas de idoneidade duvidosa. Tal fato é confirmado pelo coeficiente positivo obtido para o número de comentários positivos sobre o vendedor.

O significativo coeficiente negativo para o preço mínimo normalizado, lembrando novamente que a regressão está condicionada ao fato de ter havido venda, mostra que preços mínimos elevados reduzem a quantidade de compradores. Assim, o vendedor pode optar por uma redução no preço mínimo se ele concluir que o aumento do número de compradores mais do que compensará a redução no preço final do selo devido a uma redução no valor do preço mínimo, conforme resultado obtido da regressão anterior.

- Influência na determinação do preço mínimo

Na regressão abaixo, tem-se que:

· BOM: número de qualidades boas do selo;

· DUR: duração do leilão em segundos.

\footnotetext{
${ }^{9}$ Esta conclusão foi a única discordância entre os conjuntos de dados 0 e Gold.
} 

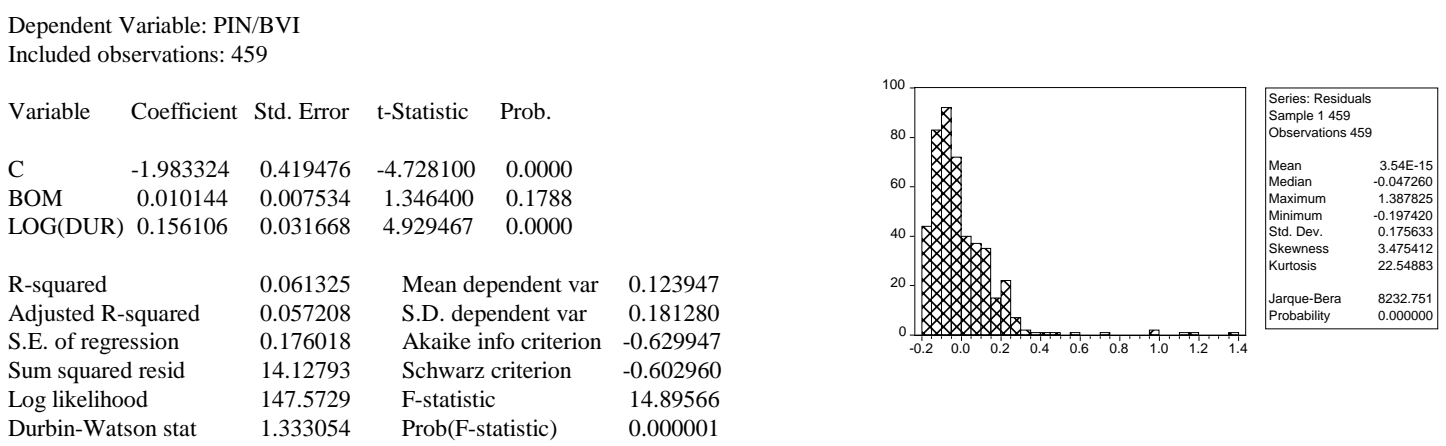

A regressão acima mostra que o preço mínimo é positivamente influenciado pela boa qualidade do selo, algo bastante plausível.

O aumento na duração do leilão também influencia positivamente no preço mínimo. Isso pode ser explicado pelo fato de o vendedor esperar que muitos potenciais compradores tenham a chance de participar do leilão e que algum deles possa ofertar o preço mínimo.

\subsection{Submissão Tardia de Lances}

Nesta subseção reporta-se apenas a existência do fenômeno da submissão tardia de lances (late bidding) no Conjunto de Dados Gold, através dos gráficos a seguir ${ }^{\circ}$. Mais adiante esta questão será abordada com mais cuidado. O único comentário importante a se fazer aqui é que este comportamento dos compradores em submeterem lances no final do leilão é uma característica comumente observada nos leilões da eBay

\footnotetext{
${ }^{10} \mathrm{O}$ mesmo fenômeno foi observado no Conjunto de Dados 0.

${ }^{11}$ Veja Roth e Ockenfels [2000].
} 


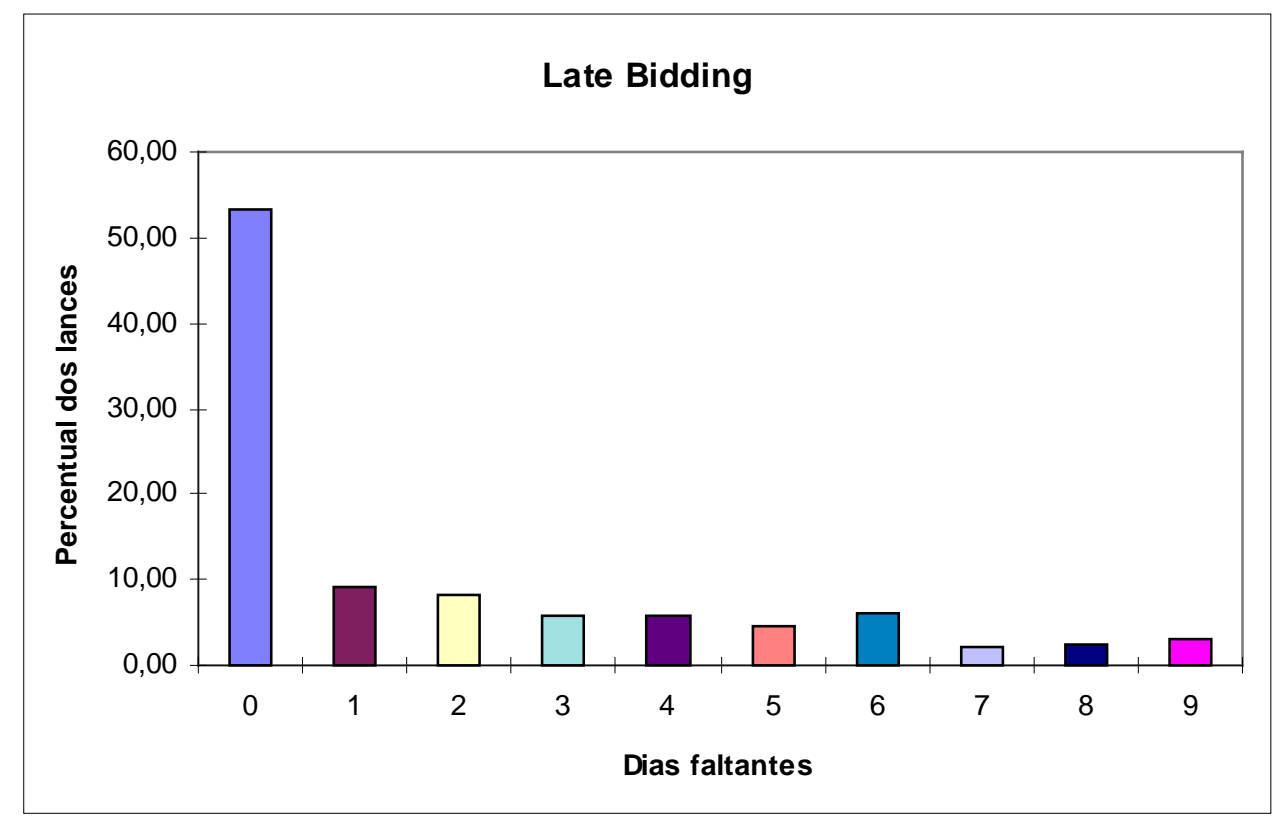

Gráfico 5.3.a - Submissão tardia de lances (em dias)

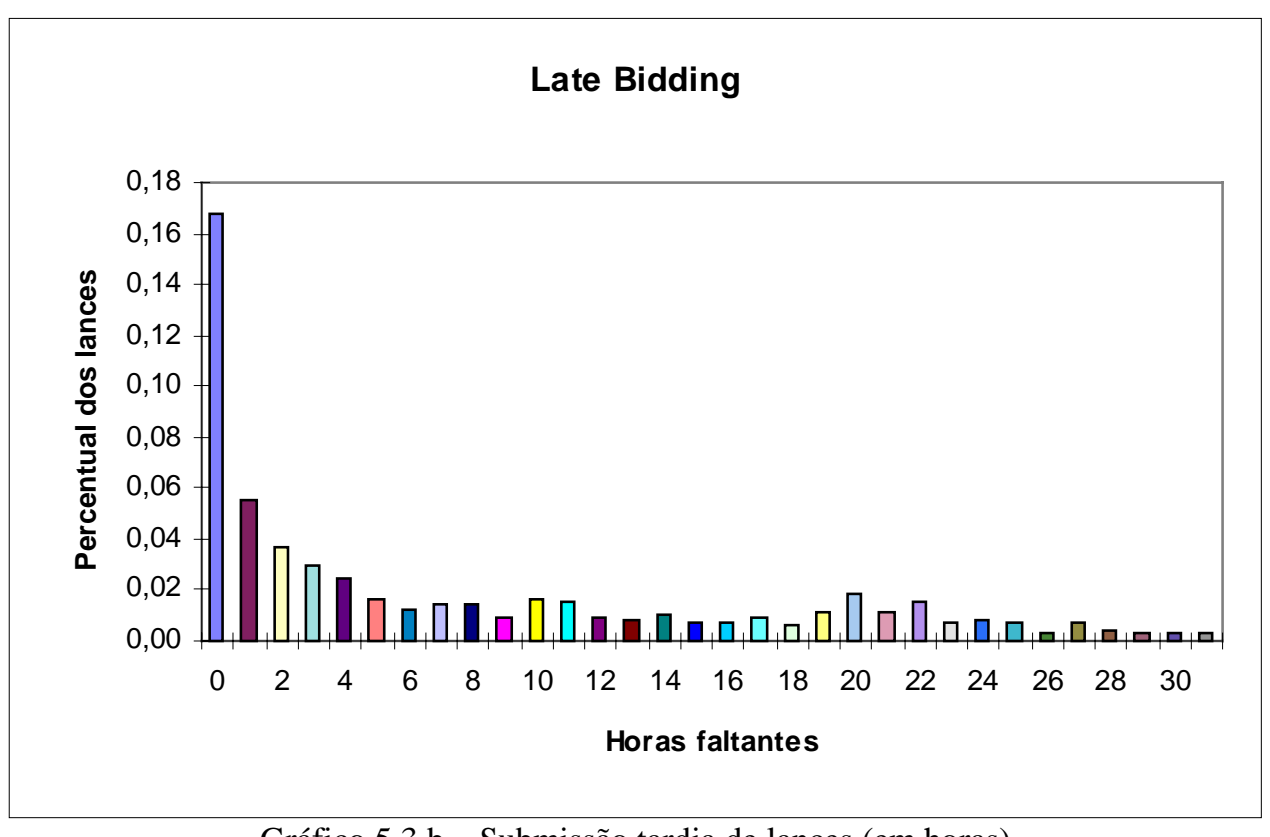

Gráfico 5.3.b - Submissão tardia de lances (em horas)

\section{Proposta de Método para Determinação do Tipo do Leilão}

Paarsch [1992] diz que a importância de se saber em qual modelo um dado leilão se enquadra, se no de valor comum ou no de valor privado, reside no fato de que o desenho de mecanismos de leilão depende criticamente da estrutura de informação dos agentes.

Neste mesmo artigo, Paarsch apresenta procedimentos complicados de determinação 
do tipo de modelo de leilões de primeiro preço de lance selado, aplicados no caso de contratos de reflorestamento na província de British Columbia, no Canadá. Além disso, Paarsch apresenta um modo muito simplificado de determinação do tipo de modelo através de regressões da receita final em função do número de competidores. Bajari e Hortaçsu [2001] utilizam esse modo simplificado em seu trabalho, mas destacam que a leitura dos resultados obtidos deve ser muito cautelosa, servindo estes apenas para lançar um pouco de luz em uma questão bastante complexa.

A próxima subseção mostra a inadequação da aplicação deste procedimento simplificado, apresentado em Paarsch [1992], no Conjunto de Dados Gold. A seguir, proponho um método simples de determinação do tipo de modelo de um leilão japonês, e que também permite inferir com qual "intensidade" um leilão se enquadra no modelo de valor comum. Este método é então aplicado no Conjunto de Dados Gold. Por fim, utilizo os resultados conseguidos para uma aplicação interessante: qual é o motivo para a submissão tardia de lances?

\subsection{Uso do Método Simplificado de Paarsch}

Nesta subseção apresento o método simplificado de Paarsch, conforme aplicado e descrito por Bajari e Hortaçsu [2001].

Para facilitar o entendimento de tal proposta, explico a idéia do que é a afiliação de sinais 12 . Dois sinais são afiliados se um sinal de valor alto faz com que seja grande a probabilidade de se ter um valor alto para o outro sinal, e isso é verdade em qualquer região do espaço a que pertencem os sinais. Dessa forma, afiliação é um conceito mais forte do que correlação, que é apenas uma estatística global, podendo-se pensar em afiliação como a necessidade de existência de correlação positiva local em qualquer região do espaço a que pertencem os sinais.

Conforme originalmente destacado por Paarsch [1992], a maldição do vencedor em um leilão de valor comum torna-se mais acentuada conforme o número de

\footnotetext{
${ }^{12}$ Para uma definição formal, veja, por exemplo, Klemperer [1999].
} 
compradores aumenta. Portanto, em um leilão de segundo preço ou ascendente de valor comum com a existência de afiliações entre os sinais dos compradores, o que causa a inexistência do "efeito competição" que contrabalançaria o efeito da maldição do vencedor, os lances (todos menos o mais baixo) devem declinar com o número de compradores no leilão (mantidos constantes os sinais recebidos). Entretanto, o número de compradores não afetaria os lances de um leilão no modelo de valor privado, visto que a estratégia dominante nestes leilões é declarar sua verdadeira avaliação (no caso de um leilão de segundo preço).

Esta observação sugere um teste empírico para distinguir entre os modelos de valor comum e de valor privado quando os sinais são afiliados. Usando as especificações de Paarsch [1992] para checar a robustez dos resultados, busca-se em cada especificação detectar ou não uma significativa relação negativa entre o número de compradores e os lances normalizados. Caso a relação se mostre negativa, então o leilão de enquadraria no modelo de valor comum.

Na tabela abaixo reporto as regressões, para o Conjunto de Dados Gold, dos lances normalizados pelo valor de catálogo (L) em função do número de compradores (NBI).

Tabela 7 - Resultados para as especificações de Paarsch (a)

\begin{tabular}{||c|c|c|c||}
\hline \hline Especificação & Linear & Quadrática & Logarítmica \\
\hline & $\mathrm{L}=\beta_{0}+\beta_{1} . \mathrm{NBI}$ & $\mathrm{L}=\beta_{0}+\beta_{1} \cdot \mathrm{NBI}+\beta_{2} . \mathrm{NBI}^{2}$ & $\mathrm{~L}=\beta_{0}+\beta_{1} \cdot \ln (\mathrm{NBI})$ \\
\hline$\beta_{0}$ & $0.250319(0.021353)$ & $0.230127(0.045437)$ & $0.234411(0.030457)$ \\
$\beta_{1}$ & $0.008474(0.003765)$ & $0.016493(0.016367)$ & $0.038354(0.018622)$ \\
$\beta_{2}$ & $\mathrm{NA}$ & $-0.000688(0.001367)$ & $\mathrm{NA}$ \\
$\mathrm{R}^{2}$ & 0.003680 & 0.003865 & 0.003085 \\
\hline
\end{tabular}

Bajari e Hortaçsu [2001] definem a seguinte medida da maldição do vencedor: o efeito da maldição do vencedor é o percentual de redução nos lances em resposta à adição de um comprador no leilão. Nesse caso não podemos quantificar o efeito da maldição do vencedor em nenhuma especificação, visto que todos os coeficientes de $\beta_{1}$ são positivos. Dessa forma, a melhor conclusão é a de que o modelo do leilão é o 
de valor privado.

O problema com as regressões da tabela acima é que o número de compradores que participam de um dado leilão é provavelmente endógeno. Se o número de compradores é correlacionado com atributos do leilão que falhamos em levar em consideração nesta especificação simplificada, então as estimativas dos coeficientes serão viesados, tornando-se difícil a medição da extensão do efeito da maldição do vencedor através destas regressões.

Além disso, se os sinais não forem afiliados, pode-se ter o aumento no número de competidores compensando o efeito da maldição do vencedor, tornando inúteis resultados em que o coeficiente de NBI é positivo ou próximo de zero. Para deixar este ponto claro, apresento a seguir a aplicação do método simplificado de Paarsch em um conjunto de dados gerados em laboratório, através do programa leilao.m, baseado em nosso modelo teórico em que não há afiliação de sinais.

O programa leilao.m recebe 4 argumentos na sua execução: o valor dos parâmetros a e b, o número de compradores e o número de leilões a serem simulados. O programa funciona da seguinte forma. Primeiro, escolhem-se os sinais de cada comprador, retirados de uma distribuição uniforme discreta [0.00;1.00] de incrementos centesimais. Então, com base no comportamento de equilíbrio, definem-se os preços de desistência dos compradores, exceto para o comprador que tem o maior sinal (o vencedor obviamente não desiste).

Fazendo $\mathrm{a}=\mathrm{b}=1$, e gerando 100 leilões para 3, 4, 5 e 6 compradores (400 leilões no total) através do programa leilão.m, foi obtido um total de 1400 preços de desistência. Na tabela abaixo reporto as regressões dos lances (preços de desistência) em função do número de compradores. 
Tabela 8 - Resultados para as especificações de Paarsch (b)

\begin{tabular}{||c|c|c|c||}
\hline Especificação & Linear & Quadrática & Logarítmica \\
\hline & $\mathrm{L}=\beta_{0}+\beta_{1} \cdot \mathrm{NBI}$ & $\mathrm{L}=\beta_{0}+\beta_{1} \cdot \mathrm{NBI}+\beta_{2} \cdot \mathrm{NBI}^{2}$ & $\mathrm{~L}=\beta_{0}+\beta_{1} \cdot \ln (\mathrm{NBI})$ \\
\hline$\beta_{0}$ & $0.294543(0.023178)$ & $0.382190(0.093553)$ & $0.282626(0.031865)$ \\
$\beta_{1}$ & $0.008786(0.004667)$ & $-0.031965(0.042397)$ & $0.0351670 .020299)$ \\
$\beta_{2}$ & $\mathrm{NA}$ & $0.004455(0.004607)$ & $\mathrm{NA}$ \\
$\mathrm{R}^{2}$ & 0.002529 & 0.003196 & 0.002142 \\
\hline
\end{tabular}

Veja que apesar de o leilão ser de valor comum, os resultados não mostram relação negativa entre os preços de desistência e o número de compradores. Os resultados nos levam à conclusão errada de que o leilão se enquadra no modelo de valor privado.

$\mathrm{Na}$ próxima seção proponho um método simples, mas que busca, de forma mais apropriada ao nosso modelo teórico, determinar o tipo de modelo de um leilão.

\subsection{Método Proposto}

Relembrando, o modelo teórico diz que a avaliação do objeto leiloado para o comprador i é $\mathrm{v}_{\mathrm{i}}=\alpha \cdot \mathrm{t}_{\mathrm{i}}+\beta . \quad \mathrm{j} \neq \mathrm{i} \mathrm{t}_{\mathrm{j}}$, onde:

$$
\begin{aligned}
& \alpha=\frac{a}{a+(n-1) \cdot b}, e \\
& \beta=\frac{b}{a+(n-1) \cdot b} .
\end{aligned}
$$

O objetivo desta subseção é o de propor um método de estimação do coeficiente b no modelo teórico, assumindo $\mathrm{a}=1, \tau=1$ e que os sinais dos compradores são retirados de uma distribuição uniforme. Perceba que existe um grau de liberdade na escolha de a e b quando se determina o valor de $\alpha$ e $\beta$. Por exemplo, se $n=2$, então, para se ter $\alpha=1 / 2$ e $\beta=1 / 2$, pode-se fazer $a=1$ e $b=1$, ou $a=2$ e $b=2$, etc. 
Só considerarei casos em que existem 3 ou mais compradores, visto que, no caso de 2 compradores, o parâmetro b é irrelevante na determinação do preço de desistência, que nesse caso é igual a receita do vendedor.

Enuncio um resultado que será útil a seguir. Dada uma distribuição uniforme $[0,1]$, tem-se que $E\left[t_{(k)} \mid t_{(n)}\right]=t_{(n)}+(n-k) \cdot\left(1-t_{(n)}\right) / n$. Para $k=n-1$ tem-se então:

$$
E\left[t_{(n-1)} \mid t_{(n)}\right]=t_{(n)}+\frac{\left(1-t_{(n)}\right)}{n}
$$

Segundo o modelo teórico utilizado neste trabalho, dados n compradores, o preço ao qual o comprador de k-ésimo maior sinal desiste é $\mathrm{P}_{(\mathrm{k})}=\beta \cdot{ }_{\mathrm{j}=\mathrm{k}+1}{ }^{\mathrm{n}} \mathrm{t}_{(\mathrm{j})}+(\alpha+(\mathrm{k}$ 1). $\beta) . t_{(k)}$. Assim, tem-se que para as duas primeiras desistências $(n>2)$ :

(i) $\quad P_{(n)}=(\alpha+(n-1) \cdot \beta) \cdot t_{(n)}$

(ii) $\quad \mathrm{P}_{(\mathrm{n}-1)}=\beta \cdot \mathrm{t}_{(\mathrm{n})}+(\alpha+(\mathrm{n}-2) \cdot \beta) \cdot \mathrm{t}_{(\mathrm{n}-1)}$

Veja que, dado $t_{(n)}, t_{(n-1)}$ é distribuída de acordo com alguma função de distribuição de probabilidade no intervalo $\left[\mathrm{t}_{(\mathrm{n})} ; 1\right]$. Podemos então escrever $\mathrm{t}_{(\mathrm{n}-1)} \mid \mathrm{t}_{(\mathrm{n})}=\mathrm{E}\left[\mathrm{t}_{(\mathrm{n}-1)} \mid \mathrm{t}_{(\mathrm{n})}\right]+$ $\mu$, onde $E\left[\mu \mid t_{(n)}\right]=0$ e $E\left[\mu^{\prime} \mu \mid t_{(n)}\right]=\sigma^{2}$.I, para algum $\sigma$.

Substituindo $t_{(n-1)}$ por $t_{(n-1)} \mid t_{(n)}$ no caso da distribuição uniforme [0;1] em (ii) chega-se à:

(ii') $\quad P_{(n-1)}=\frac{\alpha \cdot n-\alpha+n^{2} \cdot \beta-2 \cdot n \cdot \beta+2 \cdot \beta}{n} \cdot \mathrm{t}_{(n)}+\frac{\alpha+n \cdot \beta-2 \cdot \beta}{n}+\mu$

Chamando:

(iii) $\varphi_{1}=\frac{\alpha \cdot n-\alpha+n^{2} \cdot \beta-2 \cdot n \cdot \beta+2 \cdot \beta}{n}$, e 
(iv) $\quad \varphi_{2}=\frac{\alpha+n \cdot \beta-2 . \beta}{n}$,

reescreve-se (ii') como:

(ii'’) $\quad \mathrm{P}_{(\mathrm{n}-1)}=\varphi_{1} \cdot \mathrm{t}_{(\mathrm{n})}+\varphi_{2}+\mu$

Observe que $\varphi_{1}+\varphi_{2}=\alpha+(\mathrm{n}-1) \cdot \beta$. Como:

$\alpha=\frac{a}{a+(n-1) \cdot b} \quad, e$
$\beta=\frac{b}{a+(n-1) \cdot b} \quad$, tem-se:

(v) $\varphi_{1}+\varphi_{2}=1$

Também substituindo $\alpha$ e $\beta$ em (i) tem-se:

(i') $\quad \mathrm{P}_{(\mathrm{n})}=\mathrm{t}_{(\mathrm{n})}$

Ou seja, o valor de $t_{(n)}$ é observado. Portanto, usando (i') em (ii'’) tem-se:

(ii',') $\mathrm{P}_{(\mathrm{n}-1)}=\varphi_{1} \cdot \mathrm{P}_{(\mathrm{n})}+\varphi_{2}+\mu$

Veja que $\mathrm{P}_{(\mathrm{n})}$ é uma variável aleatória com função de distribuição de probabilidade conhecida. Além disso, $\mu$ pode ser interpretada como uma perturbação i.i.d. de média zero que não é distribuída normalmente. Portanto, a estimação dos valores de $\varphi_{1}$ e $\varphi_{2}$ através do método dos mínimos quadrados fornecerá estimadores não-viesados, observando-se, porém, o fato de que os testes de hipóteses não serão válidos para 
amostras pequenas.

O procedimento a ser feito é:

1) Estimar $\varphi_{1}$ e $\varphi_{2}$ sem restrição;

2) Aplicar o teste de Wald para a restrição $\varphi_{1}+\varphi_{2}=1$;

3) Caso não se rejeite a hipótese da restrição, então reestimar $\varphi_{1}$ e $\varphi_{2}$ com a restrição.

Veja que ao obter o valor de $\varphi_{1}$ e $\varphi_{2}$ podemos determinar o valor de b através de (iii) ou de (iv). Por exemplo, de (iv), tem-se:

$$
b^{*}=\frac{n \cdot \varphi_{2}^{*}-1}{n-2-n \cdot(n-1) \cdot \varphi_{2}{ }^{*}},
$$

onde $b^{*}$ é o valor estimado de b a partir de $\varphi_{2}{ }^{*}$, que é o valor estimado de $\varphi_{2}$.

Veja também que o valor de b* calculado por (iii) e por (iv) só será o mesmo se $\varphi_{1}+\varphi_{2}=1$. Por essa razão, deve-se executar o passo (3) do procedimento acima, de forma a se obter um único valor para $b^{*}$.

\subsection{Teste do Método com Dados de Laboratório}

Nesta subseção testa-se o método proposto na subseção anterior através de dados gerados em laboratório. Para isso foram desenvolvidos, além do programa leilao.m, os programas simdata.m e simauto.m escritos para o software Matlab.

Alguns resultados para $n=3$, em conjuntos de 200 leilões simulados, são mostrados a seguir. Os cálculos de $b^{*}$ foram feitos através de $c(1)$, que é o valor de $\varphi_{2} *$ pela regressão com restrição. 
Tabela 9 - Cálculo de b* para valores conhecidos de b

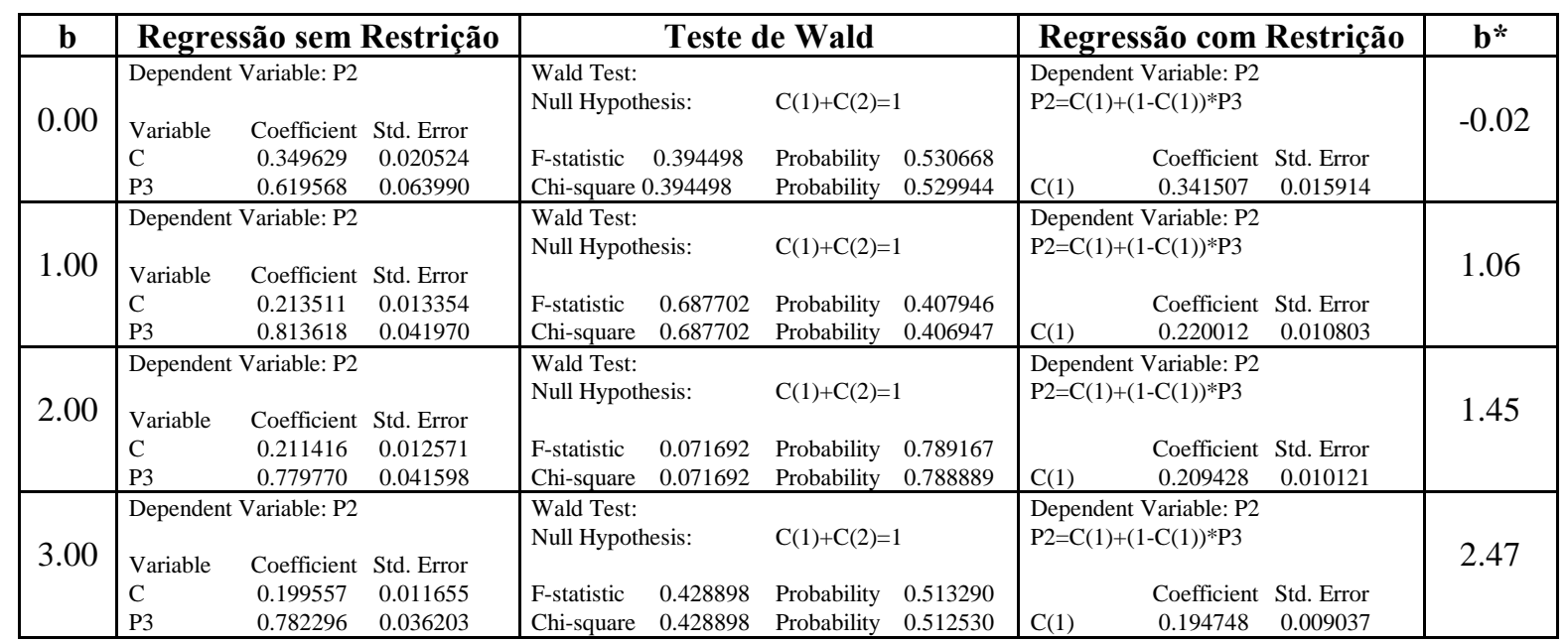

O programa simdata.m simula várias vezes conjuntos de leilões, estimando para cada conjunto o valor de b (restrito). A seguir está a tabela com os resultados das simulações, reportando a média e a variância de $b^{*}$ para conjuntos de 200 leilões simulados 1000 vezes (o procedimento foi automatizado pelo programa simauto.m):

Tabela 10 - Média e variância de b* para valores conhecidos de b e de $n$

\begin{tabular}{|c|c|c|c|}
\hline & & Média de $b^{*}$ & Variância de b* \\
\hline \multirow{5}{*}{$\mathrm{b}=0$} & $\mathrm{n}=3$ & 0.0033 & 0.0009 \\
\hline & $\mathrm{n}=4$ & -0.0001 & 0.0012 \\
\hline & $n=5$ & 0.0003 & 0.0014 \\
\hline & $n=6$ & 0.0132 & 0.0020 \\
\hline & $\mathrm{n}=7$ & 0.0100 & 0.0020 \\
\hline \multirow{5}{*}{$\mathrm{b}=1$} & $\mathrm{n}=3$ & 1.0048 & 0.0399 \\
\hline & $n=4$ & 1.1755 & 0.5205 \\
\hline & $\mathrm{n}=5$ & 1.0148 & 40.3543 \\
\hline & $n=6$ & 1.3783 & 25.7282 \\
\hline & $\mathrm{n}=7$ & 0.2036 & 112.8324 \\
\hline \multirow{5}{*}{$b=2$} & $\mathrm{n}=3$ & 2.0537 & 0.2883 \\
\hline & $n=4$ & 0.7234 & 173.8047 \\
\hline & $\mathrm{n}=5$ & 1.6290 & 285.4493 \\
\hline & $n=6$ & 2.1 & 1718.8 \\
\hline & $\mathrm{n}=7$ & -1.7255 & 259.3563 \\
\hline \multirow{5}{*}{$b=3$} & $\mathrm{n}=3$ & 3.1696 & 0.8607 \\
\hline & $n=4$ & 1.3556 & 457.0483 \\
\hline & $n=5$ & -0.9379 & 667.6079 \\
\hline & $n=6$ & 9.9 & 3249.9 \\
\hline & $\mathrm{n}=7$ & -0.5115 & 72.4383 \\
\hline \multirow{5}{*}{$b=4$} & $\mathrm{n}=3$ & 3.1386 & 1.0431 \\
\hline & $\mathrm{n}=4$ & 7.2337 & 585.9096 \\
\hline & $\mathrm{n}=5$ & 4.1553 & 598.3192 \\
\hline & $n=6$ & 0.2901 & 44.1740 \\
\hline & $\mathrm{n}=7$ & 0.9183 & 143.9388 \\
\hline
\end{tabular}


As altas variâncias registradas acima se devem a sensibilidade do cálculo de $b^{*}$ a partir da estimação de $\varphi_{2}$. Na próxima subseção mostro que pequenos desvios no valor $\varphi_{2}$ em relação ao seu valor verdadeiro podem provocar grandes desvios no cálculo de $b^{*}$, sendo que esta sensibilidade aumenta com o aumento no valor de $b$ (verdadeiro) e de n. Sendo assim, sugere-se a utilização de leilões com 3 compradores para a determinação de $b^{*}$.

\subsubsection{Sensibilidade do cálculo de $b^{*}$}

Abaixo apresento o gráfico que mostra o valor de $b^{*}$ em função do valor de $\varphi_{2}$, que é dado por:

$$
\mathrm{b}^{*}\left(\varphi_{2}\right)=\frac{\mathrm{n} \cdot \varphi_{2}-1}{\mathrm{n}-2-\mathrm{n} \cdot(\mathrm{n}-1) \cdot \varphi_{2}}
$$

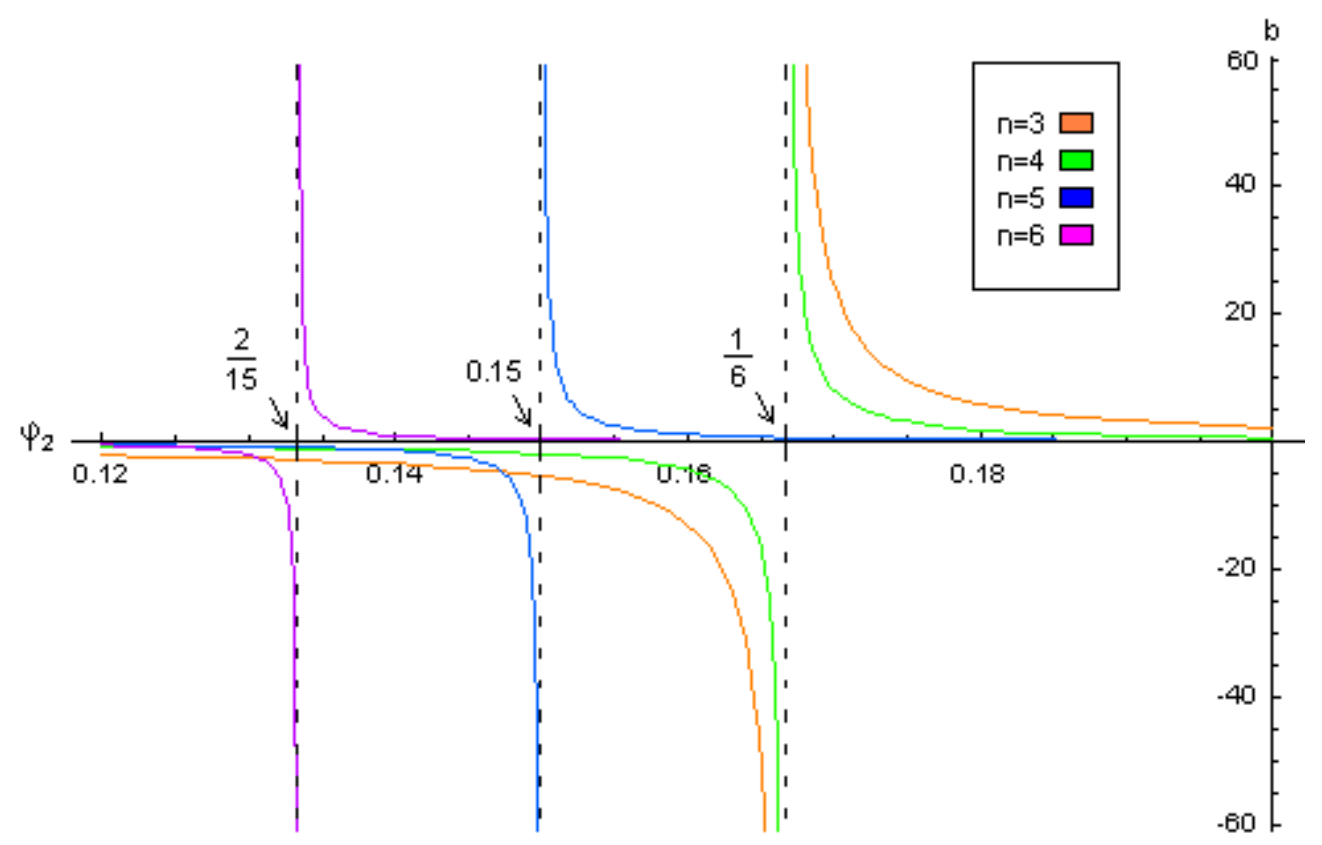

Gráfico 6.3.1.a - Valor de b em função de $\varphi_{2}$ e de n.

Para entender o efeito do aumento no valor de $n$ na estimação de b, vejamos, por exemplo, qual é o intervalo I a que $\varphi_{2}$ deve pertencer, de modo que b* pertença à $[1.5 ; 2.5]$. 
Para facilitar a exposição, veja o gráfico abaixo que magnifica o gráfico acima em torno do ponto $\varphi_{2}=0.20$. Consideraremos apenas os casos $n=3$ e $n=4$.

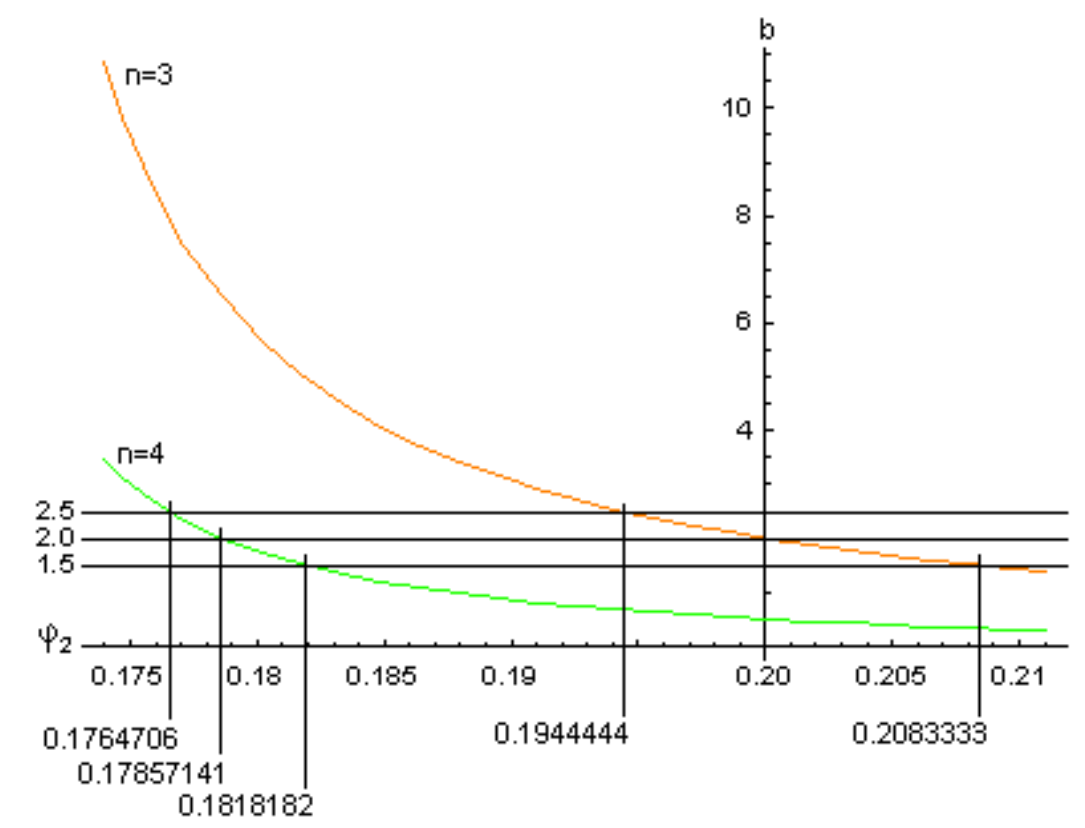

Gráfico 6.3.1.b - Valor de b em função de $\varphi_{2}$ e de n (ampliação I).

Veja que para $n=3$ temos $I_{n=3}=[0.1944444 ; 0.2083333]$, e para $n=4$ temos $\mathrm{I}_{\mathrm{n}=4}=[0.1764706 ; 0.1818182]$. Logo:

$\left|I_{n=3}\right|=0.0138889>0.0053476=\left|I_{n=4}\right|$

Portanto, o cálculo de $b^{*}$ no caso $n=4$ é mais "sensível" do que no caso $n=3$, no sentido de que idênticas variações no valor de $\varphi_{2}$ resultam em variações maiores em $b^{*}$ para $n=4$ do que para $n=3$.

Este raciocínio vale para outros valores de $\mathrm{n}$, onde um aumento no valor de $\mathrm{n}$ implica em uma maior sensibilidade no cálculo de b*.

Agora, para entender o efeito do tamanho de b em sua estimação, vejamos, por exemplo, qual é o intervalo I a que $\varphi_{2}$ deve pertencer, de modo que b* pertença à $[1.5 ; 2.5]$ e à $[3.5 ; 4.5]$.

Da mesma forma que antes, veja o gráfico abaixo que magnifica a região em torno do 
ponto $\varphi_{2}=0.20$, considerando aqui apenas o caso $n=3$.

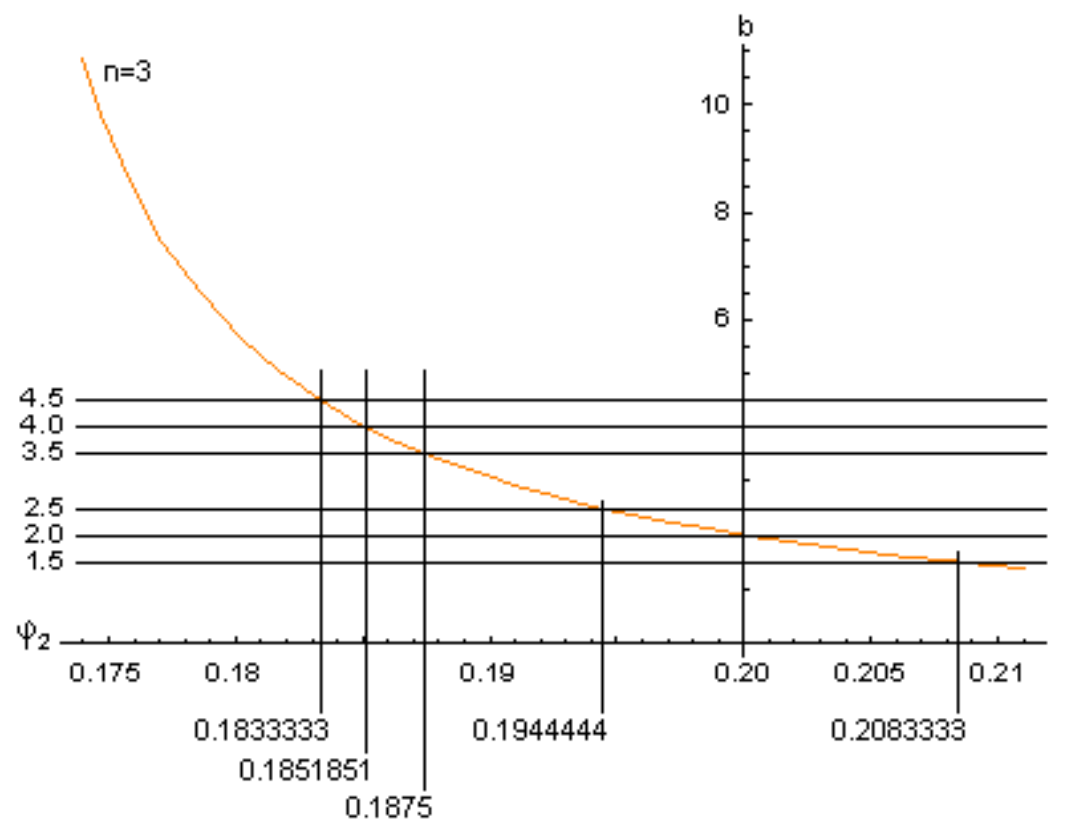

Gráfico 6.3.1.c - Valor de b em função de $\varphi_{2}$ e de n (ampliação II).

Veja que para [1.5;2.5] temos $I_{2}=[0.1944444 ; 0.2083333]$, e para [3.5;4.5] temos $\mathrm{I}_{4}=[0.1833333 ; 0.1875]$. Logo:

$\left|\mathrm{I}_{2}\right|=0.0138889>0,0041667=\left|\mathrm{I}_{4}\right|$

Portanto, o cálculo de b* no caso do intervalo [3.5;4.5] é mais "sensível" do que no caso do intervalo [1.5;2.5], no sentido de que idênticas variações no valor de $\varphi_{2}$ resultam em variações maiores em $b^{*}$ quando este pertence à [3.5;4.5] do que à $[1.5 ; 2.5]$.

Este raciocínio vale sempre, onde um aumento no valor de b (em sua região positiva) implica em uma maior sensibilidade no cálculo de b*.

\subsection{O Histograma dos Preços de Desistência no Caso da Distribuição Uniforme}

Nesta subseção utilizo o programa leilao.m para gerar dados de forma a conhecermos 
a forma com que um histograma de preços de desistência em um conjunto de leilões deve se parecer, no caso da distribuição uniforme.

A tabela abaixo mostra o histograma obtido para algumas combinações de leilões em que existem de 2 até 6 compradores, sendo $a=b=1$.

Tabela 11 - Histograma dos preços de desistência para 2 casos selecionados

\begin{tabular}{|c|c|c|c|c|c|c|c|c|}
\hline & $n=2$ & $\mathbf{n}=\mathbf{3}$ & $n=4$ & $n=5$ & $n=6$ & \multicolumn{3}{|l|}{ Histograma } \\
\hline $\begin{array}{l}\text { Quantidade } \\
\text { de leilões } \\
\text { (Total de } \\
880 \text { lances) }\end{array}$ & $\begin{array}{c}150 \\
(37 \%)\end{array}$ & $\begin{array}{c}120 \\
(29 \%)\end{array}$ & $\begin{array}{c}80 \\
(20 \%)\end{array}$ & $\begin{array}{c}50 \\
(12 \%)\end{array}$ & $\begin{array}{c}10 \\
(02 \%)\end{array}$ & $\begin{array}{lllll}10 & & & \\
\end{array}$ & 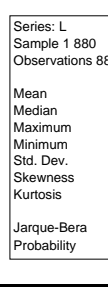 & 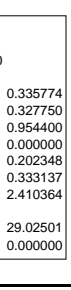 \\
\hline $\begin{array}{l}\text { Quantidade } \\
\text { de leilões } \\
\text { (Total de } \\
1040 \text { lances) }\end{array}$ & $\begin{array}{c}150 \\
(32 \%)\end{array}$ & $\begin{array}{c}150 \\
(32 \%)\end{array}$ & $\begin{array}{c}100 \\
(21 \%)\end{array}$ & $\begin{array}{c}60 \\
(13 \%)\end{array}$ & $\begin{array}{c}10 \\
(02 \%)\end{array}$ & $\begin{array}{lll} & \\
\end{array}$ & 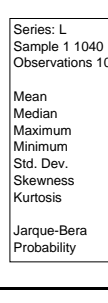 & \begin{tabular}{l|l|} 
& \\
40 \\
0.331980 \\
0.313400 \\
0.999100 \\
0.000000 \\
0.200202 \\
0.450191 \\
2.513826 \\
45.37231 \\
0.000000 \\
\end{tabular} \\
\hline
\end{tabular}

Nos gráficos acima, pode-se observar a presença de assimetria à direita. Esta característica é importante no sentido de que ela é observada na prática. Isso será mostrado quando nos depararmos com os dados reais na próxima subseção.

\subsection{Uso do Método Proposto}

Abaixo está a comparação do histograma dos lances obtidos para o Conjunto de Dados Gold, bem como a sua média, com o resultado teórico esperado, conforme a subseção anterior. 
Tabela 12 - Comparativo dos histogramas de preços de desistência: Real x Teórico

\begin{tabular}{|c|c|c|c|}
\hline $\begin{array}{c}\text { Real } \\
\text { n=2: } 25 \% \\
\text { n=3: } 22 \% \\
n=4 \text { e } 5: 16 \% \\
n=6: 09 \% \\
n=7: 07 \% \\
n=8: 03 \% \\
n=9 \text { e } 10: 01 \%\end{array}$ & - & 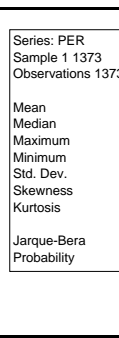 & 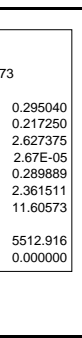 \\
\hline $\begin{array}{l}\text { Teórico }(\mathrm{p} / \text { distribuição uniforme } \mathrm{c} / \mathrm{a}=\mathrm{b}=1) \\
\text { Igual percentual dos dados reais. } \\
\text { Dados gerados através do programa leilao.m. }\end{array}$ & 'י] & 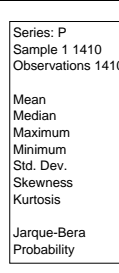 & 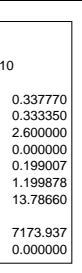 \\
\hline
\end{tabular}

A simplificação assumida no modelo teórico, de que os sinais dos compradores são extraídos de uma distribuição uniforme, não descreve muito bem os dados obtidos. Entretanto, a característica de assimetria à direita pode ser vista como um ponto favorável.

O Conjunto de Dados Gold foi subdividido por número de compradores, e a implementação do método foi feita para o caso $n=3$ (três compradores). Ao estimar o valor verdadeiro do selo leiloado, utilizo o valor de catálogo para selos em ótimo estado. À este valor é multiplicado um fator de desconto em função das condições particulares de cada selo, caso contrário ocorreria uma superestimação do valor verdadeiro, o que resultaria em valores de $\mathrm{P}_{(2)}$ e $\mathrm{P}_{(3)}$ subestimados. No anexo apresento os dados utilizados nesta implementação, onde constam os preços de desistência normalizados pelo valor verdadeiro estimado do selo, as descrições dos selos e os descontos aplicados em cada caso.

Feitas essas considerações, o resultado da estimação de b e $\mathrm{e}^{\sqrt{13}}$.

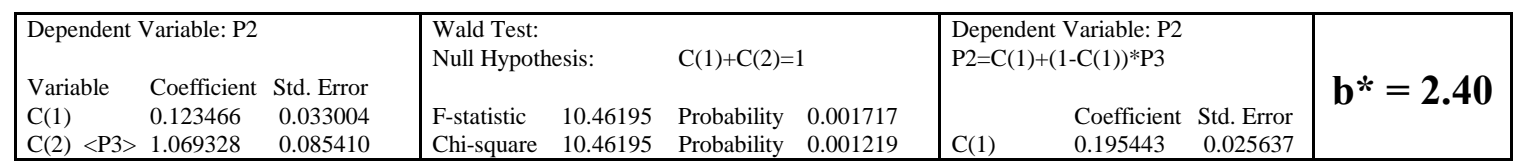

Obs: foram utilizados 90 leilões com três compradores. 
Portanto, o tipo de modelo dos leilões pertencentes ao Conjunto de Dados Gold é o de valor comum.

\subsection{Aplicação do Método: Explicação da Submissão Tardia de Lances}

Qualquer que seja o tipo de modelo do leilão, a forma de encerramento dos leilões na eBay abre a possibilidade de que o fenômeno da submissão tardia de lances seja um comportamento de equilíbrio, segundo Roth e Ockenfels [2000]. O vendedor na eBay determina a data (dia, hora, minuto e segundo) de encerramento e este não é prorrogado. Apenas para efeito de comparação, os leilões realizados na Amazon, concorrente da eBay, têm um processo de encerramento diferente. Na Amazon, caso um lance seja dado nos últimos 10 minutos do prazo previsto de encerramento, o leilão é automaticamente estendido por mais 10 minutos, e repete-se o mesmo procedimento até que, no final, seja garantido que o lance vencedor tenha ficado por no mínimo 10 minutos sem ser superado.

Se o tipo de modelo for o de valor privado, Roth e Ockenfels [2000] apresentam uma explicação baseada no congestionamento de rede que ocorre no encerramento do leilão na eBay. O que eles colocam é que se houver uma probabilidade $\mathrm{p}<1$ suficientemente grande de que um lance seja efetivamente transmitido no último segundo do leilão, então existirá um equilíbrio (porém não é o único) no qual todos os compradores ofertam o preço mínimo m no início do leilão (em outras palavras, no primeiro segundo) e todos ofertam suas verdadeiras avaliações no último segundo. $\mathrm{Na}$ prática isso significa que, no início do leilão, apenas o comprador que tiver seu lance $\mathrm{m}$ mais cedo registrado será o comprador que vai estar vencendo o leilão até o último segundo, quando então o comprador que tiver seu lance como o mais alto dentre aqueles que forem efetivamente transmitidos será o vencedor do leilão. Para uma revisão das regras de funcionamento do leilão na eBay recomenda-se a releitura da subseção Funcionamento do Leilão na eBay.

${ }^{13} \mathrm{O}$ resultado dessa estimação para o Conjunto de Dados 0 foi $\mathrm{b}^{*}=1.39$. 
Se o tipo de modelo for o de valor comum, então, conforme Bajari e Hortaçsu [2001] e Roth e Ockenfels [2000], não é de interesse de ninguém revelar sua avaliação (direta ou então indiretamente através de um lance que seja função monotônica de seu sinal) antes do último segundo. Isso porquê cada lance dado por um comprador pode revelar informação a respeito de seu sinal para os demais compradores. Dado que revelar seu sinal é uma estratégia dominada por não revelar o sinal, tem-se que nenhum comprador irá ofertar lances até o encerramento do leilão.

Conforme os resultados obtidos na subseção anterior, encontramos indícios de que os leilões de selos na eBay seguem o modelo de valor comum e, assim, concluí-se que a melhor explicação para a ocorrência do fenômeno da submissão tardia de lances é a de que os compradores não têm interesse em revelar seus sinais para os demais compradores conforme a exposição dada no parágrafo acima.

\section{Conclusão e Comentários Finais}

\section{Modelo teórico}

O modelo teórico de leilão que é utilizado neste trabalho para estudar os leilões na eBay, não considera duas características observadas na prática:

- os compradores não têm certeza do número de participantes; e

- os compradores com lances superados podem submeter novos lances.

Assim, além das usuais simplificações de simetria entre os jogadores e de utilização de uma forma específica única para o cálculo da avaliação do objeto para cada comprador, o modelo não é completo o suficiente para um estudo mais aprofundado dos leilões na eBay. A vantagem da simplicidade do modelo, por outro lado, reside na dedução de um método facilmente implementado de estimação da "intensidade" com a qual os leilões estudados se enquadram nos modelos de valor comum ou privado. 
Acredito que a mais importante sofisticação que deve ser incluída em um modelo que se propõe a estudar leilões na Internet seja a de permitir o fato de que os compradores não saibam ao certo com quantos compradores eles estão se defrontando. Além disso, deve-se também permitir a reentrada de participantes que tenham seus lances superados, característica essa presente na realidade.

O motivo pelo qual estas características não terem sido incluídas no modelo teórico foi em razão da proposta do método de estimação do parâmetro b, pois tal método depende da utilização do modelo mais simples que foi utilizado no trabalho.

Por fim, como desenvolvimento adicional do modelo, pode-se estudar a possibilidade de utilizar um modelo onde os sinais dos jogadores são afiliados.

\section{Experimentos}

Os experimentos que compõem este trabalho proporcionaram um contato com a potencialidade e os problemas enfrentados que surgem quando se utiliza a economia experimental. O primeiro experimento não foi corretamente desenhado para atingir seus objetivos, em função de uma grande restrição financeira para a sua execução e da dificuldade em obter voluntários dispostos a participar de um experimento, desconhecido para eles, que envolvia ganhos (e perdas) monetários. Entretanto, o primeiro experimento, apesar de seu insucesso, proporcionou condições para que um segundo experimento, desenhado corretamente, pudesse ser implementado.

As duas principais condições presentes para a execução do segundo experimento, e que não estavam presentes no primeiro, foram o interesse dos voluntários em participar do novo experimento, mesmo sabendo que correriam o risco de terem prejuízo, e que a probabilidade de se pagar prêmios altos aos compradores (ou receber dos compradores pagamentos decorrentes de payoffs negativos) é baixa. Isso estimulou a implementação do novo experimento com novas regras, mesmo com a existência de limitações de verba. 
Os resultados mostraram uma grande distância entre o que a teoria diz e o que foi observado. A observação prática do que aconteceu nos leilões hipotéticos realizados, sugere que novos estudos experimentais sejam feitos, de forma a caracterizar com claridade o comportamento dos participantes e, assim, propor novos modelos teóricos que incluam as estratégias utilizadas.

A importância de se observar na prática o comportamento das pessoas em situações que possuem ou não um estudo teórico aprofundado é, em minha opinião, extremamente valioso e enriquecedor. Deste trabalho levo comigo uma grande motivação de utilizar experimentos em trabalhos futuros, sempre que estes apresentem alguma relevância, seja suportando ou refutando idéias existentes, ou até mesmo lançando um pouco de luz em questões que ainda sejam obscuras.

\section{$\underline{\text { Programas de coleta de dados na Internet }}$}

Os programas de coleta de dados de leilões na Internet foram cruciais para a elaboração deste trabalho. Mais do que isso, sua reutilização para a coleta de novos dados é simples e imediata. Assim, considero os programas de coleta de dados desenvolvidos como uma das mais, ou "a" mais, importantes contribuições deste trabalho, visto que eles eliminam uma grande barreira aos estudos empíricos: obtenção de dados.

Além disso, a prática que adquiri em programação na linguagem Perl me permite ter mais facilidade na elaboração de programas que atendam a novas demandas, no que se refere a aquisição e manipulação de dados na Internet

\section{$\underline{\text { Análise dos dados }}$}

A análise exploratória das variáveis determinantes de preços de venda, número de jogadores e preços mínimos nos leilões, bem como a observação da submissão tardia de lances, não apontaram surpresas, se compararmos os resultados obtidos com os 
conseguidos em outros trabalhos que abordam esses assuntos.

O destaque fica para a verificação na prática de que a reputação do vendedor tem um efeito mensurável sobre o valor do preço final e sobre o número de participantes do leilão.

\section{Método proposto}

O método proposto de obtenção do parâmetro $b$ foi deduzido a partir do modelo teórico utilizado, não se baseando em qualquer trabalho feito anteriormente. Nesse aspecto, o método constitui uma contribuição original deste trabalho ao estudo de leilões, considerando meu conhecimento de trabalhos na área.

Sua aplicabilidade pode ser questionada em função de sua simplicidade, mas convém notar que qualquer método numérico que se proponha a descobrir o tipo de modelo de um leilão deverá estar suportado por um modelo teórico. O ponto principal é que modelos diferentes apresentarão peculiaridades que poderão tornar a tarefa de identificação de parâmetros em um trabalho bastante árduo. 
Anexo

Dados utilizados na aplicação do método proposto 
Dados do Conjunto 0 para aplicação do método proposto $(n=3)$ :

\begin{tabular}{|c|c|c|c|c|c|}
\hline & P2 & P3 & Fator & Book Value & Descrição \\
\hline 01 & 0.229167 & 0.208333 & 0.75 & 32.00 & US 622-623 Set MLH-Nicely Centered-NR \\
\hline 02 & 0.300000 & 0.200000 & 0.50 & 200.00 & Mint 556, 557, 559, 562, 566, 567, 568, 570 . \\
\hline 03 & 0.328205 & 0.307692 & 0.75 & 65.00 & Nebraska U.S. \#678 Unused NH VF \\
\hline 04 & 0.372444 & 0.221111 & 0.50 & 90.00 & 408-413, WASH.-FRANK. MINT IMPERFS \& COILS \\
\hline 05 & 0.335238 & 0.285714 & 0.75 & 7.00 & Scott \# 650 Mint, Ex-Fine, NH, CV \$7.00 \\
\hline 06 & 0.363636 & 0.256364 & 0.50 & 55.00 & \#768-70 Gutter Pairs NH and NICE, CV $\$ 55$ \\
\hline 07 & 0.777200 & 0.540400 & 0.50 & 50.00 & \#WS8 Booklet pane NH and NICE, CV \$50.00 (10 selos) \\
\hline 08 & 0.349217 & 0.278261 & 0.75 & 57.50 & 470, 8c WASH.-FRANK. MINT OG \\
\hline 09 & 0.308000 & 0.307692 & 1.00 & 32.50 & 428, 5c WASH.-FRANK. VF LH OG JUMBO \\
\hline 10 & 0.827586 & 0.708046 & 0.75 & 14.50 & 455 Mint Never Hinged $\$ 14.50$ \\
\hline 11 & 0.577778 & 0.474074 & 0.75 & 45.00 & 541 Mint Lightly Hinged, Nice $\$ 45.00$ \\
\hline 12 & 0.690286 & 0.400000 & 0.25 & 52.50 & 394 Mint Hinged $\$ 52.50$ \\
\hline 13 & 0.864000 & 0.355692 & 0.25 & 32.50 & 428 Mint Hinged, Rich Color $\$ 32.50$ \\
\hline 14 & 0.363636 & 0.254545 & 0.50 & 55.00 & 415 Mint No Gum $\$ 55.00$ \\
\hline 15 & 0.296444 & 0.296296 & 0.50 & 135.00 & 407 Mint Never Hinged $\$ 135.00$ \\
\hline 16 & 0.610286 & 0.473905 & 0.50 & 52.50 & 335 Mint Lightly Hinged $\$ 52.50$ \\
\hline 17 & 0.889394 & 0.416667 & 0.60 & 11.00 & 513 Mint Hinged, Fresh \& Well Centered $\$ 11.00$ \\
\hline 18 & 0.664421 & 0.463158 & 0.25 & 47.50 & 429 Mint Hinged, slightly disturbed gum $\$ 47.5$ \\
\hline 19 & 0.640000 & 0.320000 & 0.50 & 37.50 & $\# 347$ 5c Wash Mint CV\$37.50 \\
\hline 20 & 0.363636 & 0.363636 & 0.50 & 27.50 & $\# 3242$ 2 Jefferson Mint CV $\$ 27.50$ \\
\hline 21 & 0.400000 & 0.311111 & 0.50 & 45.00 & \#306 8c Martha Mint CV\$45 \\
\hline
\end{tabular}


Dados do Conjunto Gold para aplicação do método proposto $(\mathrm{n}=3)$ :

\begin{tabular}{|c|c|c|c|c|c|}
\hline & $\mathbf{P 2}$ & P3 & Fator & Book Value & Descrição \\
\hline 01 & 0.500000000 & 0.333333333 & 1.00 & 30.00 & 586, Mint 5c Roosevelt NH GEM $\$ 30.00+$ \\
\hline 02 & 0.571428571 & 0.440000000 & 0.50 & 52.50 & \#394 MH CV \$52.50 3c Washington Coil \\
\hline 03 & 0.244615385 & 0.192307692 & 0.25 & 26.00 & $\# 371 \mathrm{MH}$ CV $\$ 26.00$ - Imperf \\
\hline 04 & 0.603636364 & 0.454545455 & 0.25 & 11.00 & $\# 513 \mathrm{MH} \mathrm{13c}$ Franklin $\mathrm{CV} \$ 11.00$ \\
\hline 05 & 0.784313725 & 0.456470588 & 0.75 & 42.50 & 334 OGHR JUMBO GEM CAT\$42.50 \\
\hline 06 & 1.096000000 & 0.604266667 & 0.25 & 75.00 & 464 OG HR CAT\$75 \\
\hline 07 & 0.084040000 & 0.062040000 & 0.50 & 500.00 & 634a UNUSED NH CAT\$500 \\
\hline 08 & 0.800932401 & 0.582750583 & 0.25 & 42.90 & $562-5,622$ OG HR CAT $\$ 42.90$ \\
\hline 09 & 0.630857143 & 0.457142857 & 0.50 & 8.75 & \#698 Mint FVF SCV\$8.75 SOLID!! \\
\hline 10 & 0.305000000 & 0.133333333 & 0.50 & 24.00 & \#495 Mint Pair FVF SCV\$24.00 FRESH! \\
\hline 11 & 0.500000000 & 0.200000000 & 0.50 & 20.00 & 557 MINT VF LIGHTLY HINGED 1922 CV \$20.00 \\
\hline 12 & 0.89037037 & 0.185185185 & 0.75 & 9.00 & 551-54 MINT XF NEVER HINGED 1922 CV \$9.00 \\
\hline 13 & 0.750819672 & 0.656393443 & 0.50 & 30.50 & $620 \& 621 M N H F-V F 2001$ SCOTT $\$ 30.50$ \\
\hline 14 & 1.338666667 & 0.533333333 & 0.50 & 3.75 & \# 671 Mint, Hinged, XF Cat. $\$ 3.75$ \\
\hline 15 & 0.222222222 & 0.194444444 & 0.50 & 18.00 & 540 MINT NEVER HINGED TYPE III CV \$18.00 \\
\hline 16 & 0.282500000 & 0.200000000 & 0.50 & 16.00 & 537 MINT NEVER HINGED CV $\$ 16.00$ \\
\hline 17 & 0.347826087 & 0.260869565 & 0.50 & 23.00 & $528 b$ MINT LIGHTLY HINGED CV \$23.00 \\
\hline 18 & 0.312000000 & 0.133333333 & 0.75 & 15.00 & 512 MINT NEVER HINGED VF CV $\$ 15.00$ \\
\hline 19 & 1.010000000 & 0.767333333 & 0.50 & 30.00 & $\# 749$ 10c parks Plate Block Mint $* N H * C V \$ 30$ \\
\hline 20 & 0.600000000 & 0.525500000 & 0.50 & 40.00 & $\# 563$ 11c Plate Block Mint $* N H * C V \$ 40.00$ \\
\hline 21 & 0.328358209 & 0.225671642 & 0.50 & 16.75 & \#548-9 Pilgrims-Mint $* * N H * * C V \$ 16.75$ \\
\hline 22 & 0.429142857 & 0.382285714 & 0.50 & 35.00 & $\# 668$ 10c Nebraska - Mint $* * N H * * C V \$ 35.00$ \\
\hline 23 & 0.272727273 & 0.250909091 & 0.50 & 22.00 & Scott \#654-56 Set of $3 \mathrm{MNH} C \mathrm{CV} \$ 22.00$ \\
\hline 24 & 0.659375000 & 0.487500000 & 0.50 & 160.00 & US Stamps: 350 coil Mint, VF, $h(c v \$ 160.00)$ \\
\hline 25 & 0.584000000 & 0.426666667 & 0.50 & 37.50 & US Stamps: 348 coil Mint, VF, $h(c v \$ 37.50)$ \\
\hline 26 & 0.284545455 & 0.235454545 & 1.00 & 11.00 & 696 Liberty NH Gem CV \$11+ Nice Stamp! NR \\
\hline 27 & 0.294845361 & 0.082474227 & 0.50 & 48.50 & \#495 Pair Mint OGNH Cat. $\$ 48.50$ \\
\hline 28 & 0.971428571 & 0.857142857 & 1.00 & 35.00 & 431, Mint $8 \&$ SUPERB XLH GEM Cat $\$ 35.00++$ \\
\hline 29 & 0.416666667 & 0.253055556 & 1.00 & 180.00 & 327, Mint 10ழ SUPERB LH GEM Cat $\$ 180.00$ \\
\hline 30 & 0.092307692 & 0.081723077 & 0.25 & 650.00 & 499c VERT PAIR IMPERF BETWEEN NH \$650 \\
\hline 31 & 0.197142857 & 0.143571429 & 0.50 & 28.00 & 510 MINT NEVER HINGED CV \$28.00 \\
\hline 32 & 0.169800000 & 0.127700000 & 0.50 & 200.00 & 412 UNUSED NH LINE PAIR CAT\$200 \\
\hline 33 & 0.423083333 & 0.106416667 & 0.50 & 240.00 & 413 UNUSED NH LINE PAIR CAT\$240 \\
\hline 34 & 0.124080000 & 0.120000000 & 0.50 & 250.00 & 444 UNUSED OG LINE PAIR CAT\$250 \\
\hline 35 & 0.329411765 & 0.317411765 & 1.00 & 42.50 & 339 UNUSED OG CAT\$42.50 GEM \\
\hline 36 & 0.227272727 & 0.206090909 & 0.50 & 220.00 & $\# 298$ MNH- Post Office Fresh SCV $\$ 220.00$ \\
\hline 37 & 0.41034651 & 0.351390922 & 0.75 & 34.15 & US Stamps: 839-851 mint, VFNH, (cv\$34.15) \\
\hline 38 & 0.196428571 & 0.178571429 & 0.50 & 28.00 & 507 MINT LIGHTLY HINGED CV \$28.00 \\
\hline 39 & 0.19047619 & 0.047619048 & 0.75 & 35.00 & SCOTT\#616 VF NH HUGENOT-WALLOON $\$ 35.00$ \\
\hline 40 & 0.611111111 & 0.138888889 & 0.75 & 12.00 & 501 MINT XF LIGHTLY HINGED TYPE I CV \$12.00 \\
\hline 41 & 0.250000000 & 0.187500000 & 0.50 & 16.00 & $486-87$ MINT NH \& LH SET CV \$16.00 \\
\hline 42 & 0.339575758 & 0.242424242 & 0.75 & 220.00 & 378, Mint PL\# BLOCK OF 4 VF NH Cat $\$ 220.00$ \\
\hline 43 & 0.534545455 & 0.454545455 & 0.50 & 22.00 & $\# 770$ MNH Block of 4 W/Crossed Gutters CV $\$ 22$ \\
\hline 44 & 0.815789474 & 0.052631579 & 1.00 & 19.00 & 538, Mint 1c Washington NH JUMBO GEM $\$ 19.00++$ \\
\hline 45 & 0.74906367 & 0.629213483 & 0.75 & 44.50 & 617 - 619, Mint NH VF SET NICE Cat $\$ 44.50$ \\
\hline 46 & 0.364186047 & 0.232558140 & 1.00 & 21.50 & 588, Mint $7 c$ VF NH GEM Cat $\$ 21.50$ \\
\hline 47 & 0.354509804 & 0.235294118 & 0.75 & 850.00 & 480, Mint $\$ 5$ PL\# PAIR F-VF NH Cat $\$ 850.00$ \\
\hline
\end{tabular}




\begin{tabular}{|c|c|c|c|c|c|}
\hline 48 & 0.388461538 & 0.292423077 & 1.00 & 260.00 & 461, Mint 2c SUPERB NH PF CERT Cat $\$ 260.00$ \\
\hline 49 & 0.600000000 & 0.275000000 & 0.75 & 40.00 & SCOTT 720 booklet pane F/VF MNH CV\$40+ \\
\hline 50 & 0.5566666667 & 0.555555556 & 1.00 & 9.00 & 554, Mint FOUR COPIES VF - XF GEMS Cat $\$ 9.00+$ \\
\hline 51 & 0.100666667 & 0.080000000 & 1.00 & 75.00 & 464, Mint $3 c$ VF XLH GEM Cat $\$ 75.00$ \\
\hline 52 & 0.794871795 & 0.769230769 & 0.75 & 26.00 & \# 832C,833 VF NH Cat.\$26 LOOK!! \\
\hline 53 & 0.411347518 & 0.354609929 & 0.50 & 35.25 & \# 698-700 F-VF OG Cat.\$35.25 LOOK!! \\
\hline 54 & 1.333333333 & 0.850000000 & 0.50 & 30.00 & \# 586 F-VF OG NH Cat.\$30 MUST SEE!! \\
\hline 55 & 0.462222222 & 0.353777778 & 0.75 & 37.50 & \# 566 VF-XF OG NH Cat.\$37.50 MUST SEE!! \\
\hline 56 & 0.571428571 & 0.524761905 & 0.75 & 14.00 & \# 496 Pair VF NH Cat.\$14 MUST SEE!! \\
\hline 57 & 0.742222222 & 0.740740741 & 0.50 & 13.50 & \# 442 F-VF OG NH Cat.\$13.50 MUST SEE!! \\
\hline 58 & 0.247619048 & 0.200285714 & 0.50 & 210.00 & \# 438 Fine+ OG Cat.\$210 MUST SEE!! \\
\hline 59 & 0.545714286 & 0.400000000 & 0.50 & 35.00 & \# 427 Fine+ OG Cat.\$35 MUST SEE!! \\
\hline 60 & 0.579710145 & 0.348985507 & 0.75 & 11.50 & \# 384 Pair VF OG Cat.\$11.50 MUST SEE!! \\
\hline 61 & 0.327083333 & 0.317500000 & 0.75 & 96.00 & 621 , Mint 5c BLOCK OF FOUR - XF NH Cat $\$ 96.00$ \\
\hline 62 & 0.54637037 & 0.446222222 & 0.50 & 67.50 & \# 338 F-VF OG Cat.\$67.50 MUST SEE!! \\
\hline 63 & 0.209677419 & 0.161290323 & 0.50 & 62.00 & 329 NICE CORNER COPY OG NH VERY FRESH \$62 CV \\
\hline 64 & 0.366666667 & 0.200000000 & 0.50 & 15.00 & 483 MINT LIGHTLY HINGED CV $\$ 15.00$ \\
\hline 65 & 0.241600000 & 0.241584000 & 0.50 & 2500.00 & 388 Mint OGH $3 \mathrm{~mm}$ Pair SCV $\$ 2500$. \\
\hline 66 & 0.551000000 & 0.300000000 & 0.50 & 20.00 & \#424 Booklet Pane - NHW/PLATE \# - CV \$20.00++ \\
\hline 67 & 0.473684211 & 0.436842105 & 0.50 & 190.00 & \#475 Mint FVF SCV\$190.00 Franklin \\
\hline 68 & 0.051666667 & 0.022111111 & 0.50 & 180.00 & \#327 10c Map Mint cv\$180 \\
\hline 69 & 0.755555556 & 0.700000000 & 0.50 & 45.00 & $\# 541$ VLH F \& fresh...Scott catalogue $=\$ 45.00$ \\
\hline 70 & 1.263157895 & 0.736842105 & 0.50 & 19.00 & $\# 538 \mathrm{MNH} F++\&$ fresh...Scott cat. $=\$ 19.00$ \\
\hline 71 & 0.593777778 & 0.435555556 & 0.75 & 15.00 & $\# 531$ MNH VF imperf...fresh...Scott $=\$ 15.00$ \\
\hline 72 & 0.555555556 & 0.533333333 & 0.50 & 45.00 & $\# 526$ MNH F++ \& fresh...Scott cat. $=\$ 45.00$ \\
\hline 73 & 0.243555556 & 0.111407407 & 0.90 & 18.75 & 575, Mint Imperf 1c Franklin Pair GEM \$18.75+ \\
\hline 74 & 0.278888889 & 0.114444444 & 0.90 & 10.00 & 503, Mint 4c Washington LH JUMBO $\$ 10.00+$ \\
\hline 75 & 0.345555556 & 0.234444444 & 0.90 & 10.00 & 611, Mint Imperf $2 c$ Harding NH GEM $\$ 10.00+$ \\
\hline 76 & 0.375000000 & 0.125000000 & 0.50 & 16.00 & 450 MINT NEVER HINGED 1915 CV $\$ 16.00$ \\
\hline 77 & 0.694044444 & 0.391111111 & 0.75 & 37.50 & $\# 473$ VF ...fresh...Scott catalogue $=\$ 37.50$ \\
\hline 78 & 0.533333333 & 0.444444444 & 0.50 & 45.00 & $\# 435 \mathrm{MNH} F+\ldots$ fresh $\ldots .$. Scott cat.$=\$ 45.00$ \\
\hline 79 & 0.525000000 & 0.499750000 & 0.50 & 80.00 & $\# 433$ MNH F w/plate number $\ldots$..Scott $=\$ 80.00$ \\
\hline 80 & 0.333333333 & 0.222222222 & 0.50 & 45.00 & 8c M. Washington 306 Just Fine LH Scott $\$ 45$ \\
\hline 81 & 0.333333333 & 0.266666667 & 0.50 & 60.00 & 5c Lincoln 304 Just Fine LH Scott $\$ 60.00$ \\
\hline 82 & 0.600000000 & 0.572571429 & 0.50 & 17.50 & Sc \#581, 1ct. Unused--Cat. value $\$ 17.50$ \\
\hline 83 & 0.454545455 & 0.362727273 & 0.50 & 110.00 & \#546 2c Wash Bureau Type III F/VF MH Cat $\$ 110$ \\
\hline 84 & 0.384307692 & 0.353538462 & 0.50 & 65.00 & SCOTT 516 20c FRANKLIN $\quad F-V F \quad N H \quad C V \$ 65$ \\
\hline 85 & 0.500000000 & 0.417500000 & 0.50 & 24.00 & SCOTT 509 $8 c$ FRANKLIN F-VF NH CV \$24+ \\
\hline 86 & 0.402400000 & 0.200000000 & 0.50 & 25.00 & \#616 5c Walloon Mint CV\$25 \\
\hline 87 & 0.273939394 & 0.187878788 & 0.50 & 16.50 & 7253 c Plate Block Mint CV\$16.50 \\
\hline 88 & 0.366000000 & 0.225000000 & 0.50 & 20.00 & $3464 c$ Wash Mint CV $\$ 20$ \\
\hline 89 & 0.150537634 & 0.086021505 & 0.50 & 93.00 & $3012 c$ Wash Plate Strip Mint CV\$93 \\
\hline 90 & 0.421875000 & 0.284375000 & 0.50 & 32.00 & Famous Americans Set, Mint and $N H^{* *}, C V \$ 32$. \\
\hline
\end{tabular}




\section{Bibliografia}

Bajari, P. e Hortaçsu, A. [2001] Winner's Curse, Reserve Prices and Endogenous Entry: Empirical Insights from eBay Auctions. Working Paper, Stanford University.

Bazerman, M. H. e Samuelson, W. F. [1983] I Won the Auction But Don't Want the Prize. Journal of Conflict Resolution, 27, 618-634.

Bikhchandani, S. e Riley, J. G. [1991] Equilibria in Open Common Value Auctions. Journal of Economic Theory, 1991, 53, 101-130.

Bikhchandani, Sushil e Riley, J. G. [1993] Equilibrium in Open Auctions. Working Paper, University of California at Los Angeles.

Bulow, J. e Klemperer, P. D. [2000] Prices and the Winner's Curse. Working Paper, Oxford University.

Capen, E. C., Clapp, R. V. e Campbell, W. M. [1971] Competitive Bidding in High-Risk Situations. Journal of Petroleum Technology, 23, 641-653.

Deitel, H. M., Deitel, P. J., Nieto, T. R. e McPhie, D. C., Perl, How to Program. New Jersey: Prentice Hall.

Houser, D. e Wooders, J. [2000] Reputation in Auctions: Theory and Evidence from eBay. Working Paper, University of Arizona.

Kagel, J. H. e Levin, D. [1986] The Winner's Curse and Public Information in Common Value Auctions. American Economic Review, 76, 894-920.

Kagel, J. H. e Roth, A. E. (editores) [1997], The Handbook of Experimental Economics. New Jersey: Princeton University Press. 
Klemperer, P. D. [1999] Auction Theory: A Guide to the Literature. Journal of Economic Surveys, 13.

Klemperer, P. D. [2001] What Really Matters in Auction Design. Working Paper, Oxford University.

Lucking-Reiley, D. [1999] Auctions on the Internet: What's Being Auctioned, and How? Journal of Industrial Economics, vol.48, $n^{\circ .}$ 3, September.

Lucking-Reiley, D., Bryan, D., Prasad, N. e Reeves, D. [2000] Pennies from eBay: the Determinants of Price in Online Auctions. Working Paper, Vanderbilt University.

Milgrom, P. R. e Weber, R. J. [1982] A Theory of Auctions and Competitive Bidding. Econometrica, 50, 1089-1122.

Paarsch, H. J. [1992] Deciding Between the Common and Private Value Paradigms in Empirical Models of Auctions. Journal of Econometrics, 1992, 51, 191-215.

Roth, A. E. e Ockenfels, A. [2000] Last Minute Bidding and the Rules for Ending Second-Price Auctions: Theory and Evidence from a Natural Experiment on the Internet. Working Paper, Harvard University.

Thaler, R. H. [1994], The winner's curse: paradoxes and anomalies of economic life. New Jersey: Princeton University Press.

Weiner, S., Bazerman, M. H. e Carroll, J. [1987] An Evaluation of Learning in the Bilateral Winner's Curse. Unpublished Manuscript, Kellogg School of Management, Northwestern University.

Wilson, R. [1977] A Bidding Model of Perfect Competition. Review of Economic Studies, 4, 511-518. 


\section{Apêndice A}

Layout das páginas de leilões na eBay 


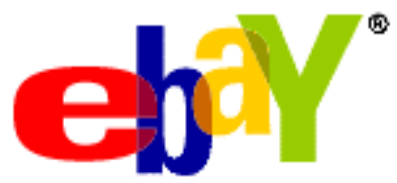

\section{Browse Sell Ser
to see the latest version.}

home | my eBay. | site map

Updated: Jun-21-01 01:00:00 PDT Check eBay official
Use your browser's reload button to see the latest version.
Search only in $\mathbf{1 9 0 1}$ to 1940 Search
Search only in 1901 to 1940: Unused
Search within titles and descriptions

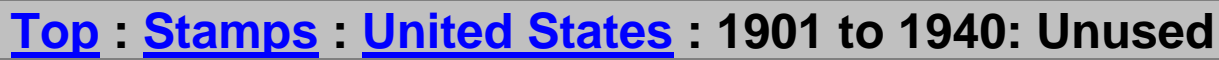 Auction Items Completed on Jun. 20, 2001}

Current || New Today || Ending Today $\|$ Completed $\|$ Going, Going, Gone

\section{All Items in 1901 to $1940:$ Unused}

Auction Items Completed on Jun. 20, 2001

For more items in this category, click on the following pages:

$$
=1=[\underline{2}][\underline{3}][\underline{4}][\underline{5}][\underline{6}]>>\underline{\text { Jun. 19, 2001 }}
$$

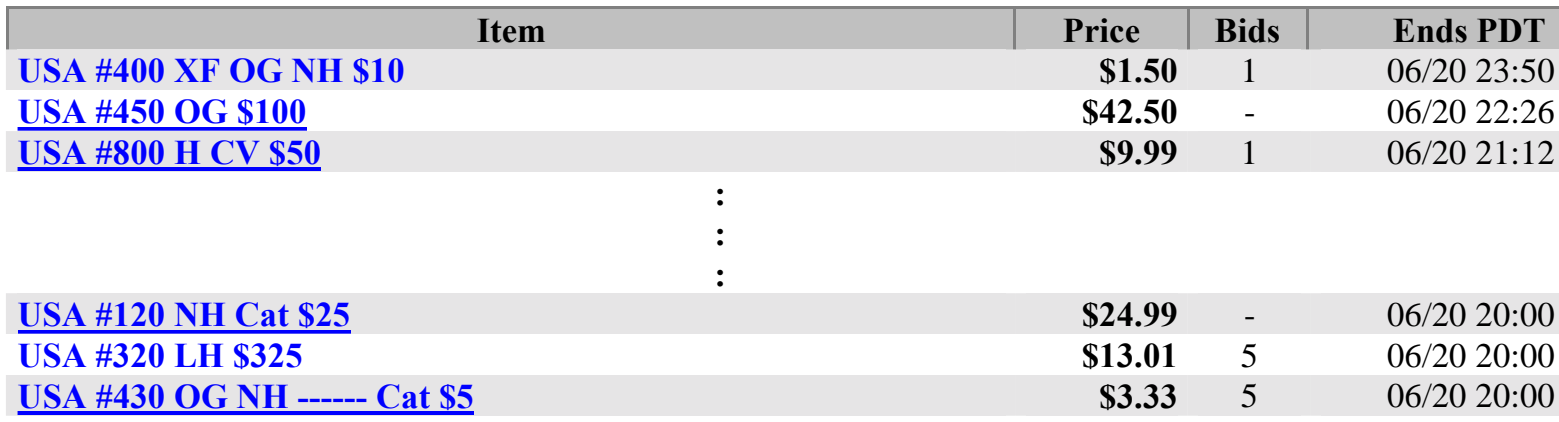

For more items in this category, click on the following pages:

$$
=1=[\underline{2}][\underline{3}][\underline{4}][\underline{5}][\underline{6}]>>\underline{\text { Jun. 19, 2001 }}
$$

\section{Top : Stamps : United States : 1901 to 1940: Unused}

Click on a title to get a description and to bid on that item. A red ending time indicates that an auction is ending in less than five hours. These items are not verified by eBay; caveat emptor. This page is updated regularly; don't forget to use your browser's reload button for the latest version. The system may be unavailable during regularly scheduled maintenance, Mondays, 12 a.m. to 4 a.m. Pacific Time (Mondays, 00:01 a.m. to 04:00 a.m., eBay time). 


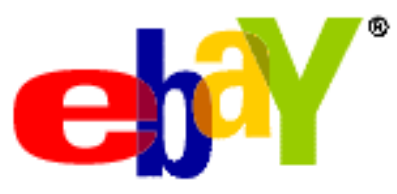

\section{home | my eBay. | site map \\ Browse \\ Sell Services \\ Search \\ Help \\ item view

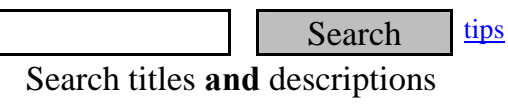

Community

- Check out LIVE auctions on eBay.

\section{eBay Bid History for}

USA \#400 Superb OG NH ----- Cat \$225 (Item \# 1234567890 )

$\begin{array}{llll}\text { Currently } & \mathbf{\$ 1 6 9 . 2 6} & \text { First bid } & \mathbf{\$ 1 . 0 0} \\ \text { Quantity } & \mathbf{1} & \text { \# of bids } & \mathbf{1 4} \\ \text { Time left } & \text { Auction has ended. } & & \\ \text { Started } & \text { Jun-17-01 20:16:50 PDT } & & \\ \text { Ends } & \text { Jun-20-01 20:16:50 PDT } & & \\ \text { Seller (Rating) } & \text { dcr-milkmoney (199) \# } & & \end{array}$

View page with email addresses (Accessible by Seller only) Learn more.

\begin{tabular}{|c|c|c|}
\hline User ID & Bid Amount & Date of Bid \\
\hline dcr-milkmoney (199) & $\$ 169.26$ & Jun-20-01 20:13:42 PDT \\
\hline$\underline{\text { strictlyusstamppro }} \underline{(72)}$ & $\$ 166.76$ & Jun-20-01 20:16:47 PDT \\
\hline bigggfish1 (108) & $\begin{array}{c}\$ 144.01 \\
\quad: \\
: \\
:\end{array}$ & Jun-20-01 20:16:44 PDT \\
\hline abcstamps (50) & $\$ 55.00$ & Jun-17-01 21:27:59 PDT \\
\hline rushen $(107)$ & $\$ 50.00$ & Jun-18-01 04:44:07 PDT \\
\hline drmacintosh (137) & $\$ 25.00$ & Jun-17-01 20:30:54 PDT \\
\hline
\end{tabular}

Remember that earlier bids of the same amount take precedence.

Bid Retraction and Cancellation History History

There are no bid retractions or cancellations.

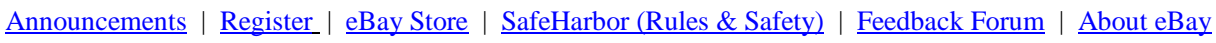

Copyright $\odot$ 1995-2000 eBay Inc. All Rights Reserved.

Designated trademarks and brands are the property of their respective owners.

Use of this Web site constitutes acceptance of the eBay User Agreement and Privacy Policy. 
Layout da página com informações sobre o vendedor de um leilão completado em 20 de junho de 2001:
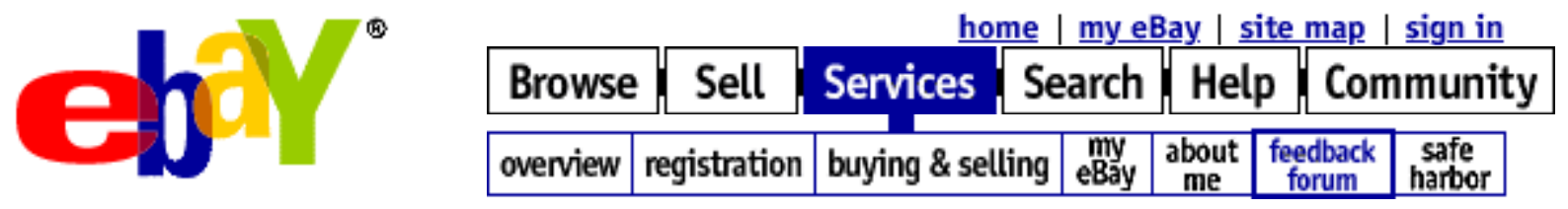

- Check out LIVE auctions on eBay.

Search Tips

Search titles and descriptions

\section{Overall profile makeup}

204 positives . 8 are from unique users and count toward the final rating

3 neutrals.

5 negatives $\mathbf{2}$ are from unique users and count toward the final rating.

\section{Ch" ID card abcdefg (199)}

Member since Sunday, Jul 12, 1998

Location: United States

Summary of Most Recent Comments

$\begin{array}{llll} & \text { Past 7 days } & \text { Past month } & \text { Past 6 mo. } \\ \text { Positive } & 47 & 158 & 204 \\ \text { Neutral } & 0 & 0 & 3 \\ \text { Negative } & 4 & 4 & 5 \\ \text { Total } & \mathbf{5 1} & \mathbf{1 6 2} & \mathbf{2 1 2} \\ \text { Bid Retractions } & \mathbf{0} & \mathbf{0} & \mathbf{0}\end{array}$

View abcdefg's Auctions $\mid \underline{\text { ID History } \mid \text { Feedback About Others }}$

\section{Abcdefg's feedback}

Feedback $1-25$ of 212

$=1=\underline{2}($ next page $)$

User: A Date: Jun-21-01 22:59:24 PDT

Praise : Very satisfied with transaction

User: C Date: Jun-21-01 22:59:24 PDT

Complaint : FAKE STAMP-RETURNED-NO REFUND SENT-OWES ME \$698 IN

REFUNDS-NEVER SENT!!

User: F Date: Jun-17-01 18:25:11 PDT

Praise : Nice Description, Great Product, Fast Service, Will use again AAA++

User: G Date: Jun-17-01 10:38:04 PDT

Praise : excellent service, merchandise as represented

$=1=\underline{2}($ next page $)$

Items $1-25$ of 1143 total

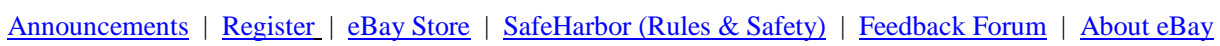

Copyright @ 1995-2000 eBay Inc. All Rights Reserved.

Designated trademarks and brands are the property of their respective owners.

Use of this Web site constitutes acceptance of the eBay User Agreement and Privacy Policy. 


\section{Apêndice B}

? Instruções dadas aos participantes do primeiro experimento

? Resultados dos leilões do primeiro e segundo experimentos 


\section{$\underline{\text { Experimento de Economia }}$}

Data: 06 de Julho de 2001

Nome:

Você é o JOGADOR \#

Sua TECLA é

Em primeiro lugar OBRIGADO por participar deste experimento. Sua participação já garante a você o recebimento de $\mathrm{R} \$ 10$ independentemente de sua performance.

O experimento consiste de 3 sessões, sendo que em cada sessão ocorrerão 30 leilões.

Todos os leilões têm uma única regra.

REGRA DOS LEILÕES:

- Será leiloado um único objeto em cada leilão, sendo que o objeto de um leilão é diferente de qualquer outro objeto leiloado em outro leilão;

- Haverá 4 potenciais compradores, chamados de competidores;

- Apenas 1 competidor ficará com o objeto, sendo este indivisível;

- Não há preço de reserva postado pelo vendedor, ou equivalentemente, o preço de reserva do vendedor é zero. Isso significa que todos os objetos leiloados serão sempre vendidos, qualquer que seja o preço atingido nos leilões;

- O intervalo entre quaisquer 2 leilões será de 30 segundos;

- Cada competidor recebe antes de cada leilão um valor, chamado de "sinal". Este sinal é um valor retirado de uma distribuição uniforme discreta de 0 até 100 , ou seja, todos os valores discretos de 0 até 100 têm igual probabilidade de serem escolhidos. Cada sinal só é conhecido pelo competidor que o recebe. Portanto um dado competidor não sabe os sinais que os demais competidores receberam. Não é permitido que o sinal de um competidor seja divulgado para outro competidor;

- O valor do objeto leiloado é o mesmo para todos os competidores, consistindo da média aritmética dos sinais recebidos pelos competidores. Assim, se os sinais são, por exemplo, 10, 20, 50 e 80, então o objeto vale 40 para todos;

- Todo leilão será realizado por meio de um programa de computador. Cada competidor terá associado a ele uma tecla do computador. Se esta tecla for pressionada, isso significará que o competidor está desistindo de participar do leilão em curso;

- O leiloeiro começa o leilão com o preço zero e sobe este continuamente em acréscimos unitários. Os competidores indicam, ao não pressionar sua tecla, se eles estão interessados em comprar o objeto ao preço corrente. Quando um competidor desiste, apertando sua tecla, ele não pode reentrar no leilão. A cada preço, as identidades de todos os competidores ativos (que não desistiram) nesse preço são de conhecimento comum. Sempre que um ou mais competidores saem em um dado preço, o leiloeiro pára de subir o preço e aguarda 10 segundos antes de continuar a subir o preço. Se algum(ns) competidor(es) desiste(m), o leiloeiro aguarda novos 10 segundos antes de continuar a subir o preço. Este processo continua até que não ocorram mais desistências. Se ainda houver dois ou mais competidores ativos, o leiloeiro começa a subir o preço novamente do ponto em que havia parado. $\mathrm{O}$ leilão termina quando em um dado preço existe apenas um competidor ativo. Este competidor é então 
declarado o vencedor e o leilão termina. O vencedor fica com o objeto e "paga" o preço corrente. Os demais compradores não "pagam" nada.

- Veja que mesmo no caso em que 2 ou mais competidores desistem em um dado preço, nunca ocorrerá uma desistência simultânea, visto que a desistência é condicionada ao fato de uma tecla ser pressionada. Assim vale o critério do mais rápido como forma de determinar a ordem das desistências;

- Ao final de cada leilão será calculado o payoff de todos os competidores. Todo competidor que não for o vencedor recebe payoff zero. Já o vencedor recebe como payoff o valor do objeto menos o valor "pago" pelo objeto. Estes payoffs e o valor verdadeiro do objeto leiloado não serão divulgados antes do fim da sessão em curso;

- Ao final de cada sessão será reservado um período de 40 minutos, onde serão divulgados os resultados (payoffs e valores verdadeiros dos objetos) de cada leilão da sessão;

- O competidor que tiver a maior valor resultante da soma de seus payoffs nos 30 leilões de uma sessão será declarado como sendo o $1^{\text {o. }}$ colocado da sessão. A ele será dado o prêmio de $\mathrm{R} \$ 6$. $\mathrm{O}$ competidor que tiver o segundo maior valor resultante da soma de seus payoffs nos 30 leilões de uma sessão será declarado como sendo o $2^{\text {o. }}$ colocado da sessão. A ele será dado o prêmio de $\mathrm{R} \$ 3$. $\mathrm{O}$ competidor que tiver o terceiro maior valor resultante da soma de seus payoffs nos 30 leilões de uma sessão será declarado como sendo o $3^{\text {o. }}$ colocado da sessão. A ele será dado o prêmio de R $\$ 1,50$. O competidor que tiver o menor valor resultante da soma de seus payoffs nos 30 leilões de uma sessão será declarado como sendo o $4^{\text {o. }}$ colocado da sessão. A ele não será dado prêmio algum.

- As sessões são independentes, isto é, no início de cada sessão os competidores têm seus payoffs obtidos anteriormente descartados. Portanto, no início de cada sessão todos estão empatados, começando com zero em suas somas de payoffs.

Antes do início da $1^{\text {a. }}$ sessão, serão realizados 5 simulações no computador com o objetivo de familiarizar os competidores com o programa que realizará o leilão. Não serão divulgados os resultados (payoffs e valores verdadeiros dos objetos) das simulações.

O pagamento dos prêmios será feito ao final da $3^{\text {a. }}$ sessão.

O tempo estimado de duração de cada leilão é de 1 minuto e 30 segundos.

O tempo estimado de duração de cada sessão é de 1 hora.

O tempo total estimado de duração do experimento será de 4 horas e 20 minutos.

Entre as sessões 1 e 2 e entre as sessões 2 e 3 será oferecido um coffee-break. Ao final da $3^{\text {a. }}$ sessão, será oferecido um lanche.

Por favor, ao final do experimento preencha a ficha de FEEDBACK e a entregue em seguida.

Mais uma vez, OBRIGADO! 


\section{$\underline{\text { Experimento de Economia }}$}

Data: 06 de Julho de 2001

Nome:

Você é o JOGADOR \#

\section{FEEDBACK:}

Orientação escrita do experimento fornecida:
[ ]Muito Deficiente
[ ]Deficiente
[ ]Regular
[ ]Bom
[ ]Muito Bom

Comentário:

Programa de computador que realizou os leilões:
[ ]Muito Deficiente
[ ]Deficiente
[ ]Regular
[ ]Bom
[ ]Muito Bom

Comentário:

Prêmios e alimentação:

[ ]Muito Deficiente [ ]Deficiente [ ]Regular [ ]Bom [ ]Muito Bom

Comentário:

Instalações físicas:

[ ]Muito Deficiente [ ]Deficiente [ ]Regular [ ]Bom [ ]Muito Bom

Comentário:

Participaria novamente de um experimento em condições semelhantes:
[ ]Nunca mais
[ ]Talvez
[ ]Com certeza

Comentário: 
$\underline{\text { Resultados do primeiro experimento: }}$ 
$\underline{\text { Resultados do segundo experimento: }}$ 


\section{Apêndice C}

Programas:

- spider1.pl

- spider2.pl

- spider3.pl

- blemish.pl

- dados.pl

- latebid.pl

- prices.pl

- bids.pl

- curse.pas

- leilao.m 
\#!c:|perl|bin|perl.exe

\# SPIDER1.PL

use strict;

use warnings;

use LWP::Simple;

my @mes31=qw(Feb Apr Jun Aug Sep Nov Jan); \# Estas listas dizem qtos.

my @mes30=qw(May Jul Oct Dec); \# dias tem o mês anterior

\# ao mês que aparece na lista. Obs: Feb=28dias.

my \$mesant; \# 1: 31dias, 0: 30dias, -2: 28dias

my @urlpage1; \# Lista das páginas 1 de cada dia

my @url; \# Lista de páginas onde se encontram os ID's dos leilões

my @ID; \# Lista dos ID's dos leilões

\# -------------------- Obtenção da data atual

my \$string = substr(scalar(localtime()),4,3); \# Mes atual (variável auxiliar)

my $\$$ dia=substr(scalar(localtime()),8,2); \# Dia atual

foreach (@mes31) \{ \$mesant=1 if \$string eq \$_; \# Define qual o

foreach (@mes30) $\{$ \$mesant=0 if \$string eq $\$$; $\}$ \# tipo do

foreach (@mes28) \{ \$mesant=-2 if \$string eq \$ ; \# mês anterior (0, 1 ou -2)

\# -------------------- Montagem de @urlpage1

for (my $\$ \mathrm{i}=\$$ dia- $1 ; \$ \mathrm{i}>0$; $\$ \mathrm{i}--)$ \# monta @urlpage1 com os dias do mês atual

\$string="http://cayman.ebay.com/aw/listings/completed/category3461/day".\$i."page1.html"; push (@urlpage1,\$string);

for (my $\$ \mathrm{i}=30+\$$ mesant; $\$ \mathrm{i}>=\$$ dia ; $\$ \mathrm{i}--)$ \# monta @urlpage1 com os dias do mês anterior \{

\$string="http://cayman.ebay.com/aw/listings/completed/category3461/day".\$i."page1.html"; push (@urlpage1,\$string); \}

\# -------------------- Montagem de @url

my \$j; \# Variável auxiliar DELAY

my \$site; \# Variável auxiliar

my \$page; \# Variável auxiliar

my \$day; \# Variável auxiliar p/ contar o dia

my \$num; \# Variável auxiliar p/ contar o num. de pags. no dia

my \$key = "]</a>"."In"."\&"; \# chave de busca de forma a encontrar [??]

print " $\mid n^{\star *}$ Creating url ** $\mid n \backslash n "$;

$\$$ day $=\$$ dia;

foreach \$site (@urlpage1)

\$day--;

$\$$ day $=30+\$$ mesant if $\$$ day $==0$;

push (@url,\$site);

for $(\$ \mathrm{j}=1 ; \$ \mathrm{j}<500000 ; \$ \mathrm{j}++)\{\}$ \# Delay

print "Day ",\$day," ==> ";

\$page = get $(\$ s i t e)$

\$num=substr(\$page,index (\$page,\$key)-2,2); \# encontra número de pags. no dia $\$$ num=chop(\$num) if substr(\$num,0,1) eq "["; \# se tiver 1 dig. pegue só ele

print "total of ",\$num," pages $\backslash n "$;

for (2..\$num)

\{

\$string="http://cayman.ebay.com/aw/listings/completed/category3461/day".\$day."page".\$_.".html"; push (@url,\$string);

\}

\# ----------------- Montagem de @ID

my \$pos; 


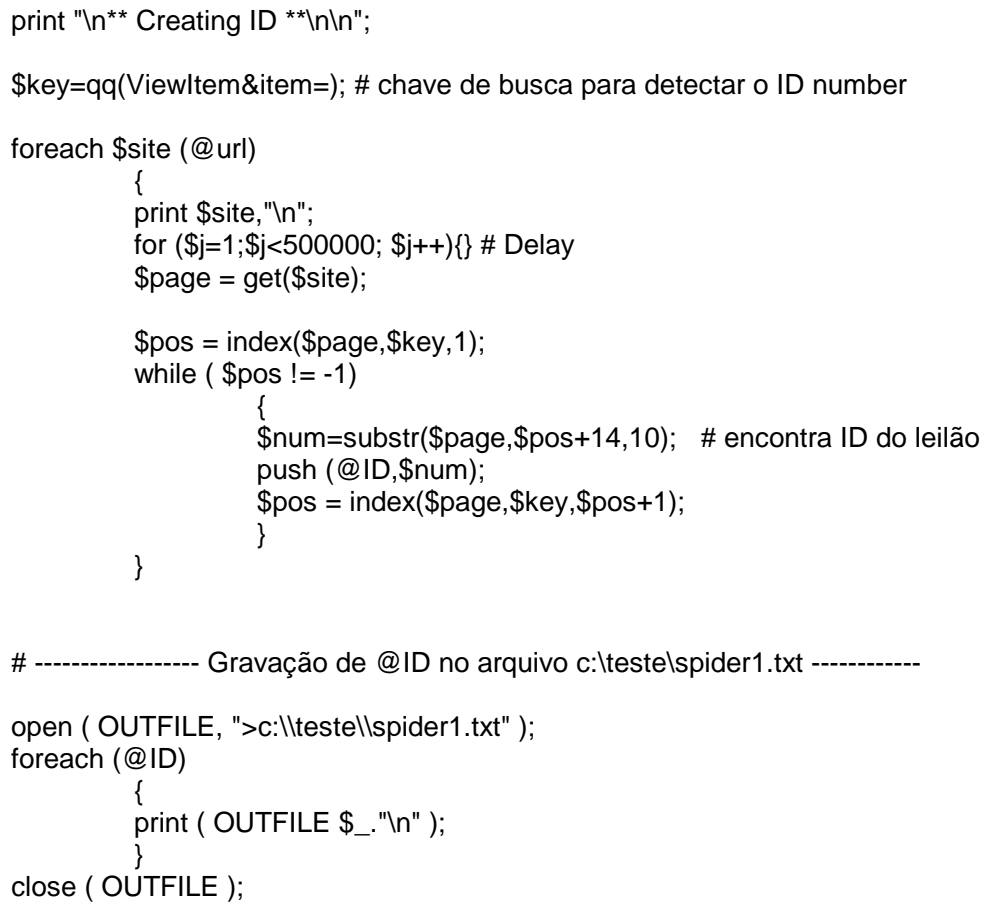


\#!c:Iperllbin lperl.exe \# SPIDER2.PL

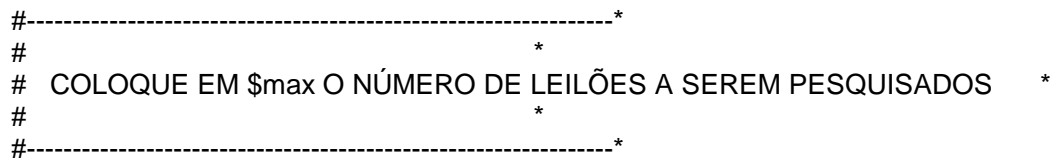

use strict;

use warnings;

use LWP::Simple;

my \$ID; \# ID do leilão

my \$max=2000; \# Número máximo de leilões a serem lidos de spider1.txt

my \$counter=0; \# Variável auxiliar: contador

my \$site; \# Endereço da página que contém os dados dos leilões

my \$page; \# Variável auxiliar: página recebida

my \$pos; \# Variável auxiliar: posição corrente em \$page

my \$pos2; \# Variável auxiliar de \$pos

my \$pos3; \# Variável auxiliar de \$pos e \$pos2

my \$i; \# Variável auxiliar: laço

my @bidders; \# Lista que será usada na contagem de bidders por leilão

my \$repet; \# Flag de repetição usada com @biddders

my @mes31=qw(Jan Mar May Jul Aug Oct Dec); \# Meses de 31 dias

my @mes30=qw(Apr Jun Sep Nov); \# Meses de 30 dias

my @mes28=qw(Feb); \# Mês de 28 dias

my \$mes; \# Variável auxiliar de dias no mes: 31: 31dias , 30: 30dias, 28: 28dias

my \$dia1; \# Variável auxiliar

my \$dia2; \# Variável auxiliar

my \$alfa; \# Variável auxiliar de \$dia1

my \$beta; \# Variável auxiliar de \$dia2

my @des; \# Descrição

my@bvi; \# Book value informado

my @pfi; \# Preço final

my @pin; \# Preço inicial

my @nor; \# Número de ofertas registradas

my @buy; \# Buy it now

my @din; \# Data de início

my @den; \# Data de encerramento

my @tem; \# Tempo de duração do leilão (em minutos)

my@ven; \# Nome do vendedor

my @com; \# Nome, lance, data e tempo antes de encerramento do comprador my @nbi; \# Número de compradores (bidders)

my $\$$ key $0="</$ b $>$ "; \# Chave delimitadora de algumas buscas

my \$key1="eBay Bid History for"; \# Chave 1 de busca para encontrar "Descrição"

my \$key2="<b>"; \# Chave 2 de busca para encontrar "Descrição"

my \$key3="(Item \\#"; \# Chave de busca para encontrar o fim de "Descrição"

my \$key4="|\$"; \# Chave de busca para encontrar "Book value informado"

my $\$$ key $5="><b>\mid \$ " ;$ \# Chave de busca para encontrar "Preço Final"

my \$key6="><b> $>$ "; \# Chave de busca para encontrar "Preço Inicial"

my \$key7="।\# of bids"; \# Chave 1 de busca para encontrar "Num. ofertas registradas"

my \$key8="<b>"; \# Chave 2 de busca para encontrar "Num. ofertas registradas"

my \$key9="Auction has ended"; \# Chave de busca para encontrar "Buy it now"

my \$key10="Started"; \# Chave 1 de busca para encontrar "Data de início"

my \$key11="<td colspan=|"4|">"; \# Chave 2 de busca para encontrar "Data de início"

my \$key12="<td colspan=|"4|">"; \# Chave de busca para encontrar "Data de encerramento"

my \$key13="requested="; \# Chave de busca para encontrar "Nome do vendedor"

my \$key14="\&amp"; \# Chave de busca para encontrar o fim de "Nome do vendedor/comprador"

my \$key15="requested="; \# Chave de busca para encontrar "Nome do comprador"

my $\$$ key $16="|\%| ">\mid \$ "$; \# Chave de busca para encontrar "Lance do comprador"

my \$key17="T</td >"; \# Chave de busca para encontrar "Data do lance do comprador"

my \$key18="</td>"; \# Chave delimitadora de lance dos compradores

my \$key19="Date of bid and retraction"; \# Chave que impede a leitura das retractions

open (IN, "c:Itestellspider1.txt");

$\$ /=" \mid n " ; \#<1 \mathrm{~N}>$ devolve o texto até encontrar " $\mid \mathrm{n} "$

for $(\$ \mathrm{i}=1 ; \$ \mathrm{i}<1001 ;++\$ \mathrm{i})\{\$ \mathrm{ID}=<\mathrm{IN}>;\}$ \# Ignora os primeiros 1000 leilões registrados

$\$ \mathrm{ID}=<\mathrm{IN}>$;

while $(++\$$ counter $<=\$$ max and $\$$ ID) 


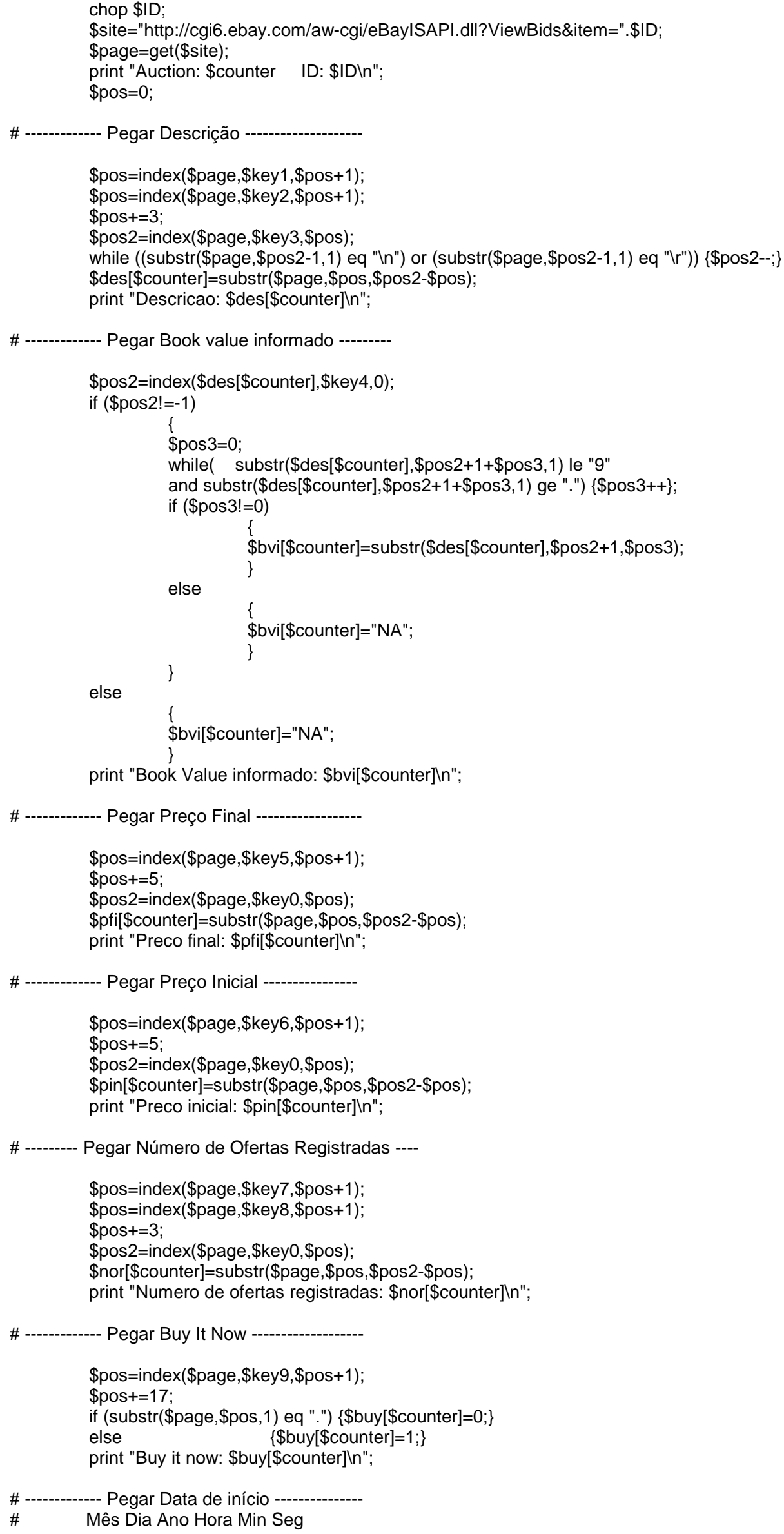


$\$ p o s=$ index $(\$ p$ age,$\$$ key $10, \$$ pos +1$)$ $\$$ pos=index $(\$ p a g e, \$$ key $11, \$$ pos +1$)$ $\$$ pos $+=16$;

\$din[\$counter]=substr(\$page,\$pos,3)." ". substr(\$page,\$pos+4,2)." ". substr(\$page,\$pos+7,2)." ". substr(\$page,\$pos+10,2)." ". substr(\$page,\$pos+13,2)." ". substr $(\$$ page, $\$$ pos $+16,2)$;

$\$$ dia1 $=$ substr $(\$ p a g e, \$ p o s+4,2) ;$

$\$$ alfa $=\operatorname{substr}(\$$ page,$\$$ pos $+16,2)+60 *$ substr $(\$$ page,$\$$ pos $+13,2)+60 * 60 * \operatorname{substr}(\$$ page, $\$$ pos $+10,2)$; foreach (@mes31) \{\$mes=31 if substr $(\$ p a g e, \$ p o s, 3)$ eq $\$ ;\}$

foreach (@mes30) $\{\$$ mes $=30$ if substr $(\$ p a g e, \$ p o s, 3)$ eq $\$+;\}$

foreach (@mes28) $\left\{\$\right.$ mes=28 if substr $(\$ p a g e, \$ p o s, 3)$ eq $\left.\$ \_;\right\}$

print "Data de inicio: \$din[\$counter]\n";

\# ----------- Pegar Data de encerramento

$\$$ pos=index $(\$ p a g e, \$$ key $12, \$ p o s+1)$;

$\$$ pos $+=16$;

\$den[\$counter]=substr(\$page,\$pos,3)." ".

substr(\$page,\$pos+4,2)." ".

substr(\$page,\$pos+7,2)." ".

substr(\$page,\$pos+10,2)." ".

substr(\$page,\$pos+13,2)." ".

substr(\$page,\$pos+16,2);

$\$$ dia2=substr $(\$$ page,$\$$ pos $+4,2)$;

$\$$ beta $=$ substr $(\$$ page, $\$$ pos $+16,2)+60 *$ substr $(\$$ page,$\$$ pos $+13,2)+60 * 60 * \operatorname{substr}(\$$ page,$\$$ pos $+10,2)$;

print "Data de encerramento: \$den[\$counter] $\backslash n "$;

\# ------------- Calcular Tempo de duração ----------

\$tem $\left[\right.$ counter] $=\left((\$ \text { dia2 }-\$ \text { dia1 })^{*} 24^{*} 60 * 60+\$\right.$ beta-\$alfa $)$ if $((\$$ dia2-\$dia1 $)>=0)$;

$\$$ tem $[\$$ counter $]=\left((\$ \text { mes }+\$ \text { dia2 }-\$ \text { dia1 })^{*} 24^{*} 60^{*} 60+\$\right.$ beta-\$alfa $)$ if $((\$$ dia2 $-\$$ dia 1$)<0)$;

print "Tempo de duracao (em seg.): \$tem[\$counter] $]$ n";

\# ------------- Pegar Vendedor

$\$ p o s=$ index $(\$ p$ age,$\$$ key $13, \$$ pos +1$)$

$\$$ pos+=10;

\$pos2=index(\$page,\$key14,\$pos)

\$ven[\$counter]=substr(\$page,\$pos, \$pos2-\$pos);

print "Vendedor: \$ven[\$counter]\n";

\# ---- Pegar Nome, lance, data e tempo antes do encerr. do(s) comprador(es) ----

@bidders=(); \# Zera lista de bidders

\$com[\$counter]="';

while $\quad(((\$ p o s=$ index $(\$ p a g e, \$$ key $15, \$ p o s+1)) !=-1)$ and $($ rindex $(\$ p a g e, \$$ key $19, \$ p o s)=-1))$

\$repet=0; \# Zera flag (novo bidder=0 / bidder já existente=1)

$\$$ pos $+=10$;

\$pos2=index(\$page,\$key14,\$pos);

$\$$ com $[\$$ counter] $=\$$ com $[\$$ counter]." ".substr(\$page, $\$$ pos,\$pos2-\$pos); foreach (@bidders)

$$
\text { if }
$$
\}

(\$_eq substr $(\$ p a g e, \$ p o s, \$ p o s 2-\$ p o s))\{$ \$repet=1;\};

if (!(\$repet)) \{push(@bidders,substr(\$page,\$pos,\$pos2-\$pos))\};

$\$$ pos=index $(\$ p a g e, \$$ key16,\$pos+1);

$\$$ pos $+=4$;

\$pos2=index(\$page,\$key18,\$pos);

\$com[ $\$$ counter]=\$com[\$counter]." ".substr(\$page,\$pos,\$pos2-\$pos);

$\$$ pos=index $(\$ p a g e, \$$ key $17, \$$ pos +1$)$;

$\$$ pos- $=21$;

\$com $[\$$ counter $]=\$$ com $[$ counter]." ".substr $(\$ p a g e, \$ p o s, 3)$.

" ".substr(\$page,\$pos+4,2).

" ".substr(\$page,\$pos $+7,2)$

" ".substr(\$page,\$pos+10,2).

" ".substr(\$page,\$pos+13,2)

\$dia1=substr $($ page, $\$$ pos $+4,2)$; 


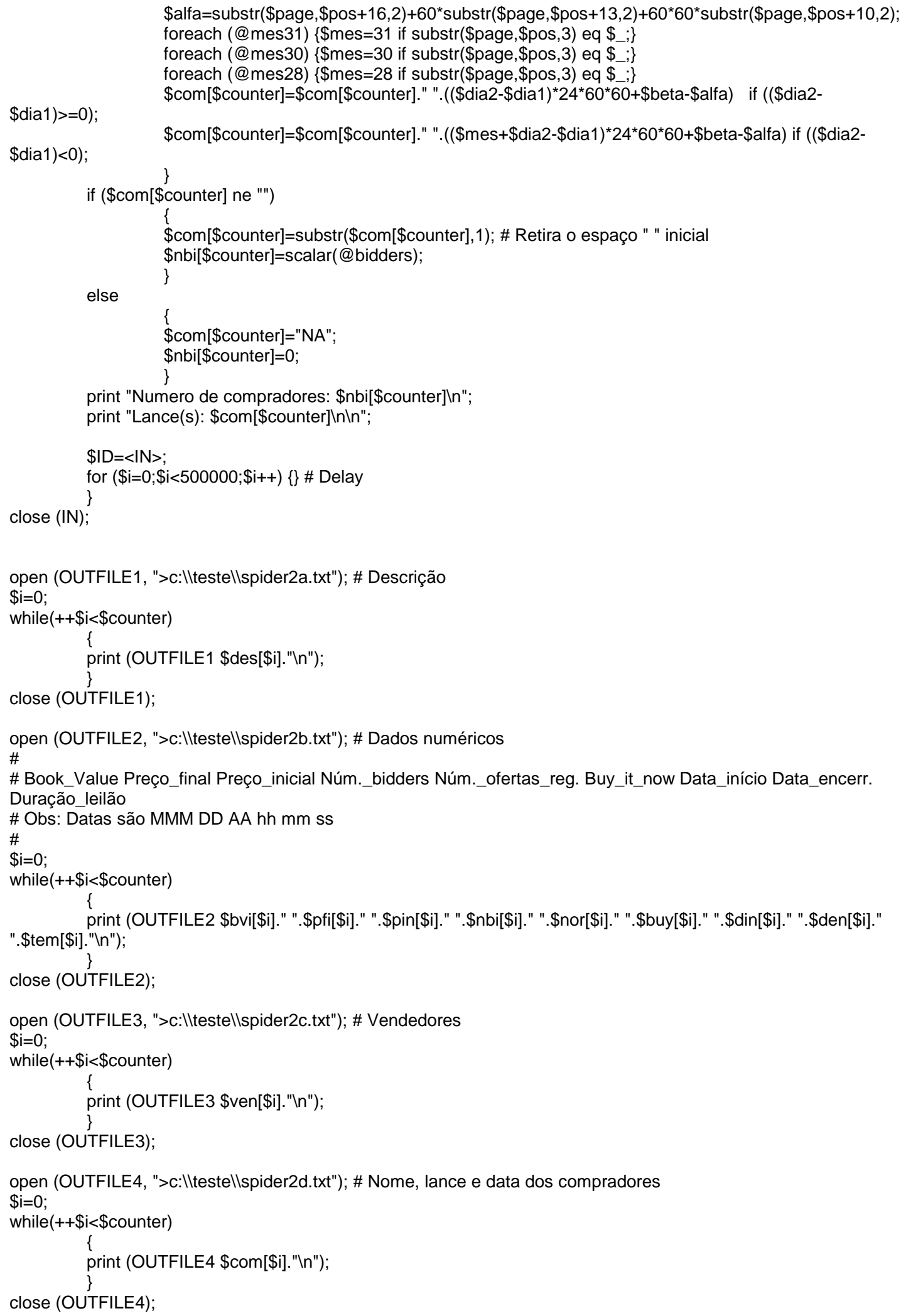


\#!c:|perllbinlperl.exe

\# SPIDER3.PL

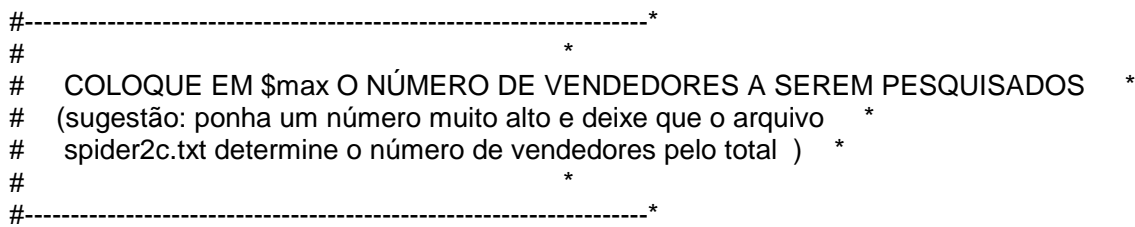

use strict;

use warnings;

use LWP::Simple;

my \$max=99999; \# Número máximo de vendedores (sellers) a serem lidos de spider2c.txt

my \$counter=0; \# Variável auxiliar: contador

my \$counter2=0; \# Variável auxiliar: contador2

my \$seller; \# Nome do vendedor

my \$sellerdata;

my \$flag; \# Flag para repetição no nome do vendedor

my \$site; \# Endereço da página que contém os dados dos leilões

my \$page; \# Variável auxiliar: página recebida

my \$pos; \# Variável auxiliar: posição corrente em \$page

my \$pos2; \# Variável auxiliar de \$pos

my \$i; \# Variável auxiliar: laço

my \$j; \# Variável auxiliar: laço2

my @rat; \# Rating (positivo, neutro e negativo)

my @vend; \# Nome do vendedor

my \$key0="<b>"; \# Chave 2 de busca

my \$key1="</b>"; \# Chave delimitadora das buscas

my \$key2="positives"; \# Chave 1 de busca para encontrar "Positivos"

my \$key3="neutrals"; \# Chave 1 de busca para encontrar "Neutros"

my \$key4="negatives"; \# Chave 1 de busca para encontrar "Negativos"

my \$posit; \# Contador de comentários positivos

my \$neutr; \# Contador de comentários neutros

my \$negat; \# Contador de comentários negativos

open (IN1, "c:Itestel|spider2c.txt");

\$/="|n"; \# <IN1> devolve o texto até encontrar "In"

$\$$ seller $=<\mid \mathrm{N} 1>$;

while (++\$counter $<=\$$ max and $\$$ seller $)$

chop \$seller;

print "Auction: \$counter Seller: \$seller ";

\$flag=0;

for $(\$ \mathrm{j}=1 ; \$ \mathrm{j}<\$$ counter; $\$ \mathrm{j}++)$

\{if (\$vend[\$]] eq \$seller)

\{

$\$$ flag $=1$;

$\$$ counter $2=\$$;

$\$ \mathrm{j}=\$$ counter;

\}

\}

if $\quad(\$ f l a g==1)$

\{

\$vend[ $\$$ counter]=\$vend[\$counter2]

\$rat $[\$$ counter] $=\$$ rat $[\$$ counter2];

else

\$site="http://cgi2.ebay.com/aw-cgi/eBayISAPI.dll?ViewFeedback\&userid=".\$seller;

\$page $=$ get $(\$$ site $)$;

$\$$ pos $=0$;

\# ------------- Pegar Positivos

$\$ p o s=$ index $(\$ p a g e, \$$ key2, $\$$ pos +1$)$;

$\$$ pos=index $(\$ p a g e, \$ k e y 0, \$ p o s-50)$ 
$\$$ pos $+=3$;

\$pos2=index (\$page, $\$$ key $1, \$ p o s) ;$

\$posit=substr(\$page,\$pos,\$pos2-\$pos);

\# --------- Pegar Neutros

$\$$ pos=index $(\$$ page, $\$$ key $3, \$$ pos +1$)$;

$\$$ pos=index $(\$ p a g e, \$$ key0,\$pos-20);

$\$$ pos $+=3$;

$\$$ pos2=index $(\$ p a g e, \$$ key $1, \$ p o s) ;$

\$neutr=substr(\$page,\$pos,\$pos2-\$pos);

\# ------------ Pegar Negativos

$\$$ pos=index $(\$$ page,$\$$ key $4, \$$ pos +1$)$;

$\$$ pos=index $(\$ p a g e, \$$ key0, $\$$ pos- 50$)$;

$\$$ pos $+=3$;

$\$$ pos2=index $(\$ p a g e, \$ k e y 1, \$ p o s) ;$

\$negat=substr(\$page,\$pos,\$pos2-\$pos);

\$sellerdata="\$posit "."\$neutr "."\$negat ";

\$vend[ $\$$ counter]=\$seller;

\$rat $[\$$ counter]=\$sellerdata;

\}

print "Ratings: \$rat[\$counter]\n";

$\$ /=" \mid n " ;$

$\$$ seller=<IN1 >;

close (IN1);

open (OUTFILE1, ">c:IItestellspider3.txt"); \# Ratings

$\$ \mathrm{i}=0$;

while $(++\$ \mathbf{i}<\$$ counter $)$

\{

close (OUTFILE1);

print (OUTFILE1 \$rat[\$i]."In"); 
\#!c:lperllbinlperl.exe \# BLEMISH.PL

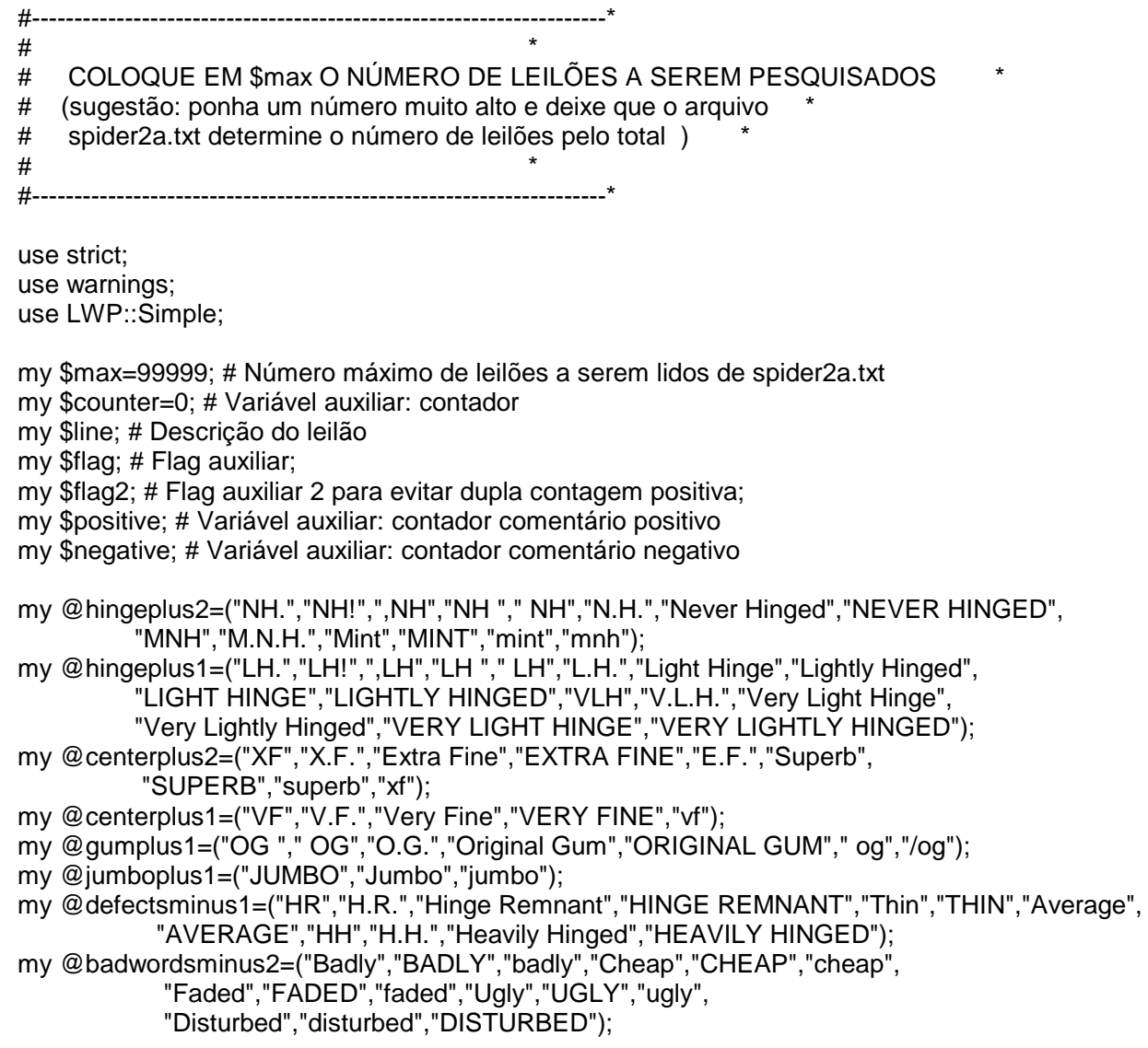




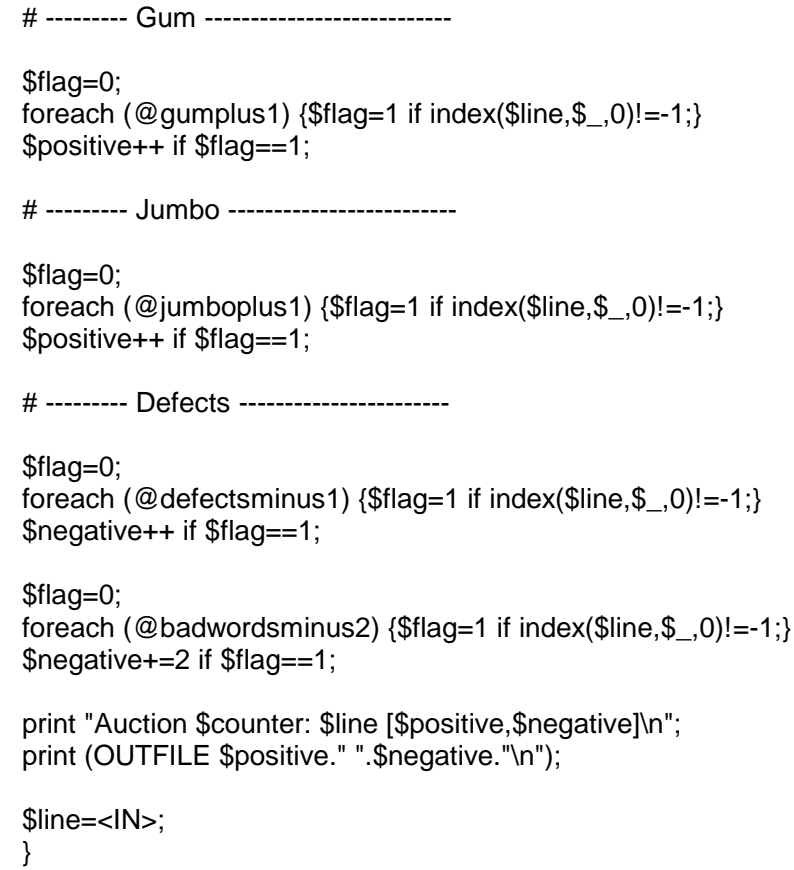




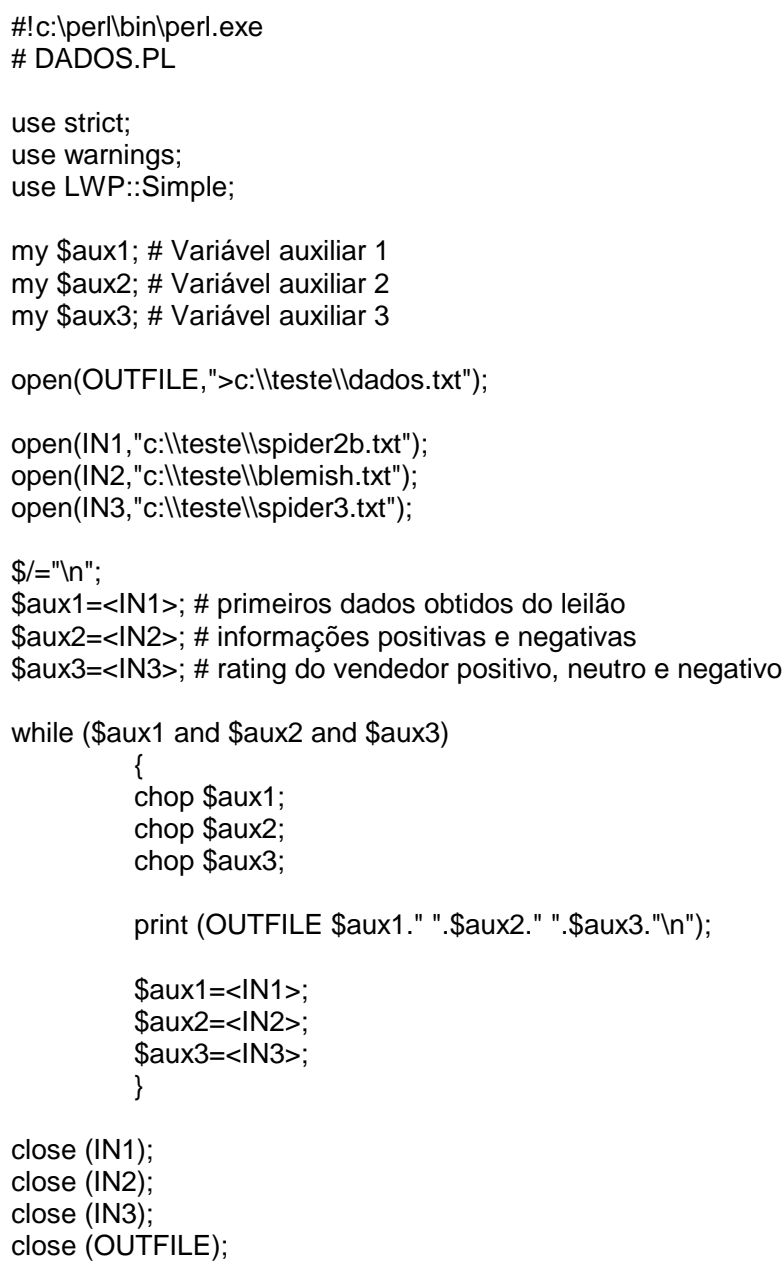


\#!c:|perllbinlperl.exe

\# LATEBID.PL

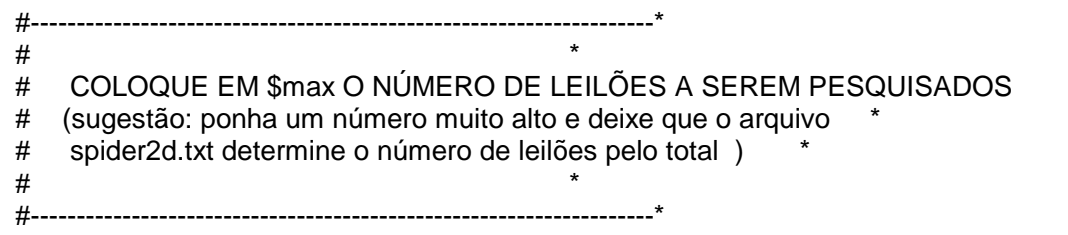

use strict;

use warnings;

use LWP::Simple;

my \$max=99999; \# Número máximo de leilões a serem lidos de spider2d.txt

my \$counter=0; \# Variável auxiliar: contador

my $\$$ total=0; \# Total de lances computados

my \$lances; \# Lances dados em um leilão

my \$pos; \# Variável auxiliar: posição corrente em \$page

my \$pos2; \# Variável auxiliar de \$pos

my \$i; \# Variável auxiliar: laço

my \$; \# Variável auxiliar: laço2

my \$seg; \# Variável auxiliar: segundos

my \$flag; \# Flag auxiliar

my @day; \# \$day[0]=lances do últ. dia, \$day[1]=lances do penúlt. dia, ...

my @hour; \# \$hour[0]=lances da últ. hora, ...

open (IN1, "c:Itestel|spider2d.txt");

for $(\$ \mathrm{i}=0 ; \$ \mathrm{i}<31 ;++\$ \mathrm{i})\{\$$ day $[\$ \mathrm{i}]=0 ;\}$

for $\left(\$ \mathrm{i}=0 ; \$ \mathrm{i}<\left(31^{*} 24\right) ;++\$ \mathrm{i}\right)\{\$$ hour $[\$ \mathrm{i}]=0 ;\}$

$\$ /=" \backslash n " ;$ \# <IN1> devolve o texto até encontrar "In"

\$lances $=<|\mathrm{N} 1\rangle$;

while (++\$counter $<=\$$ max and $\$$ lances)

\{

chop \$lances;

unless (\$lances eq "NA")

$\$$ pos $=0$;

while (\$pos != -1)

for $(\$ \mathrm{i}=0 ; \$ \mathrm{i}<8 ;++\$ \mathrm{i})\{\$$ pos=index $(\$$ lances," ",\$pos +1$) ;\}$

$\$$ pos++;

\$pos2=\$pos;

while (substr(\$lances,\$pos2,1) ge "0" and

substr(\$lances,\$pos2,1) le "9") \{\$pos2++;\}

$\$$ seg=substr $(\$$ lances, $\$$ pos, $\$$ pos2-\$pos);

$\$$ day[int $\left(\$\right.$ seg $\left.\left./\left(24^{*} 60^{*} 60\right)\right)\right]++$;

\$hour $\left[\right.$ int $\left.\left(\$ s e g /\left(60^{*} 60\right)\right)\right]++$;

\$total++;

$\$ p o s=i n d e x(\$ l a n c e s, " ~ ", \$ p o s+1) ;$

\} \}

\$lances $=<\mid \mathrm{IN} 1>$

\}

$\$$ flag=1;

$\$ \mathrm{i}=30$;

while (\$flag)

if $(\$$ day $[\$ i--]==0)$

\{ pop(@day);

else

\{

$\$$ flag $=0$;

\} \}

$\$$ flag=1; 


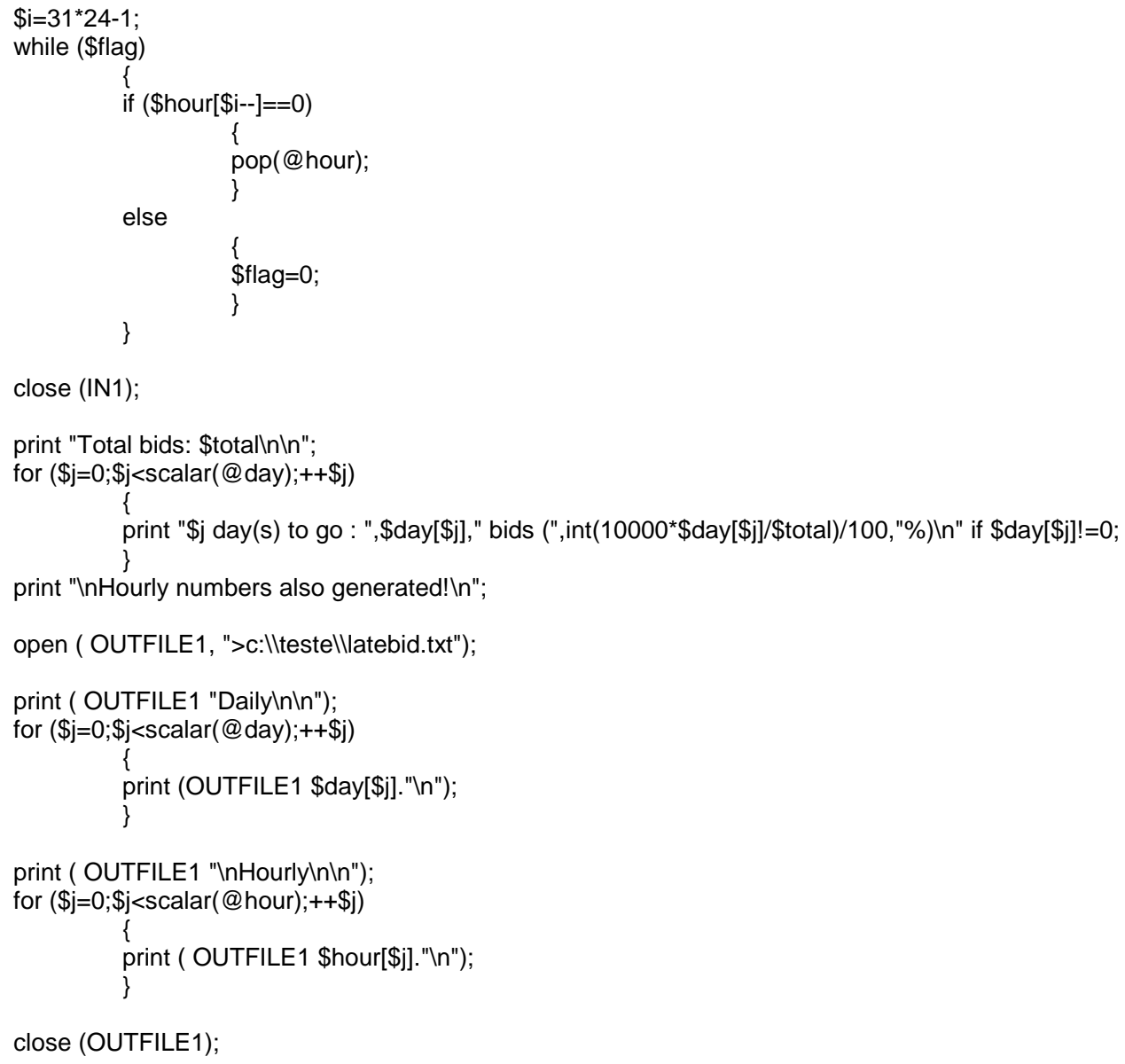


\#!c:Iperllbin $\mid$ perl.exe \# PRICES.PL

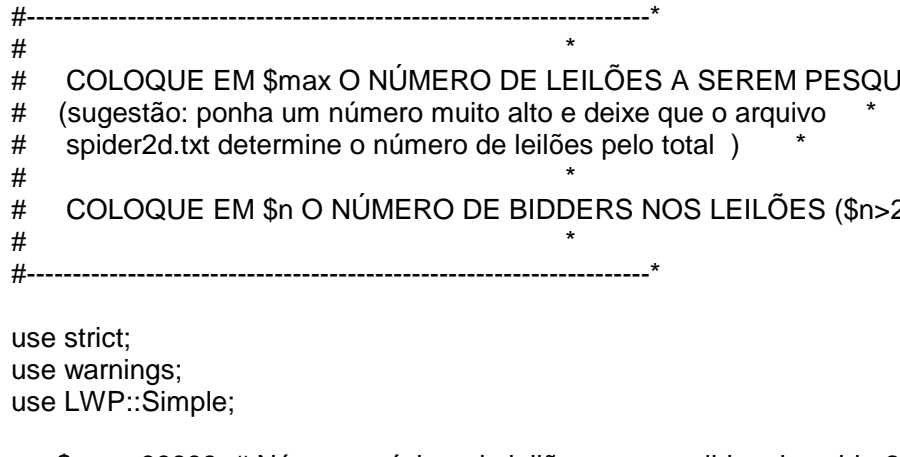

my \$max=99999; \# Número máximo de leilões a serem lidos de spider2d.txt my $\$ n=3 ; \#$ Número de compradores no leilão

my \$counter=0; \# Variável auxiliar: contador

my \$counter2=0; \# Variável auxiliar: contador

my \$counter3=0; \# Variável auxiliar: contador

my \$lances; \# Lances dados em um leilão

my \$dados; \# Dados do leilao

my \$bvi; \# bvi do leilão

my \$pos; \# Variável auxiliar: posição corrente em \$page

my \$pos2; \# Variável auxiliar de \$pos

my \$i; \# Variável auxiliar: laço

my \$j; \# Variável auxiliar: laço2

my \$k; \# Variável auxiliar: laço3

my \$flag; \# Flag de aviso se um nome tem mais de um lance dado

my \$aux; \# Variável auxiliar: contador

my @preco; \# Armazena lances

my @nome; \# de cada leilao

my @preco2; \# Variáveis auxiliares no cômputo

my @nome2; \# de P(n) P(n-1) em cada leilao

my @priceu; \# P(n)

my @pricep; \# P(n-1)

my @bviaux; \# bvi p/ arquivo prices.txt

open (IN1, "c:Itestellspider2d.txt");

open (IN2, "c:|ltestellspider2b.txt");

$\$ /=" \backslash n " ; \#<I N 1>$ e <IN2> devolvem o texto até encontrar "\n"

\$lances $=<\mathrm{IN1}>$;

$\$$ dados $=<$ IN2>;

while (++\$counter<=\$max and \$lances) \# spider2b e spider2d tem o mesmo número de linhas \{

\# ------------- Pega bvi do leilão seguinte

\$pos=index $(\$ d a d o s, " ~ ", 0) ;$

$\$ b v i=$ substr(\$dados,0,\$pos);

\# -------------- Pega lances no leilão seguinte ----------------

for $(\$ \mathrm{i}=0 ; \$ \mathrm{i}<50 ;++\$ i)$ \# 50 lances no máximo

\{

$\$$ preco[\$i]=-1;

\$nome $[\$ i]="$ ";

$\$$ preco2[\$i]=-1;

\$nome2[\$i]=" ";

\}

chop \$lances

unless (\$lances eq "NA")

\{

$\$ p o s=0$

$\$ p o s 2=0$

$\$ \mathrm{j}=0$;

while (\$pos $!=-1)$ 


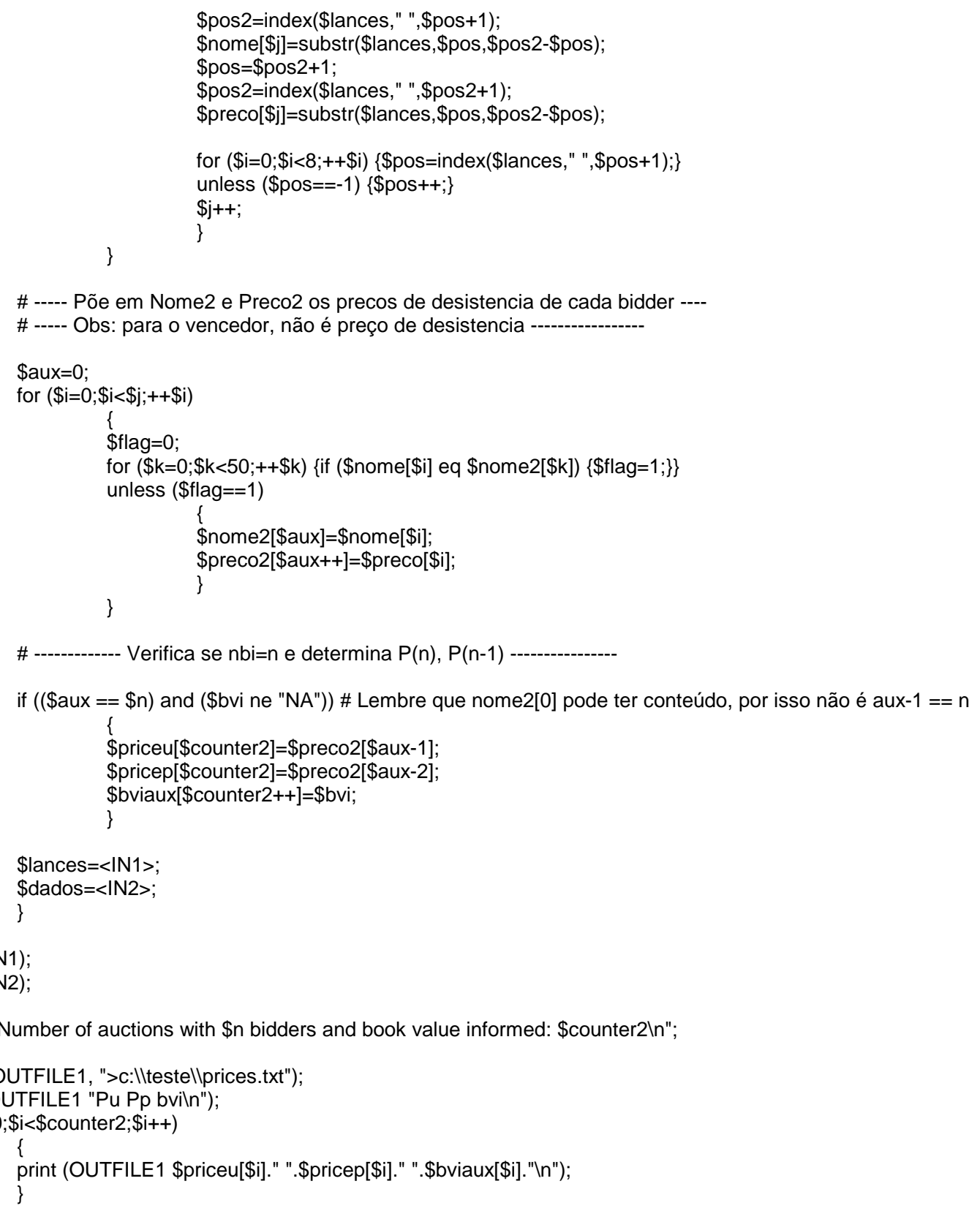


\#!c:|perllbin $\mid$ perl.exe

\# BIDS.PL

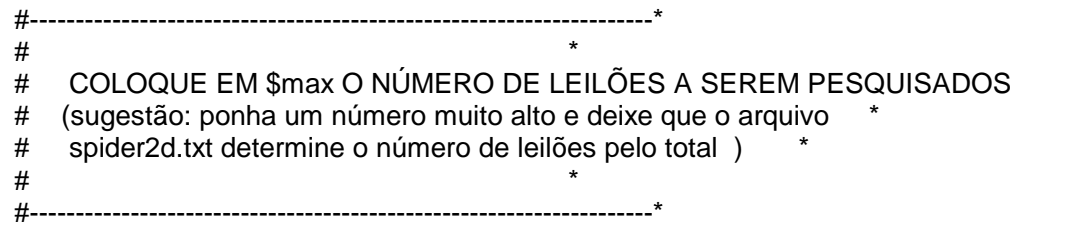

use strict;

use warnings;

use LWP::Simple;

my \$max=99999; \# Número máximo de leilões a serem lidos de spider2d.txt

my \$counter=0; \# Variável auxiliar: contador

my \$counter2=0; \# Variável auxiliar: contador

my \$counter3=0; \# Variável auxiliar: contador

my \$lances; \# Lances dados em um leilão

my \$dados; \# Dados do leilao

my \$bvi; \# bvi do leilão

my \$nbi; \# nbi do leilão

my \$pos; \# Variável auxiliar: posição corrente em \$page

my \$pos2; \# Variável auxiliar de \$pos

my \$i; \# Variável auxiliar: laço

my \$j; \# Variável auxiliar: laço2

my \$k; \# Variável auxiliar: laço3

my \$flag; \# Flag de aviso se um nome tem mais de um lance dado

my \$aux; \# Variável auxiliar: contador

my @preco; \# Armazena lances

my @nome; \# de cada leilao

my @preco2; \# Variáveis auxiliares no cômputo

my @nome2; \# de P(n) P(n-1) em cada leilao

my @bid; \# bids

my @bviaux; \# bvi p/ arquivo bids.txt

my @nbiaux; \# nbi p/ arquivo bids.txt

open (IN1, "c:||testellspider2d.txt");

open (IN2, "c:Itestellspider2b.txt");

$\$ /=" \mid n " ; \#<I N 1>$ e $<I N 2>$ devolvem o texto até encontrar "In"

\$lances $=<\mid \mathrm{N} 1>$;

$\$$ dados $=<\mid \mathrm{N} 2>$;

while $(++\$$ counter $<=\$ \max$ and $\$$ lances) \# spider2b e spider2d tem o mesmo número de linhas \{

\# ------------- Pega bvi e nbi do leilão seguinte

$\$$ pos=index $(\$$ dados," ",0);

$\$$ bvi $=$ substr $(\$$ dados, $0, \$$ pos $)$;

for $(\$ \mathrm{i}=1 ; \$ \mathrm{i}<3 ;++\$ \mathrm{i})\{\$ \mathrm{pos}=$ index $(\$$ dados," ",\$pos +1$) ;\}$

\$pos++;

\$pos2=index (\$dados," ",\$pos);

\$nbi=substr(\$dados,\$pos,\$pos2-\$pos);

\# ------------- Pega lances no leilão seguinte

for $(\$ \mathrm{i}=0 ; \$ \mathrm{i}<50 ;++\$ i) \# 50$ lances no máximo

\{

\$preco[\$i]=-1;

\$nome[\$i]=" ";

\$preco2[\$i]=-1;

\$nome2[\$i]=" ";

\}

chop \$lances;

unless (\$lances eq "NA")

\{

$\$$ pos $=0$;

$\$$ pos2 $=0$; 
$\$ \mathrm{j}=0$;

while (\$pos != -1)

\$pos2=index $(\$$ lances," ",\$pos+1);

\$nome[\$j]=substr(\$lances,\$pos,\$pos2-\$pos);

$\$ p o s=\$ p o s 2+1$;

\$pos2=index(\$lances," ",\$pos2+1);

\$preco[\$j]=substr(\$lances,\$pos,\$pos2-\$pos);

for $(\$ \mathrm{i}=0 ; \$ \mathrm{i}<8 ;++\$ \mathrm{i})\{\$ \mathrm{pos}=$ index $(\$$ lances," ",\$pos +1$) ;\}$

unless $(\$ p o s==-1)\{\$ p o s++;\}$

$\$ \mathrm{j}++$;

\}

\}

\# ----- Põe em Nome2 e Preco2 os precos de desistencia de cada bidder ---.

\# ----- Obs: para o vencedor, não é preço de desistencia

\$aux=0;

unless (\$bvi eq "NA")

\{

for $(\$ \mathrm{i}=0 ; \$ \mathrm{i}<\$ \mathrm{j} ;++\$ \mathrm{i})$

\$flag $=0$;

for $(\$ \mathrm{k}=0 ; \$ \mathrm{k}<50 ;++\$ \mathrm{k})\{$ if $(\$ \mathrm{nome}[\$ \mathrm{i}]$ eq $\$$ nome2[\$k]) $\{\$ \mathrm{flag}=1 ;\}\}$

unless $(\$$ flag $==1)$

\{

\$

\$preco2[\$aux++]=\$preco[\$i];

\} \}

\}

for $(\$ \mathrm{i}=1 ; \$ \mathrm{i}<\$$ aux; $\$ \mathrm{i}++)$ \# Todos os bids (preços de desist.) menos o vencedor, obviamente.

\{

\$bid $[\$$ counter2] $=\$$ preco2[ $\$$ i];

\$bviaux[\$counter2] $=\$$ bvi;

\$nbiaux[ $\$$ counter $2++]=\$ n b i ;$

\}

\$lances $=<\mathrm{IN} 1>$

$\$$ dados $=<\mid \mathrm{N} 2>$

\}

close (IN1);

close (IN2);

print "InNumber of bids: \$counter2ln";

open ( OUTFILE1, ">c:Itestellbids.txt");

print ( OUTFILE1 "bid bvi nbiln");

for $\left(\$ \mathrm{i}=0 ; \$ \mathrm{i}<\$\right.$ counter $\left.2 ; \$ \mathrm{i}_{++}\right)$

\{

print (OUTFILE1 \$bid[\$i]." ".\$bviaux[\$i]." ".\$nbiaux[\$i]."In"); 
program CURSE ;

uses

CRT,Graph;

var

Gd, Gm : Integer;

i : integer;

p1,p2,p3 : char;

aux1, aux2, aux3 : integer;

flag1, flag2, flag3, flag4 : boolean;

ch : char;

drops : integer;

begin

Gd := Detect; InitGraph(Gd, Gm, ");

if GraphResult <> grOk then Halt(1);

rectangle $(10,5,630,470)$;

SetTextStyle(DefaultFont, HorizDir,2);

setcolor(15);

OutTextXY(120,300,'Jogador 1 participando');

OutTextXY(120,330,'Jogador 2 participando');

OutTextXY (120,360,'Jogador 3 participando');

OutTextXY(120,390,'Jogador 4 participando');

drops: $=0$;

aux1:=0; aux2:=0; aux3:=0;

flag1:=true; flag2:=true; flag $3:=$ true; flag $4:=$ true;

for $\mathrm{i}:=0$ to 100 do begin

if (drops $>2)$ or $(i=100)$ then begin

if drops $>2$ then aux1:=aux $1-1 ;\}$

SetTextStyle(DefaultFont, HorizDir,5);

setcolor(12);

sound(1000); delay(1000); nosound; delay(250);

sound(2000); delay(1000); nosound; delay(250);

sound(3000); delay (1000); nosound;

OutTextXY(50,220,'FIM DO LEILAO');

end;

if aux $1>9$ then begin aux1:=0; aux2:=aux $2+1$; end;

if aux2>9 then begin aux2:=0; aux3:=aux $3+1$; end;

$\mathrm{p} 1:=\operatorname{char}(48+\mathrm{aux} 1)$;

p2:=char(48+aux2);

p3:=char(48+aux3);

SetFillStyle $(9,15)$;

$\operatorname{bar}(90,20,515,145)$;

SetTextStyle(DefaultFont, HorizDir, 15);

setcolor $(1)$;

OutTextXY $(400,30, \mathrm{p} 1)$;

OutTextXY(250,30,p2);

OutTextXY(100,30,p3);

aux1:=aux1+1;

ch:='a';

if drops $<3$ then while $\quad(i<100)$ and

(ch<>'-') and

not ( $\quad\left(\left(\mathrm{ch}={ }^{\prime} 11^{\prime}\right)\right.$ and flag1) or

((ch='2') and flag2) or

$\left(\left(\mathrm{ch}=\mathbf{\prime}^{\prime}\right)\right.$ and flag3) or

do ch:=readkey

$\left(\left(\mathrm{ch}=\mathbf{\prime}^{\prime}\right)\right.$ and flag4))

else $\mathrm{i}:=100$;

if $\left(\mathrm{ch}={ }^{\prime} 1{ }^{\prime}\right)$ and $(\mathrm{drops}<3)$ and flag 1 then begin

flag $1:=$ false;

$\mathrm{i}:=\mathrm{i}-1$;

aux1:=aux1-1;

drops:=drops +1 ;

SetTextStyle(DefaultFont, HorizDir,2);

SetFillStyle $(1,0)$;

bar $(47,297,500,318)$;

setcolor(8);

OutTextXY(50,300,'Jogador 1 desistiu no preço'); 


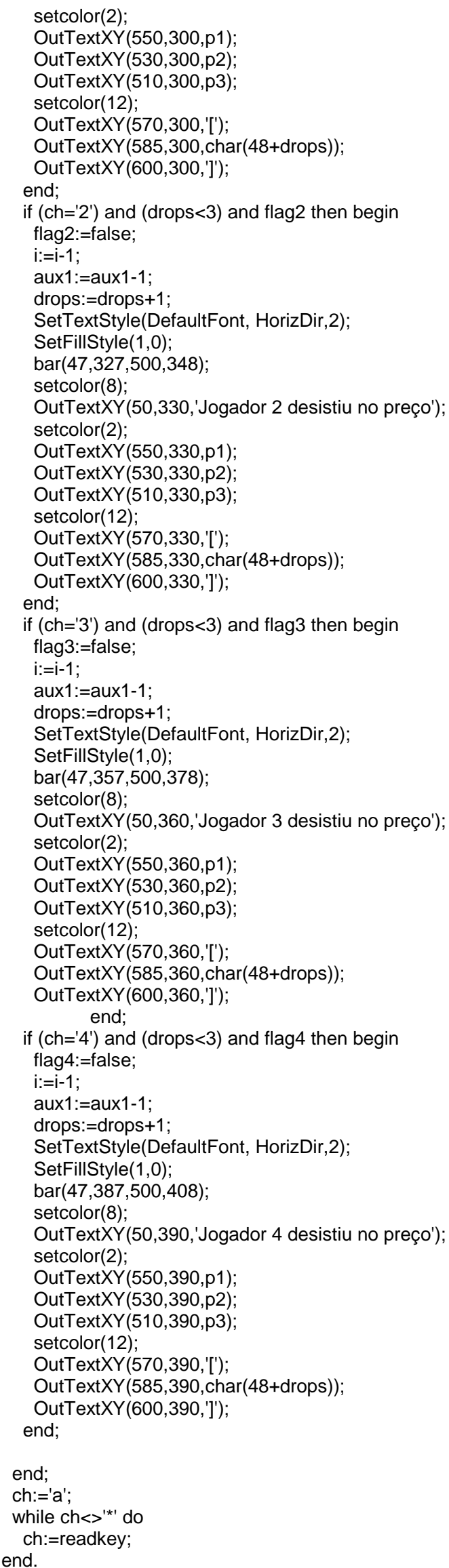




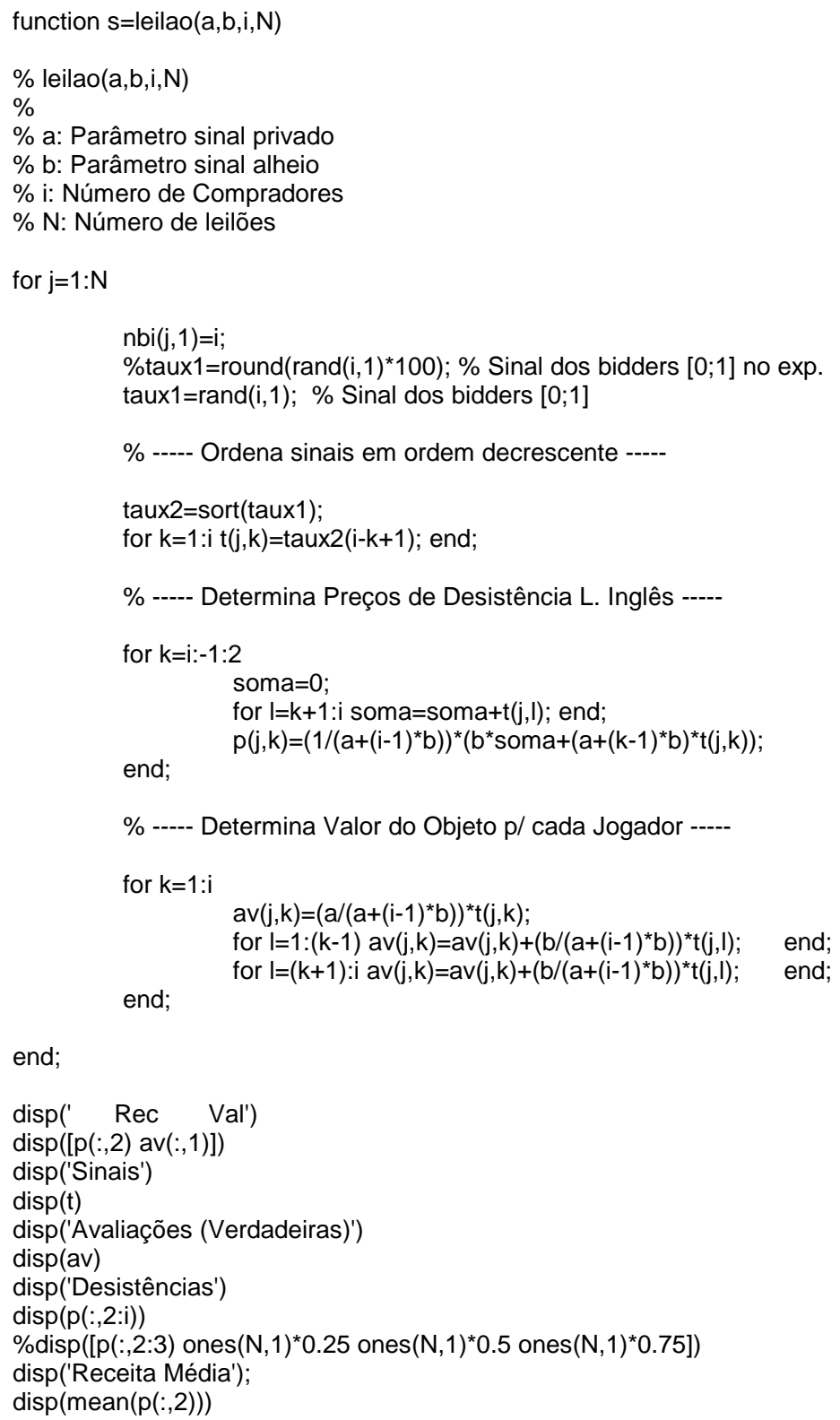

